\author{
Universidade de São Paulo \\ Instituto de Física
}

\title{
Luminescência Opticamente Estimulada com aplicações em Radioterapia: dependência da dose absorvida e da energia de fótons produzidos em aceleradores clínicos e Microtron - IFUSP
}

\author{
Carlos Eduardo Freitas
}

Orientador: Prof. ${ }^{\text {a }}$ Dr. ${ }^{\text {a }}$ Elisabeth Mateus Yoshimura

Dissertação de mestrado apresentada ao Instituto de Física para a obtenção do título de Mestre em Ciências

Banca Examinadora:

Profa. Dra. Elisabeth M. Yoshmura (IFUSP)

Prof. Dr. Alessio Mangiarotti (IFUSP)

Profa. Dra. Laura Natal Rodrigues (HC/FMUSP) 


\section{FICHA CATALOGRÁFICA \\ Preparada pelo Serviço de Biblioteca e Informação do Instituto de Física da Universidade de São Paulo}

Freitas, Carlos Eduardo

Luminescência opticamente estimulada com aplicações em radioterapia: dependência da dose absorvida e da energia de fótons produzidos em aceleradores clínicos e Microtron - IFUSP. São Paulo, 2017.

Dissertação (Mestrado) - Universidade de São Paulo. Instituto de Física. Depto. de Física Nuclear.

Orientador: Profa. Dra. Elisabeth Mateus Yoshimura

Área de Concentração: Física Médica

Unitermos: 1. Física médica; 2. Dosimetria luminescente; 3. Luminescência opticamente estimulada; 4. Radioterapia.

USP/IF/SBI-033/2017 
"A renúncia é a libertação. Não querer é poder" Fernando Pessoa 


\section{AGRADECIMENTOS}

À minha família por tudo.

À Kely pelo carinho, amizade e incentivos.

À minha orientadora pela paciência, amizade, ensinamentos, compreensão e por ser um exemplo de profissionalismo.

À Nancy pelos incontáveis auxílios no manejo dos equipamentos do laboratório.

Ao Alexandre Malafronte, Alfredo e o Prof. Marcos Martins do LAL pela grande ajuda para fazer o Microtron funcionar da melhor forma possível.

Ao Serviço de Radioterapia do Hospital A. C. Camargo pelo auxílio com as irradiações.

Aos companheiros do "Clube do Vinho" (Josi, Alejandro, Lorena e Louise) pelos magníficos encontros e pela grande amizade que floresceu.

À Juliana pelas boas conversas (que muitas vezes eram monólogos) e pelo companheirismo nas atividades acadêmicas.

Ao Marcelo Sousa pela amizade, ajuda e pelo entusiasmo.

Ao Prof. Dr. Fuad Daher Saad pelo grande incentivo desde a graduação.

Ao Mané e Caio Fukumori pelo auxílio na confecção do porta-alvo e no sistema de varredura.

À Josiane Martins pela grande amizade e parceria no trabalho. 


\section{RESUMO}

Atualmente a utilização de fótons de raios $X$ e gama na Medicina (radiodiagnóstico e radioterapia) gerou a necessidade do conhecimento da dose absorvida nos tecidos dos pacientes. Para isso, utiliza-se detectores com diversas funcionalidades a fim de conhecer a deposição de energia. Para ser possível a utilização destes materiais, é necessário caracterizá-los tanto quanto à resposta em função da dose absorvida, quanto à dependência com a energia. Neste trabalho foi estudada a dependência energética da resposta OSL dos dosímetros compostos por $\mathrm{BeO}$ e $\mathrm{Al}_{2} \mathrm{O}_{3}$ em feixes de raios $\mathrm{X}$ convencional com espectro largo, feixes de raios $\mathrm{X}$ de aceleradores clínicos e do acelerador Microtron do Instituto de Física da USP e fontes gama de Cs-137 e Co-60, em uma faixa de doses desde centenas de mGy até aproximadamente 2 Gy. Foram utilizadas em conjunto simulações em Monte Carlo com o código PENELOPE, que simula o transporte de fótons e elétrons na matéria, a fim de conhecer a deposição de energia nos materiais. Os espectros utilizados nas simulações foram validados através da comparação das características dos feixes tais como a deposição de dose com a profundidade, camada semirredutora, energia média e resolução espectral. Utilizando um sistema de varredura por câmara de ionização controlado remotamente, foi estudada a distribuição de doses no campo de irradiação para definir uma região de irradiação com dose uniforme para pode realizar a irradiação de um conjunto de dosímetros simultaneamente.

Foram encontrados valores do fator de dependência energética experimental para os feixes mais energéticos (Co-60, Microtron $5 \mathrm{MeV}$ e aceleradores clínicos de 6 e $15 \mathrm{MeV}$ ), com desvio menor que $3 \%$ para $\circ \mathrm{Al}_{2} \mathrm{O}_{3}$ e $5 \%$ para o $\mathrm{BeO}$, indicando independência com a energia do feixe de irradiação. Já nos feixes de baixa energia, os fatores de dependência energética relativos à energia do Co-60 para $\circ \mathrm{Al}_{2} \mathrm{O}_{3}$ foram de 1,68 e 1,42, e, para o $\mathrm{BeO}$, de 0,78 e 0,90 para os feixes W150 e W200 respectivamente. Estes valores indicam que, nesta faixa de energia, a resposta OSL depende mais fortemente da energia do feixe. As simulações em Monte Carlo feitas para os fatores de dependência energética se mostraram bem consistentes com os valores experimentais para $\circ \mathrm{BeO}$ em toda faixa de energia e para $\circ \mathrm{Al}_{2} \mathrm{O}_{3}$, excetuando-se os feixes de baixa energia, possivelmente pelo não completo conhecimento de todos os elementos constituintes do dosímetro empregado (fita de 
Luxel( $\left({ }^{\circledR}\right)$. Quanto às curvas de emissão OSL para as diferentes energias de irradiação, foi observado que o sinal decai mais rápido quanto mais elevada é a energia média do feixe para o $\mathrm{BeO}$. Para o $\mathrm{Al}_{2} \mathrm{O}_{3}$, o efeito foi mais sutil e oposto. Os estudos do feixe do Microtron mostraram que, desde que a corrente seja monitorada durante as irradiações para posterior correção da dose, é possível realizar estudos utilizando um feixe de fótons de Bremsstrahlung produzido com alvo externo e energias médias (simuladas e ainda não validadas experimentalmente) próximas às energias das fontes gama de Cs-137 e Co-60. Os resultados experimentais para as respostas OSL dos dois materiais foram compatíveis com as simulações. 


\section{ABSTRACT}

Nowadays the use of $X$ and gamma-ray photons in Medicine (radiodiology and radiotherapy) has generated the necessity of knowing the absorbed dose to the tissues of patients. For this purpose, detectors with diverse functionalities are used to know the energy deposition. To make possible the use of these materials, it is necessary to characterize the dose response, as well as the energy dependence of the response. In this work the energy dependence of the OSL response of the $\mathrm{BeO}$ and $\mathrm{Al}_{2} \mathrm{O}_{3}$ dosimeters was studied for conventional $\mathrm{X}$-ray beams with wide energy spectrum, X-ray beams from clinical accelerators and from the Microtron accelerator of the Institute of Physics (University of São Paulo), and for gamma sources of Cs137 and Co-60, in a dose range from hundreds of mGy to about 2 Gy. Monte Carlo simulations were used with the PENELOPE code, which simulates the photons and electrons transport of in the matter, to know the energy deposition in the materials. The energy spectra used in simulations were validated by comparison with beam characteristics such as depth dose deposition, half-value layer, mean energy and spectral resolution. Using a remotely controlled ionization chamber scanning system, the dose distribution within the irradiation field was evaluated to define a uniform dose region for irradiation or a set of dosimeters simultaneously.

Experimental energy dependence factor values were obtained for the highenergy beams (Co-60, Microtron $5 \mathrm{MeV}$, and clinical accelerators of 6 and $15 \mathrm{MeV}$ ), with a deviation of less than $3 \%$ for $\mathrm{Al}_{2} \mathrm{O}_{3}$ and $5 \%$ for $\mathrm{BeO}$, indicating independence with the beam energy. For the low-energy $\mathrm{X}$-ray beams, the energy dependence factors, relative to the Co-60 energy, for $\mathrm{Al}_{2} \mathrm{O}_{3}$ were 1.68 and 1.42, and, for $\mathrm{BeO}$, 0.78 and 0.90 for $\mathrm{W} 150$ and $\mathrm{W} 200$ beams respectively. These values indicate that, in this energy range, the OSL response depends on beam energy. Monte Carlo simulations for the energy dependence factors were consistent with experimental values for the $\mathrm{BeO}$ in entire energy range and for the $\mathrm{Al}_{2} \mathrm{O}_{3}$, with the exception of low energy beams, possibly due to the incomplete knowledge of all the elements that

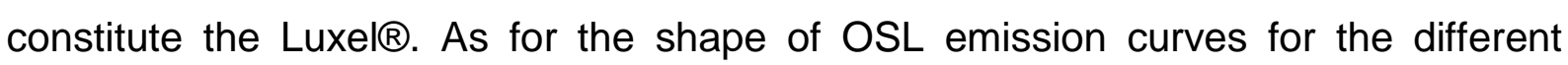
irradiation energies, it was observed that the signal decays faster the higher is the average beam energy for $\mathrm{BeO}$. For $\mathrm{Al}_{2} \mathrm{O}_{3}$, the effect was more subtle and opposite. 
The Microtron beam scanning has shown that, as long as the current is monitored during irradiation for further dose-rate correction, it is possible to carry out studies using a beam of Bremsstrahlung photons produced with external target and mean energies (simulated but still not validated experimentally) close to the energies of the Cs-137 and Co-60 sources. The experimental results for the OSL responses of both materials were compatible with simulations. 


\section{SUMÁRIO}

RESUMO

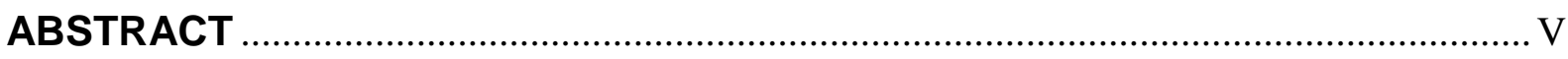

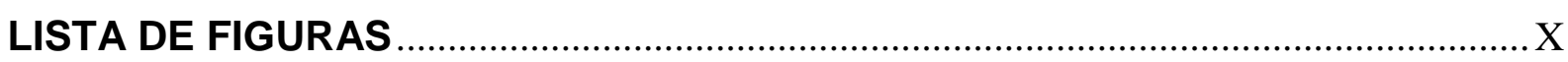

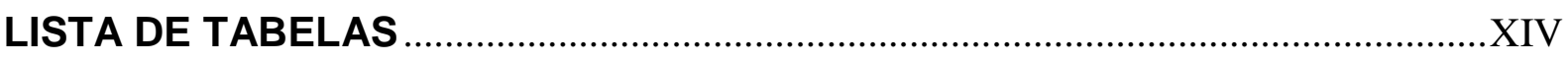

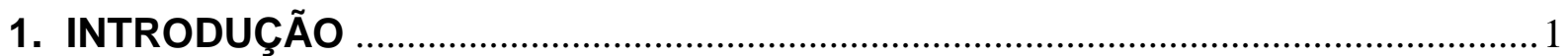

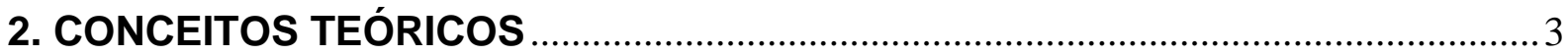

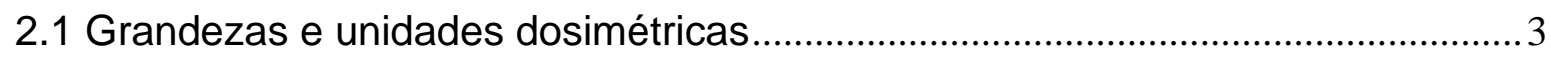

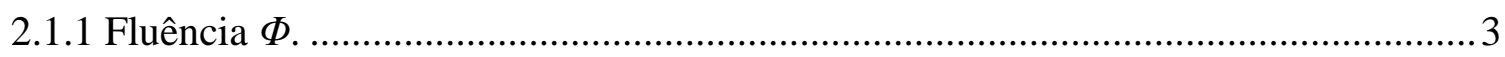

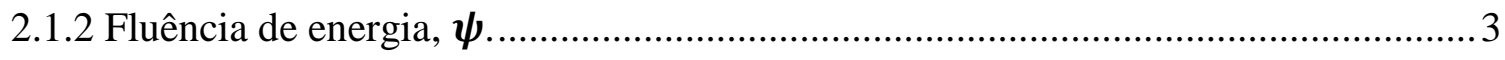

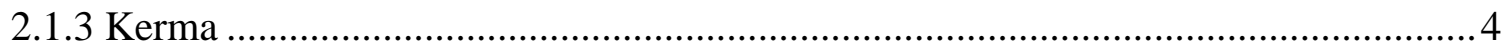

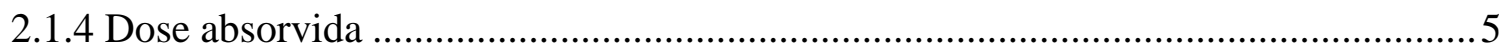

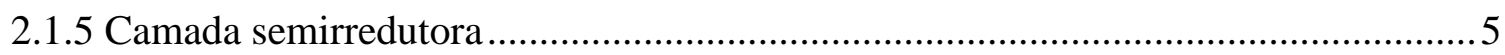

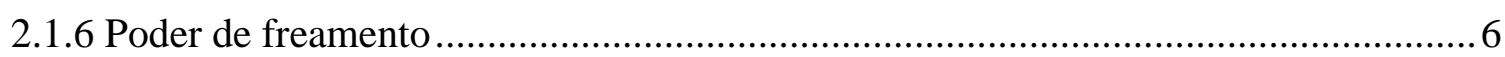

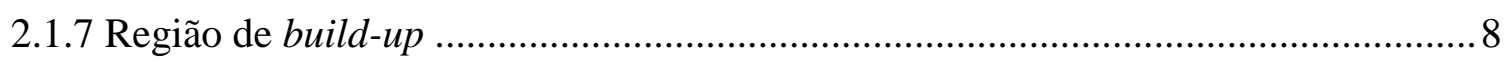

2.1.8 Deposição da energia com a profundidade ...........................................................

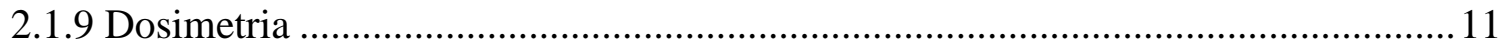

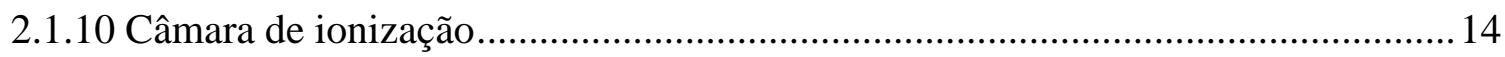

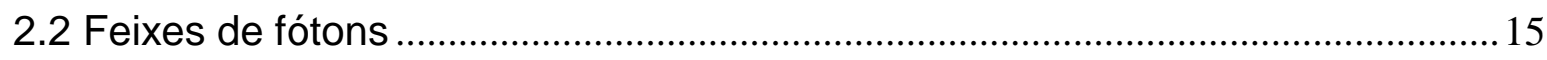

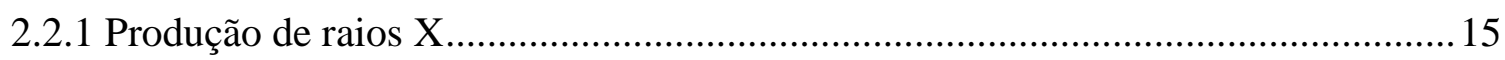

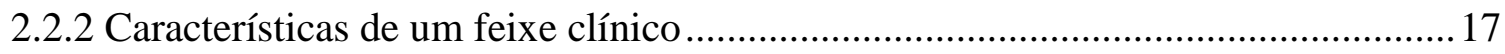

2.3 Luminescência opticamente estimulada .......................................................... 19

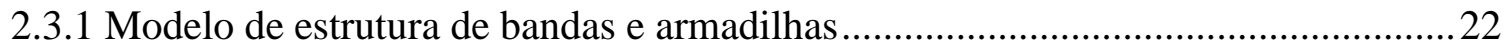

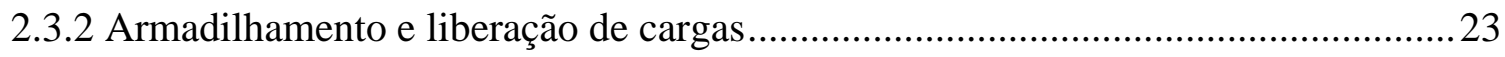

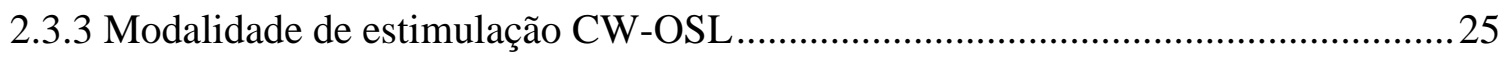

2.4 Simulação do transporte de radiação por Monte Carlo ........................................26

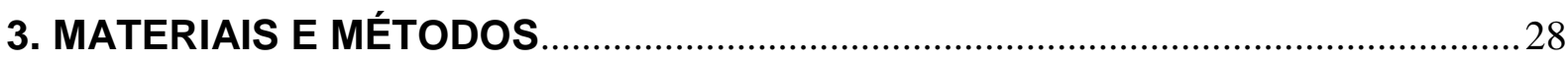

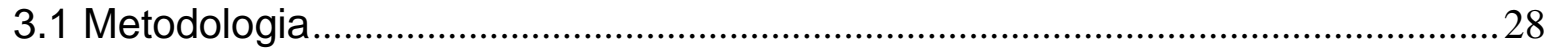

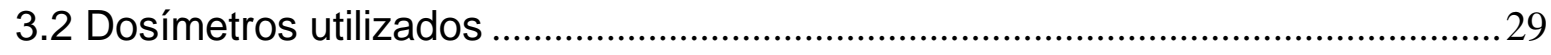

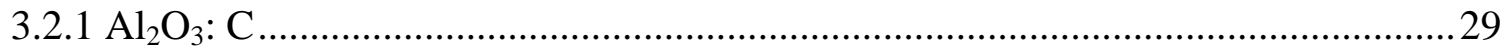

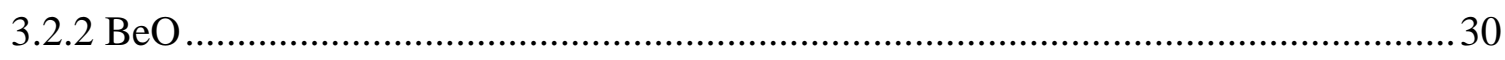

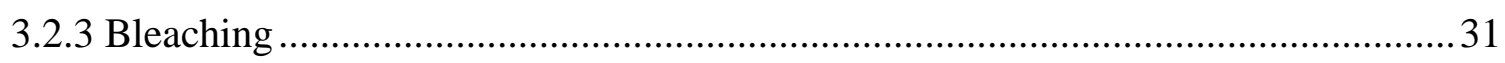




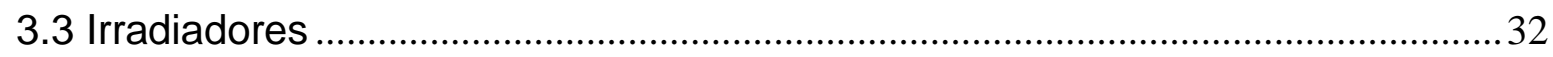

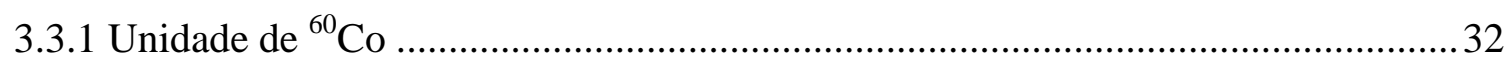

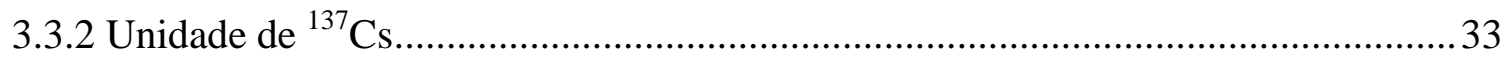

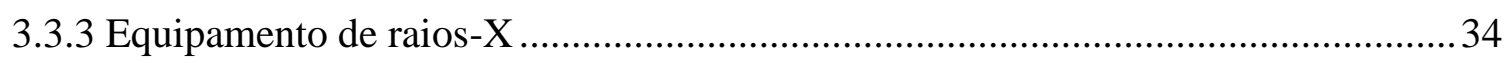

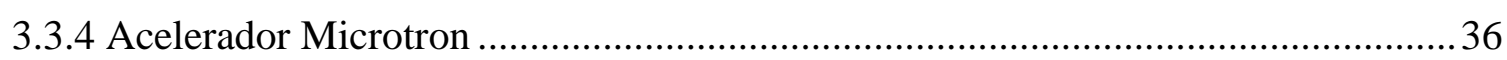

3.3.4.1 Características do alvo................................................................................... 38

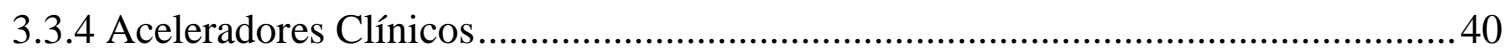

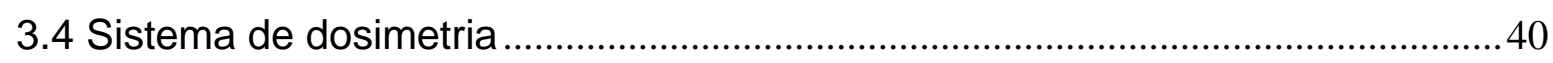

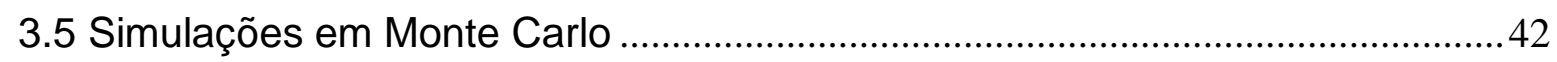

3.5.1 Características gerais e materiais simulados …………………………………..... 42

3.5.2 Fator de dependência energética simulado ........................................................... 44

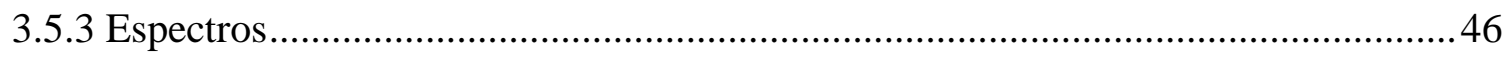

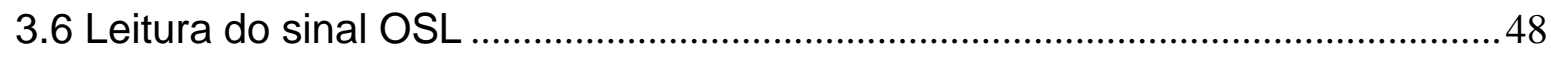

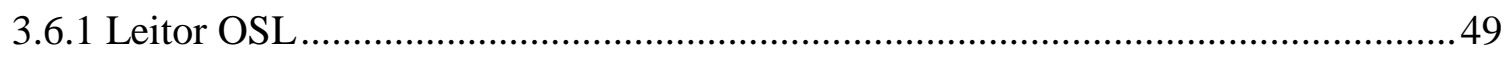

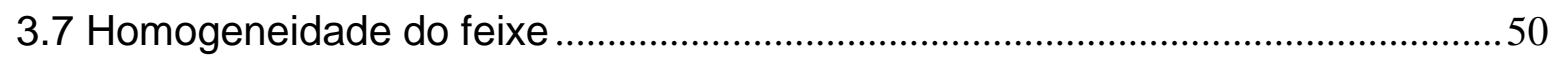

3.8 Parâmetros de irradiação..................................................................................

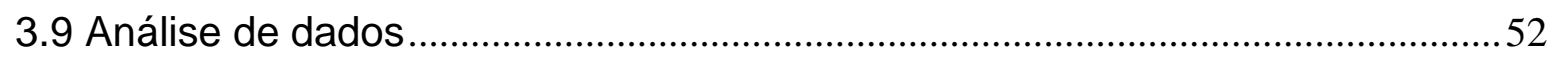

4.1 Método de redução de incerteza para o conjunto de dosímetros ..........................53

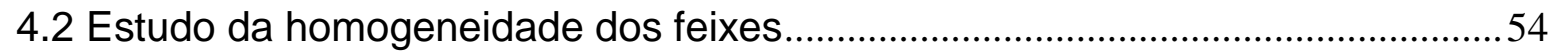

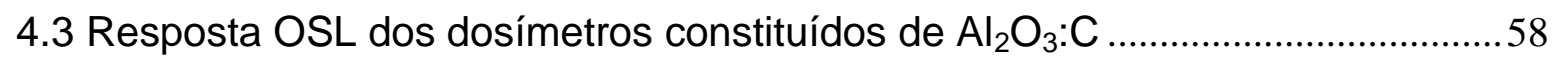

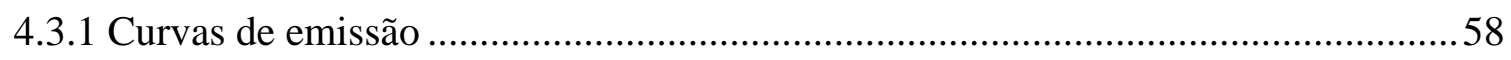

4.3.2 Dependência energética da resposta dosimétrica …………………………….......59

4.4 Resposta OSL dos dosímetros constituídos de $\mathrm{BeO}$.................................................

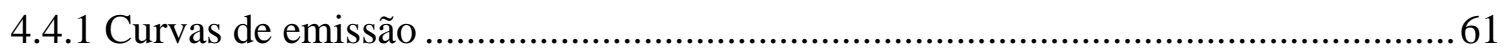

4.4.2 Dependência energética da resposta dosimétrica …………………………….........62

4.5 Fator de dependência energética experimental ......................................................64

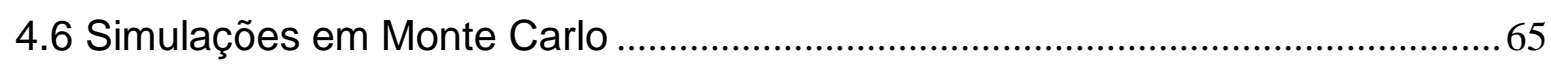

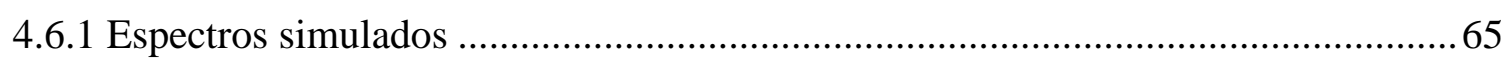

4.6.2 Validação dos feixes convencionais de espectro largo...............................................66

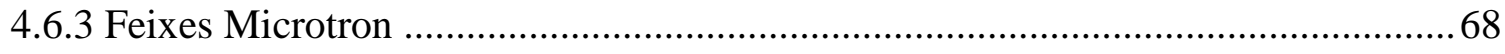

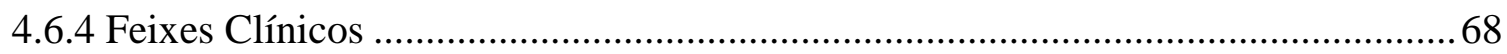

4.6.5 Fator de dependência energética simulado ............................................................ 70

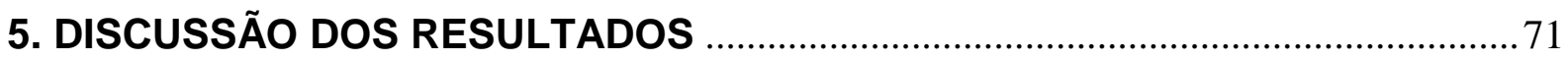

5.1 Dispersão das respostas do lote de dosímetros ................................................. 71 


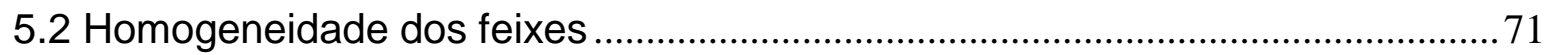

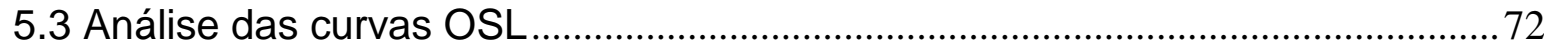

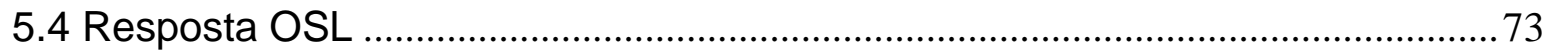

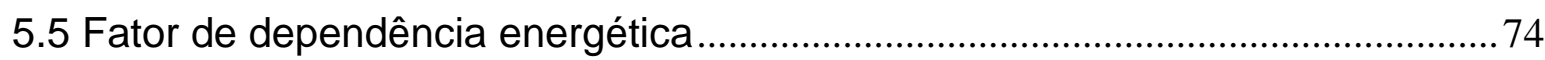

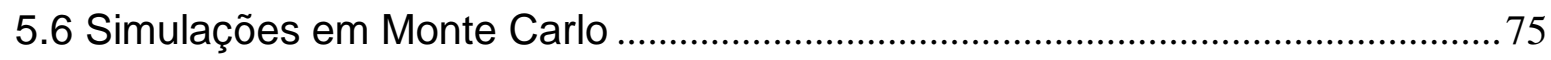

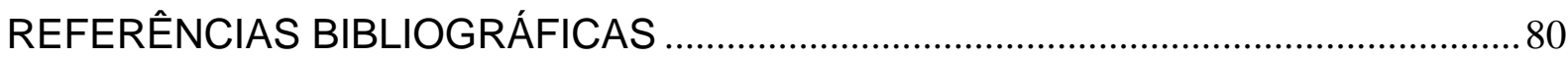




\section{LISTA DE FIGURAS}

Figura 1: Curva de transmissão percentual por espessuras de CSRs, para um feixe monoenergético de fótons.

Figura 2: Na região de build-up a dose absorvida aumenta com a profundidade até alcançar o valor máximo em uma profundidade que tem relação com o alcance dos elétrons. Nesta figura, o kerma e a dose absorvida diminuem com a profundidade por conta da atenuação de fótons. Caso este fenômeno não ocorresse, a dose se manteria no valor máximo e igual ao kerma que se manteria constante. Adaptado de ATTIX, 1986

Figura 3: Geometria da medição da dose absorvida em função da profundidade. $O$ ponto $Q$ é um ponto arbitrário no centro do feixe a uma profundidade $z$ cuja referência é a interface de incidência do feixe no phantom. Fonte: PODGORSAK (2005).

Figura 4: (A) Fluência $\Phi$ de partículas carregadas cruzando a interface entre os meios w e g considerando a fluência contínua na região fronteiriça e a razão das doses depositadas em cada meio sendo iguais à relação dos poderes de freamento dos meios. (B) Fluência através de uma fina camada que se encontra entre dois meios compostos por mesma substância. Fonte: ATTIX, 1986.

Figura 5: Razão entre os coeficientes de absorção mássicos para alguns materiais dosimétricos com relação ao tecido biológico cujo número atômico efetivo é igual a 7,35. Fonte: BOS, 2001.

Figura 6: Componentes de uma câmara de ionização. Fonte: SANTOS, J. C. 2013.15

Figura 7: Distribuição angular dos fótons de bremsstrahlung para diversas energias de elétrons. Fonte: KHAN, 2003.

Figura 8: Variação da intensidade da radiação em função do ângulo para diversos alvos espessos. O feixe de elétrons incide a $0^{\circ}$. Fonte: W.W. BUECHNER et al,1948.

Figura 9: Disposições de níveis de energia sendo que em (a) o elétron está livre, (b) oscilador harmônico simples (c) poço de potencial e (d) sequência de poços de potencial periódicos. Adaptado de BUBE, R. H., 1960.

Figura 10: Tipos de defeitos em cristais. Adaptado de KEER, H. V., 1993. 
Figura 11: Diagrama de energia do processo de luminescência opticamente estimulada. Os elétrons ficam armadilhados mais próximos à banda de condução. $\mathrm{Na}$ parte intermediária ficam os níveis defeituosos e que são responsáveis pela recombinação elétron-lacuna e emissão OSL. Nesta região as probabilidades de captura de um elétron e de captura de uma lacuna são iguais. Os níveis mais próximos à banda de valência armadilham lacunas. Adaptado de ATTIX, 1986........24

Figura 12: curva de emissão OSL em CW: decaimento do sinal OSL com o tempo ao aplicar luz de estimulação com intensidade constante.

Figura 13: Curva de emissão OSL em $\mathrm{CW}$ para os dosímetro de $\mathrm{BeO}$ quando irradiado no feixe com energia de 1,9 MeV do Microtron.

Figura 14: Embalagem para dosímetros de cor preta cuja finalidade é a proteção contra iluminação espúria.

Figura 15: Irradiador Theratron 80 utilizado na irradiação com feixes gama de ${ }^{60} \mathrm{Co}$.

Figura 16: Irradiador Cs-137. 34

Figura 17: Equipamento de raios X do Grupo de Dosimetria das Radiações e Física Médica.

Figura 18: Diagrama de um microtron tipo race-track. Fonte: RIOS, P. B., 2002 …...36

Figura 19: Componentes do acelerador Microtron. Fonte: site LAL-IFUSP 37

Figura 20: Suporte com alvo acoplado feito a partir de liga tungstênio, cobre e níquel utilizado para a produção de fótons de bremsstrahlung.

Figura 21: Aceleradores Clinac 6EX e Clinac iX.

Figura 22: Capa de build-up de PMMA com suporte para câmara de ionização.

Figura 23: Eletrômetro UNIDOS E e câmara de ionização Farmer utilizadas nas medições.

Figura 24: Geometria utilizada nas simulações. D representa a distância utilizada na situação experimental.

Figura 25: Espectro de energia dos fótons de raios $X$ de aceleradores clínicos de $6 \mathrm{MeV}$ e $15 \mathrm{MeV}$. 
Figura 26: Espectros calculados pelo modelo TBC para as energias máximas de 150 e $200 \mathrm{keV}$.

Figura 27: Geometria de obtenção dos espectros.

Figura 28: Leitor OSL RIS $\varnothing-$ TL/OSL DA-20 (RIS $\varnothing$ National Laboratory, Denmark).49

Figura 29: Espectro de transmissão do filtro U-340 e espectro de intensidade de luz emitida do conjunto de LEDs do equipamento Risø (Risø National Laboratory, Denmark).

Figura 30: Sistema de movimentação da câmara de ionização. A foto à esquerda mostra a câmara de ionização fixa no suporte enquanto é movimentada em uma barra rosqueada. A graduação onde se monitorou a posição da câmara está na foto à direita.

Figura 31: Histogramas do sinal OSL após a irradiação no feixe de Co-60 e do sinal normalizado pela dose de referência do feixe beta para os conjuntos de $\mathrm{Al}_{2} \mathrm{O}_{3}$ e $\mathrm{BeO}$. A abcissa dos gráficos foi normalizada pelo valor médio de cada distribuição.

Figura 32: Razão taxa de dose absorvida por corrente obtida por varredura com câmara de ionização para o feixe de raios $X$ produzido por elétrons com energia de $1,9 \mathrm{MeV}$ e $5,0 \mathrm{MeV}$. Na legenda estão os deslocamentos verticais em relação ao ponto central a $50 \mathrm{~cm}$ do alvo. As correntes utilizadas foram da ordem de $1 \mu \mathrm{A} e$ $10 \mu \mathrm{A}$ respectivamente.

Figura 33: Varredura do feixe de espectro largo com potencial máximo 150 e $200 \mathrm{kV}$ respectivamente, variando-se as alturas de modo a determinar a região de irradiação. A corrente foi mantida em $15 \mathrm{~mA}$ durante a varredura................................56

Figura 34: Curvas de emissão OSL para $\circ \mathrm{Al}_{2} \mathrm{O}_{3}$ irradiado com doses absorvidas aproximadamente 2 Gy para quatro dos feixes estudados nos primeiros $80 \mathrm{~s}$ de leitura. As curvas para irradiações com os demais feixes são semelhantes e não estão apresentadas para melhor visualização.

Figura 35: Curvas de emissão OSL normalizadas pelo valor máximo para os dosímetro de $\mathrm{Al}_{2} \mathrm{O}_{3}$ quando irradiados no feixe com energia de $1,9 \mathrm{MeV}$ do Microtron.

Figura 36: Resposta normalizada dos dosímetros de óxido de alumínio a diversos feixes.

Figura 37: Curvas de emissão OSL para $\circ \mathrm{BeO}$ irradiado com doses absorvidas aproximadamente 2 Gy para quatro dos feixes estudados nos primeiros $80 \mathrm{~s}$ de 
leitura. As curvas para as irradiações com os demais feixes são semelhantes e não estão apresentadas para melhor visualização.

Figura 38: Curvas de emissão OSL normalizadas pelo valor máximo para os dosímetro de $\mathrm{BeO}$ quando irradiados no feixe com energia de 1,9 MeV do Microtron.

Figura 39: Resposta OSL normalizada para os dosímetros de $\mathrm{BeO}$ irradiados nos feixes descritos.

Figura 40: Gráfico da dependência energética experimental dos dosímetros em função da energia média do feixe.

Figura 41: Os espectros à direita são os espectros largos conforme a norma (ABNT ISO 4037-1) e à esquerda são os espectros obtidos neste trabalho através da geração de espectros por TBC e da simulação por Monte Carlo utilizando o código PENELOPE, através da atenuação do feixe nos filtros metálicos indicados na Tabela 1.

Figura 42: Curva de kerma de colisão no ar relativa de fótons para o cálculo das camadas semirredutoras para o feixe W150 simulado com o código PENELOPE. Em vermelho está a curva ajustada.

Figura 43: Espectros simulados em PENELOPE para os feixes do Microtron nas energias máximas de 1,9 e 5,0 MeV.

Figura 44: Comparação entre as curvas PDP simuladas e medidas para os aceleradores clínicos com energias máximas de $6 \mathrm{MeV}$ e $15 \mathrm{MeV}$ respectivamente. A normalização foi feita pelo ponto onde é depositada a maior dose.

Figura 45: Diferença percentual entre a simulação e os valores medidos das curvas de PDP.

Figura 46: Gráfico da dependência energética experimental e simulada dos dosímetros em função da energia média do feixe. 


\section{LISTA DE TABELAS}

Tabela 1: Características requeridas da série de espectros largos segundo a norma ABNT NBR ISO 4037-1.

Tabela 2: Características do acelerador. Fonte: LAL-IFUSP. 38

Tabela 3: Características do alvo feito a partir da liga composta de tungstênio, cobre e níquel.

Tabela 4: Características dos materiais utilizados nas simulações. O alvo composto pela liga de tungstênio, cobre e níquel é apresentado em proporções mássicas, diferentemente dos outros materiais cujas proporções foram dadas em relação ao número de elementos.

Tabela 5: Parâmetros de irradiação. 52

Tabela 6: Dispersões (representadas pelo coeficiente de variação) da resposta OSL dos dosímetros sem nenhum tipo de seleção ou normalização.

Tabela 7: Resposta OSL após normalização com irradiação por fonte beta durante 2 s.

Tabela 8: Planura dos feixes na região central e deslocado acima (+) e abaixo (-)...57

Tabela 9: Valores da simetria dos feixes de espectro largo, Microtron e aceleradores clínicos.

Tabela 10: Dependência energética da resposta dosimétrica para o $\mathrm{Al}_{2} \mathrm{O}_{3}$.

Tabela 11: Dependência energética da resposta dosimétrica do BeO.

Tabela 12: Fatores de dependência energética obtidos experimentalmente para os materiais OSL utilizados nos diferentes feixes. Os valores foram calculados por ajuste linear.

Tabela 13: Comparação entre as camadas semirredutoras simuladas e os valores da norma (ISO 4037-1).

Tabela 14: Comparação entre as energias médias simuladas e da norma. 68

Tabela 15: Fatores de dependência energética simulados para os diversos feixes usando o código PENELOPE. 


\section{INTRODUÇÃO}

Mensurar grandezas físicas faz parte do cotidiano da humanidade desde a antiguidade devido às trocas, ao comércio de mercadorias e à necessidade de padronização das grandezas envolvidas. Atualmente este fato não mudou, e por isso a humanidade desenvolveu padrões de medidas confiáveis e criou normas a fim de assegurar a fidedignidade do valor de uma grandeza e da sua concretização em quantidades mensuradas.

$\mathrm{Na}$ área de radiações ionizantes não é diferente, pois com a utilização cada vez mais frequente de raios $X$ e de elementos radioativos, principalmente em tratamentos e diagnósticos médicos, criou-se a necessidade de conhecer melhor a quantidade de energia depositada pela radiação, tanto para avaliar a eficácia de um tratamento quanto para proteção dos indivíduos expostos. Esses temas são incluídos em áreas do conhecimento como Dosimetria e Física Médica.

No final do século $X I X$ e início do século $X X$ utilizavam-se raios $X$ em hospitais militares indiscriminadamente, se construíam aparelhos de raios $X$ caseiros, o que culminou com o surgimento de doenças devidas às radiações, e, com os estudos a respeito, houve a produção de conhecimento e de muitos artigos científicos tratando dessas enfermidades (Okuno e Yoshimura, 2010). Assim, em 1925, nasceu a ICRU (International Commission on Radiation Units and Measurements), com a finalidade de padronizar as grandezas e unidades de medida para as radiações. Desde então tem sido um dos objetivos desse e outros comitês internacionais a padronização de protocolos de medição e recomendação de limites de exposição para os Indivíduos Ocupacionalmente Expostos e para o público. Com isso a proteção radiológica e a dosimetria têm se desenvolvido muito em todo o mundo (ICRP, 2008).

Para mensurar as radiações, podemos utilizar diversos tipos de medidores como câmaras de ionização, dosímetros luminescentes, filmes radiográficos e materiais semicondutores. As características desses medidores e as grandezas medidas em cada caso diferenciam o possível uso de cada um deles. Neste projeto, serão estudados os dosímetros luminescentes do grupo conhecido como OSL, que é a abreviatura em inglês para Optically Stimulated Luminescence cuja tradução é 
luminescência opticamente estimulada. Como dosímetros padrão empregamos câmaras de ionização.

Os materiais que apresentam emissão luminescente quando são opticamente estimulados em resposta a irradiações com fótons de raios $X$, gama e elétrons e que foram empregados neste trabalho são o óxido de alumínio e óxido de berílio. Seu emprego como dosímetros na área de radioterapia externa com fótons e elétrons exige um conhecimento da variação da resposta com a energia da radiação. Para estudar essa variação serão empregados feixes de fótons de raios $X$ (Microtron, aceleradores hospitalares e equipamento de raios X do Grupo de Dosimetria das Radiações e Física Médica do Instituto de Física da USP) e de raios gama de fontes radioativas (cobalto-60 e césio-137). O conhecimento da resposta de um dosímetro em função da dose para diversas energias permite saber que correções haverá necessidade de empregar por conta desta dependência. Com este parâmetro conhecido podemos calibrar os dosímetros para apenas uma qualidade de feixe.

Este trabalho tem como objetivo verificar a variação da resposta OSL de $\mathrm{Al}_{2} \mathrm{O}_{3}$ e $\mathrm{BeO}$ com a energia de fótons de raios $\mathrm{X}$ e gama e com a dose absorvida $\mathrm{e}$ comparar com respostas esperadas pela deposição de energia nos materiais obtidas por simulações de Monte Carlo. Outros objetivos foram a produção de um feixe de raios $X$ a partir do feixe de elétrons do acelerador Microtron com as energias de 1,9 e 5,0 MeV; a obtenção, por simulação Monte Carlo ou por métodos analíticos, dos espectros de energia dos feixes de raios $\mathrm{X}$ dos diversos irradiadores de pesquisa e a observação de potenciais mudanças produzidas nas curvas de emissão OSL dos dois dosímetros devido às energias dos raios $\mathrm{X}$ e gama. 


\section{CONCEITOS TEÓRICOS}

Incialmente definiremos algumas grandezas e termos necessários que foram utilizados neste trabalho.

\subsection{Grandezas e unidades dosimétricas}

\subsubsection{Fluência $\Phi$.}

A fluência de partículas, $\Phi$, é a razão entre a quantidade de partículas, $d N$, que cruzam uma área, $d a$, por unidade de área. Sua unidade no Sistema Internacional (SI) é o $\mathrm{m}^{-2}$,

$$
\Phi=\frac{d N}{d a}
$$

\subsubsection{Fluência de energia, $\psi$.}

Também podemos definir a fluência de energia $\Psi$, que é energia radiante incidente em uma secção de área $d a$, por unidade de área. A unidade no SI para a fluência de energia é $\mathrm{J} / \mathrm{m}^{2}$. Para feixes monoenergéticos de partículas:

$$
\Psi=\frac{d N}{d A} E=\Phi E
$$

Onde $d N$ é o número de partículas com energia $E$. No caso polienergético, deve-se integrar (ou somar) para todo o intervalo de energia.

$$
\Psi=\int_{E=0}^{\operatorname{Emax}} \Psi_{E}(E) d E
$$


Onde $\Psi_{E}(E)$ é a distribuição diferencial de fluência de energia para as partículas.

\subsubsection{Kerma}

Kerma, do inglês "kinetic energy released per unit mass" é uma grandeza que relaciona a energia cinética transferida por radiações indiretamente ionizantes (fótons e nêutrons) para partículas carregadas. A unidade no SI para esta grandeza é o J/kg, que recebe o nome especial de gray (ICRU, 1980):

$$
K=\frac{d E_{t r}}{d m}
$$

A energia transferida $d E_{t r}$ é a soma das energias cinéticas iniciais de todas as partículas ionizantes carregadas liberadas por partículas sem carga em um material de massa $d m$ (ICRU, 1980).

Para obter o kerma em um material com número atômico $Z$ sendo irradiado por um feixe com espectro de fluência de energia $\Psi(E)$, utilizamos a Equação 5.

$$
K=\int_{E=0}^{E \max } \Psi^{\prime}(E)\left(\frac{\mu_{t r}}{\rho}\right)_{E, Z} d E
$$

Sendo $\left(\frac{\mu_{t r}}{\rho}\right)_{E, Z}$ o coeficiente mássico de transferência de energia, $\Psi^{\prime}(E)$ é a distribuição diferencial de fluência de energia para fótons e $\rho$ a densidade do material.

O kerma pode ser separado em duas parcelas, colisão e radiação. Um elétron rápido (liberado por interação de fótons, por exemplo) ao interagir com um material absorvedor pode perder sua energia cinética através de interações coulombianas produzindo ionização e excitação. Estas interações são contabilizadas para a parte colisional do kerma. Já interações que resultam na emissão de radiação (bremsstrahlung) contribuem para o kerma de radiação (ATTIX, 1986). 


\subsubsection{Dose absorvida}

A dose absorvida é definida como a energia cedida ao meio devido às radiações ionizantes (direta ou indiretamente ionizantes) depositada por unidade de massa.

$$
D=\frac{d \epsilon}{d m}
$$

Onde $d \epsilon$ é a energia absorvida, $d m$ é a massa contida no volume irradiado e a unidade é $\mathrm{J} / \mathrm{kg}$ que, assim como para o kerma, também foi denominada gray. A energia absorvida é dada por:

$$
\epsilon=R_{n c}^{e}+R_{c}^{e}-R_{n c}^{s}-R_{c}^{s}+\sum M
$$

Onde

$R_{n c}^{e}$ e $R_{c}^{e}$ são as energias radiantes proveniente de partículas sem carga e com carga respectivamente que incidem no volume;

$R_{n c}^{S}$ e $R_{c}^{s}$ são as energias radiantes de partículas sem e com carga que deixam o volume de interesse e

$\sum M$ é a energia líquida derivada de conversões entre massa de repouso e energia radiante originada no volume (ATTIX, 1986).

A energia absorvida é a parcela da energia da radiação ionizante que fica no volume de massa $\mathrm{dm}$.

\subsubsection{Camada semirredutora}

Camada semirredutora, ou CSR, é a espessura de um material absorvedor necessária para reduzir a taxa de kerma de colisão no ar para metade do seu valor inicial em um feixe de raios $X$ ou gama. Num feixe polienergético os valores da primeira e da segunda camada semirredutora diferem por conta da diferença de absorção das várias energias do feixe no material (os fótons de energia menor são mais interagentes). Por isso, para classificar um feixe polienergético são medidas as CSRs (primeira e segunda) em materiais padrão como alumínio ou cobre (ATTIX, 1986) para determinar a energia efetiva do feixe, que seria o equivalente à energia de um feixe monoenergético com mesma primeira camada semirredutora. Na Figura 
1 está apresentado um exemplo de transmissão percentual em função da quantidade de camadas semirredutoras para um feixe monoenergético. Conhecidas duas primeiras camadas semirredutoras podemos determinar o coeficiente de homogeneidade:

$$
h=\frac{1^{\mathrm{a}} \operatorname{CSR}}{2^{\underline{\mathrm{a}}} C S R}
$$

quanto mais próximo de 1 for o coeficiente $h$, mais filtrado é o feixe de raios $\mathrm{X}$.

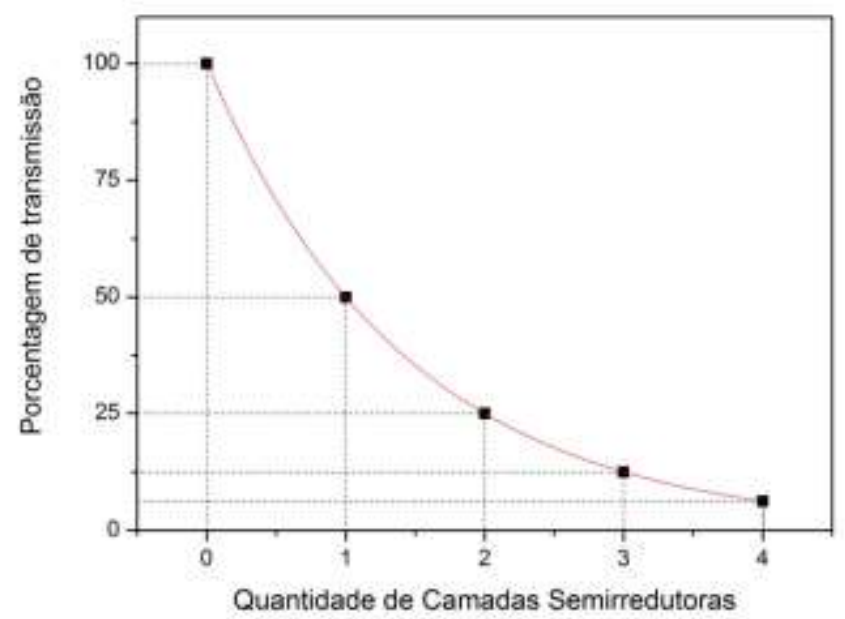

Figura 1: Curva de transmissão percentual por espessuras de CSRs, para um feixe monoenergético de fótons.

\subsubsection{Poder de freamento}

O poder de freamento é a média da perda de energia por unidade de comprimento de um conjunto de partículas carregadas idênticas e com mesma energia. Como o número de colisões por unidade de comprimento é grande, podemos considerar que o valor médio tem uma variação estatística pequena (ICRU, 1984b). Esta grandeza pode ser classificada em dois tipos diferentes: de colisão, quando partículas carregadas energéticas interagem com elétrons atômicos transferindo energia cinética a esses elétrons, e de radiação, quando há interação dos elétrons com o campo coulombiano do núcleo (ou de elétrons) e dessas interações resulta emissão de fótons por processos de freamento (bremsstrahlung). 
Uma colisão suave ocorre quando uma partícula carregada passa a uma grande distância do núcleo atômico, neste caso o parâmetro de impacto é muito maior que o raio do núcleo e a transferência de energia é pequena. Já em uma colisão dura (parâmetro de impacto próximo ao raio de camada eletrônica) existe grande probabilidade de uma ionização. O poder de freamento costumeiramente é dividido pela densidade do meio absorvedor para reduzir a dependência do material absorvedor. Neste caso, esta grandeza é conhecida como poder de freamento mássico. Na Equação 9 temos o poder de freamento mássico de colisão para elétrons com velocidade $v$ e energia cinética $T$. Já foi contabilizado nesta equação o fato do elétron, ao colidir com outro elétron, transferir a ele no máximo metade de sua energia por conta da indistinguibilidade das partículas.

$$
\left(\frac{d T}{\rho d x}\right)_{c o l}=\frac{N_{a} Z \pi r_{0}^{2} 2 m_{e} c^{2}}{A \beta^{2}}\left\{\ln \left(\frac{T}{I}\right)^{2}+\ln \left[1+\left(\frac{\tau}{2}\right)\right]+F(\tau)-\delta\right\}
$$

Onde

$$
F(\tau)=\left(1-\beta^{2}\right)\left[1+\frac{\tau^{2}}{8}-(2 \tau+1) \ln 2\right]
$$

$N_{a}$ é o número de Avogadro;

$m_{e}$ é a massa do elétron;

$r_{0}$ é o raio clássico do elétron;

$Z$ e A são é o número atômico e o número de massa do material;

I é o potencial de ionização médio do meio;

$\delta$ é uma correção para o efeito de densidade;

$\tau=T / m_{e} c^{2}$ e $\beta=v / c$, sendo $T$ a energia cinética, $v$ a velocidade $e c$ a velocidade da luz no vácuo (ICRU, 1984a).

A correção do efeito de densidade $\delta$ é devido ao fato do campo elétrico da partícula carregada polarizar os átomos ao longo de sua trajetória. Por conta desta polarização, os elétrons que se encontram longe do caminho da partícula serão blindados da intensidade máxima do campo elétrico e com isso contribuirão menos para a perda de energia durante as colisões. Este efeito se torna relevante com o aumento da energia da partícula incidente (ICRU, 1984b).

$O$ poder de freamento de radiação é a taxa de perda de energia das partículas carregadas que resultam na produção de fótons (bremsstrahlung). A 
Equação 11 mostra a dependência com $Z$ do poder de freamento de radiação enquanto que na Equação 9, há pouca dependência em $Z$ (a razão $Z / A$ varia muito pouco ao longo da tabela periódica, restando, praticamente, a dependência em I), sendo possível concluir que, para materiais com alto número atômico, há maior emissão de energia radiante (fótons).

$$
\left(\frac{d T}{\rho d x}\right)_{\text {rad }}=\frac{\alpha e^{4} N_{a} Z^{2}}{A\left(4 \pi \varepsilon_{0} m_{e} c^{2}\right)^{2}}\left(T+m_{e} c^{2}\right) B_{r}
$$

Onde

$\alpha$ é a constante de estrutura fina, $\varepsilon_{0}$ é a constante de permissividade do vácuo e $B_{r}$ é uma função do número atômico e da energia cinética que varia entre 5,33 e 15 para energias entre 0,5 e $100 \mathrm{MeV}$ (ICRU, 1984b).

Também é possível notar que haverá mais radiação emitida com o aumento da energia cinética $T$ das partículas carregadas que incidem no alvo. O poder de freamento de radiação será maior que o de colisão a partir da Energia Crítica $E_{c}$, que é a energia na qual os poderes de freamento se igualam. A Equação 12 mostra a aproximação de Bethe e Heitler para a estimativa da Energia Crítica (LEO, 1994).

$$
E_{c}=\frac{1600 m_{e} c^{2}}{Z}
$$

\subsubsection{Região de build-up}

O equilíbrio eletrônico é um conceito primordial quando lidamos com a dose depositada em um material ao relacionar dose absorvida com o kerma no meio de interesse. Quando há equilíbrio, cada elétron que deixa o volume de interesse é compensado por outro com mesma energia que entra no volume.

A dose absorvida nem sempre tem proporcionalidade com a ionização produzida no meio por fótons, embora o kerma de colisão sempre guarde a proporcionalidade. $\mathrm{Na}$ região de build-up (termo em inglês que significa crescimento), a dose não tem essa correspondência por não satisfazer a condição de equilíbrio eletrônico. Neste caso, o valor da dose é menor do que o valor em equilíbrio, fazendo-se necessário a inclusão de material com dimensão comparável ao alcance de um elétron secundário liberado no material para que as irradiações ocorram em equilíbrio eletrônico e com proporcionalidade entre kerma e dose absorvida. 
A Figura 2 mostra o aumento da dose com a profundidade próxima à superfície e a região de build-up.

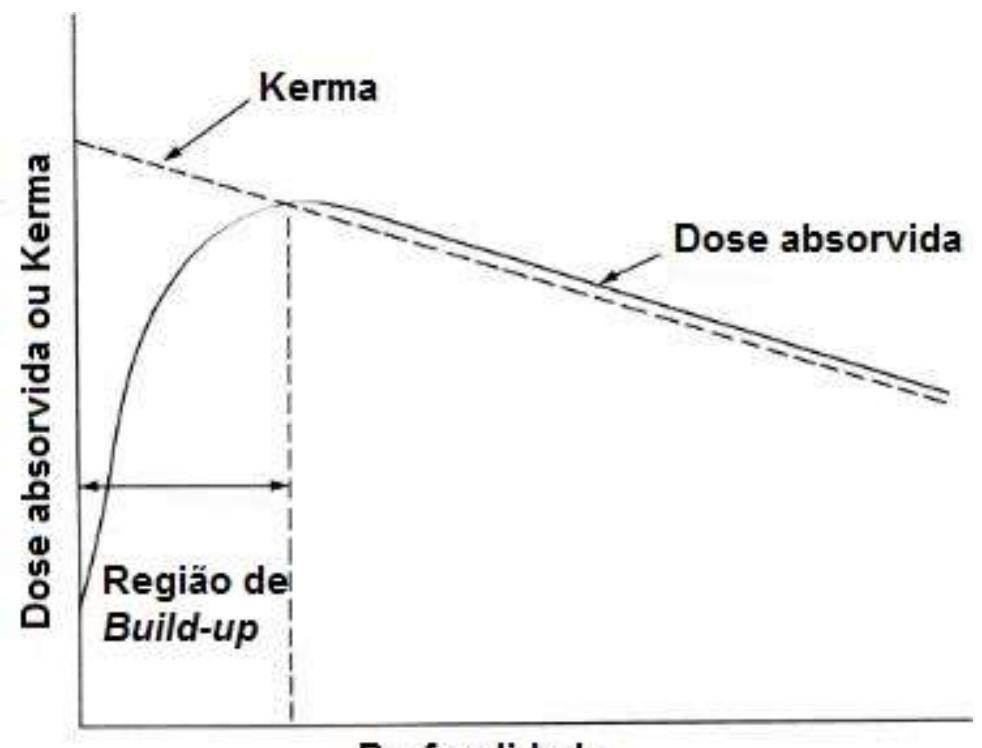

Profundidade

Figura 2: Na região de build-up a dose absorvida aumenta com a profundidade até alcançar o valor máximo em uma profundidade que tem relação com o alcance dos elétrons. Nesta figura, o kerma e a dose absorvida diminuem com a profundidade por conta da atenuação de fótons. Caso este fenômeno não ocorresse, a dose se manteria no valor máximo e igual ao kerma que se manteria constante. Adaptado de ATTIX, 1986.

\subsubsection{Deposição da energia com a profundidade}

Conhecer como se dá a deposição de energia (distribuição de dose absorvida) em pacientes é importante nos tratamentos. Por conta disso e da dificuldade em saber diretamente como se dá essa deposição, pode-se analisar como é a distribuição de dose absorvida com relação à profundidade em um phantom de água. Um phantom é um material utilizado como um simulador de paciente com o objetivo de comparar sistemas de medição, controle de parâmetros técnicos e costumeiramente é feito de material cujas características se assemelham a da composição do tecido humano como, por exemplo, a água. Segundo as recomendações da IAEA, a água é o meio de referência para medidas de dose absorvida para fótons e elétrons em radioterapia. Os phantoms devem ter, lateralmente, pelo menos 5 centímetros a mais do que o maior tamanho de campo utilizado na profundidade na qual a medida é feita (IAEA TRS-398, 2000).

Essa distribuição de doses é geralmente normalizada pelo valor máximo de dose absorvida. Na Figura 3 temos a geometria do estudo da distribuição da dose 
com a profundidade. Um phantom de água está posicionado a uma distância SSD (ou $f$ ) da fonte. Na situação apresentada para um determinado feixe com energia definida, largura de campo também definida, há uma região onde a dose cresce com

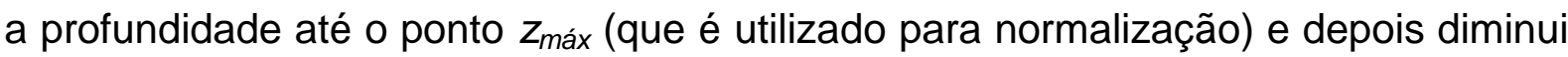
com a profundidade. A distribuição de dose com a profundidade é influenciada pela distância SSD, largura do campo de irradiação e energia do feixe (KHAN, 2003).

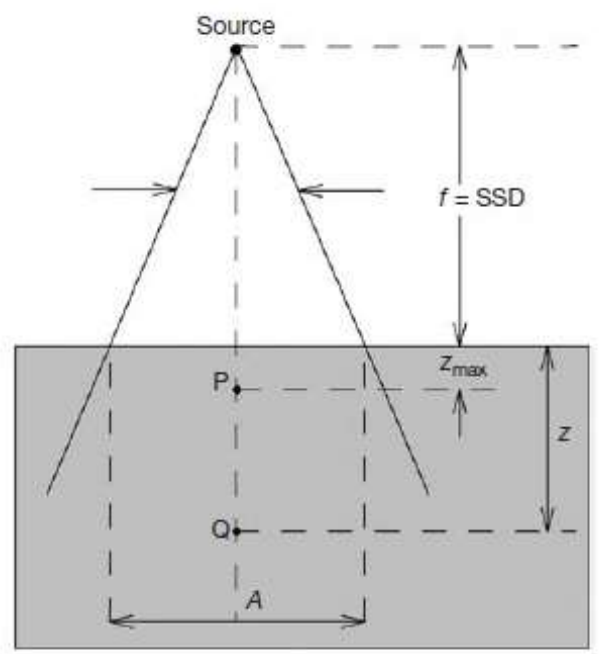

Figura 3: Geometria da medição da dose absorvida em função da profundidade. O ponto Q é um ponto arbitrário no centro do feixe a uma profundidade $z$ cuja referência é a interface de incidência do feixe no phantom. Fonte: PODGORSAK (2005).

Com a geometria apresenta na Figura 3 é possível definir uma relação importante quando se trata da deposição de dose em um objeto simulador, a PDP. Esta abreviação vem da tradução do inglês de Percent Depth Dose (Porcentagem de Dose Profunda) e é a razão entre as doses distribuídas nas diversas profundidades $\left(D_{Q}\right)$ e a dose absorvida no ponto de máxima dose $\left(z_{\max }\right)$ do phantom $\left(D_{P}\right)$ no eixo central para certo campo de radiação $A$, com energia $h v$ e distância $f$ entre fonte de radiação e phantom conforme a Equação 13.

$$
P D P(z, A, f, h v)=100 \frac{D_{Q}}{D_{P}}
$$




\subsubsection{Dosimetria}

Dosimetria é a área do conhecimento que lida com a determinação direta ou indireta das grandezas físicas relacionadas às interações da radiação ionizante com a matéria, em particular kerma e dose absorvida.

Um dosímetro é um dispositivo que, com a sua resposta, fornece um valor para a energia depositada por unidade de massa em seu volume sensível devido à radiação ionizante. É utilizado, muitas vezes, para conhecer indiretamente a dose absorvida em um meio (ATTIX, 1986). Por exemplo, uma câmara de ionização é formada por um volume no qual, por ação de um campo elétrico aplicado neste, coleta-se a carga proveniente da interação da radiação incidente com o elemento constituinte do meio, envolto por uma parede de outro material cuja função é proteger mecanicamente, confinar o campo elétrico e manter o equilíbrio eletrônico. Através da teoria de cavidades é possível estimar a relação entre a dose no invólucro e na cavidade, e a dose no meio no qual a câmara de ionização (ou um dosímetro em geral) está imersa. As paredes devem ter dimensões maiores que o alcance dos elétrons liberados devido ao feixe de fótons incidente, de forma a garantir o equilíbrio eletrônico.

A resposta do dosímetro pode depender de vários fatores tais quais a taxa de dose, dose absorvida total, energia do feixe, tipo de partícula do feixe, etc. O caso ideal seria uma resposta linearmente dependente da dose e independente da energia das partículas do feixe de radiação, porém não é o que ocorre muitas vezes. Por conta desse fato, podem-se aplicar correções para situações específicas.

Em um feixe de partículas carregas idênticas com fluência $\Phi$ que sai de um meio $w$ e entra em um meio diferente $g$ com certa energia cinética $T$ podemos calcular a dose absorvida nos meios por:

$$
D_{w}=\Phi\left(\frac{d T}{\rho d x}\right)_{w}
$$

e

$$
D_{g}=\Phi\left(\frac{d T}{\rho d x}\right)_{g}
$$


Sendo $\left(\frac{d T}{\rho d x}\right)$ o poder de freamento mássico para um meio e assumindo a fluência contínua na interface quando um feixe de partículas carregadas cruza do meio $w$ para o meio $g$ :

$$
\frac{D_{w}}{D_{g}}=\frac{\left(\frac{d T}{\rho d x}\right)_{w}}{\left(\frac{d T}{\rho d x}\right)_{g}}
$$

A Figura 4 ilustra a situação de um feixe de partículas carregadas saindo de uma região $w$, depositando uma dose $D_{w}$, cruzando uma região $g$, depositando uma dose $D_{g}$, e, por fim, indo para a região $w$.

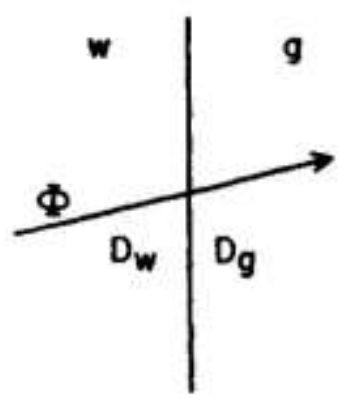

A

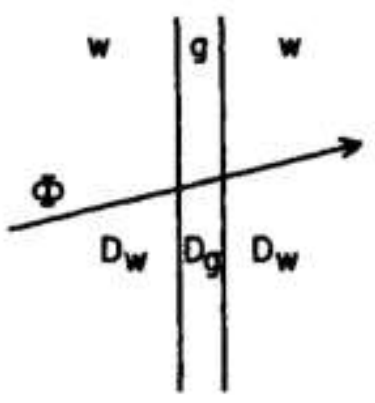

B

Figura 4: (A) Fluência $\Phi$ de partículas carregadas cruzando a interface entre os meios $w$ e $g$ considerando a fluência contínua na região fronteiriça e a razão das doses depositadas em cada meio sendo iguais à relação dos poderes de freamento dos meios. (B) Fluência através de uma fina camada que se encontra entre dois meios compostos por mesma substância. Fonte: ATTIX, 1986.

Se a camada $g$ for menor que o alcance das partículas carregadas que incidem nela de modo a não perturbar o campo de partículas carregadas, a dose será aproximadamente igual ao kerma por conta da igualdade da fluência e a manutenção do equilíbrio eletrônico (ATTIX, 1986). Outra condição é que a dose absorvida na cavidade é proveniente apenas de partículas carregadas produzidas fora do meio e que o cruzam.

Satisfeitas estas condições podemos calcular a dose absorvida em uma cavidade considerando a fluência contínua na interface. Uma câmara de ionização, bem como outros tipos de medidores de dose absorvida, pode ser tratada pela teoria de cavidade dependendo do meio em que está imersa e da energia da radiação incidente (fótons). 
Para fótons, satisfeitas as condições da teoria de cavidades, o equilíbrio eletrônico é alcançado e com isso, podemos calcular utilizando a Equação 17 a dose absorvida em um meio considerando a aproximação da dose absorvida $D$ pelo kerma de colisão $K_{c}$.

$$
D=K_{c}=\psi\left(\frac{\mu_{e n}}{\rho}\right)
$$

Onde $\left(\frac{\mu_{e n}}{\rho}\right)$ é o coeficiente de absorção de energia mássico.

Com a Equação 18 podemos relacionar a dose absorvida em um meio $x$ com a dose absorvida no meio $w$ sob as mesmas condições de irradiação com fótons desde que haja equilíbrio eletrônico. Esta expressão é válida para cavidades grandes.

$$
D_{x}=D_{w} \frac{\left(\frac{\mu_{e n}}{\rho}\right)_{x}}{\left(\frac{\mu_{e n}}{\rho}\right)_{w}}
$$

Um detector de radiação ideal deveria ser feito do mesmo material do meio de interesse em conhecer a dose absorvida, porém não é o que ocorre na prática por conta da diferença da composição do material detector. Com isso, a interação com o campo de radiação é diferente obtendo, assim, respostas diferentes em função da energia do feixe.

Dosímetros cuja razão de seus coeficientes de absorção de energia mássicos em relação ao tecido (ou à água) é aproximadamente unitário possuem deposição de energia no material igual à energia depositada no tecido quando expostos ao mesmo feixe de radiação (YUKIHARA e MCKEEVER, 2011). A Figura 5 mostra esta razão em função da energia dos fótons para diversos materiais utilizados como dosímetros OSL e TL. É possível ver nesta figura que a dose absorvida pelo $\mathrm{Al}_{2} \mathrm{O}_{3}$ em energias abaixo de $50 \mathrm{keV}$ é aproximadamente entre duas e três vezes maior que a dose absorvida no tecido. Já na região próxima a $1 \mathrm{MeV}$ os materiais têm comportamento muito semelhante ao do tecido no que se refere à absorção de energia. 


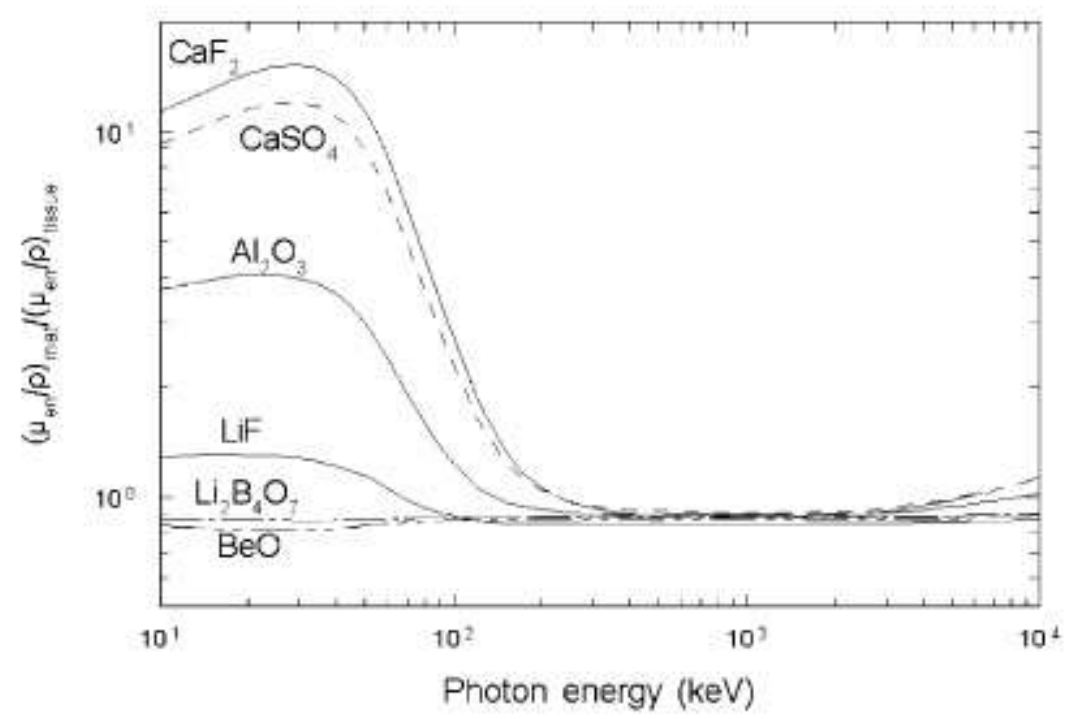

Figura 5: Razão entre os coeficientes de absorção mássicos para alguns materiais dosimétricos com relação ao tecido biológico cujo número atômico efetivo é igual a 7,35. Fonte: BOS, 2001.

\subsubsection{Câmara de ionização}

A câmara de ionização é um dispositivo muito usado para estimativa de dose absorvida que consiste em uma cavidade preenchida pelo material no qual será feita a coleta dos íons através da aplicação de uma diferença de potencial entre eletrodos. A dose absorvida medida é proporcional à carga coletada nos eletrodos, podendo ser convertida diretamente por um eletrômetro inserindo as informações sobre volume, temperatura e pressão. Correções devem ser feitas, pois a massa de ar que preenche o volume da câmara varia com temperatura e pressão ambiental, devido à variação da densidade do meio (ar).

As paredes que envolvem toda a cavidade têm como funções principais manter o equilíbrio eletrônico e proteger contra choques mecânicos e possíveis avarias ou deformações do meio. Na Figura 6 temos a ilustração dos componentes principais de uma câmara de ionização: 


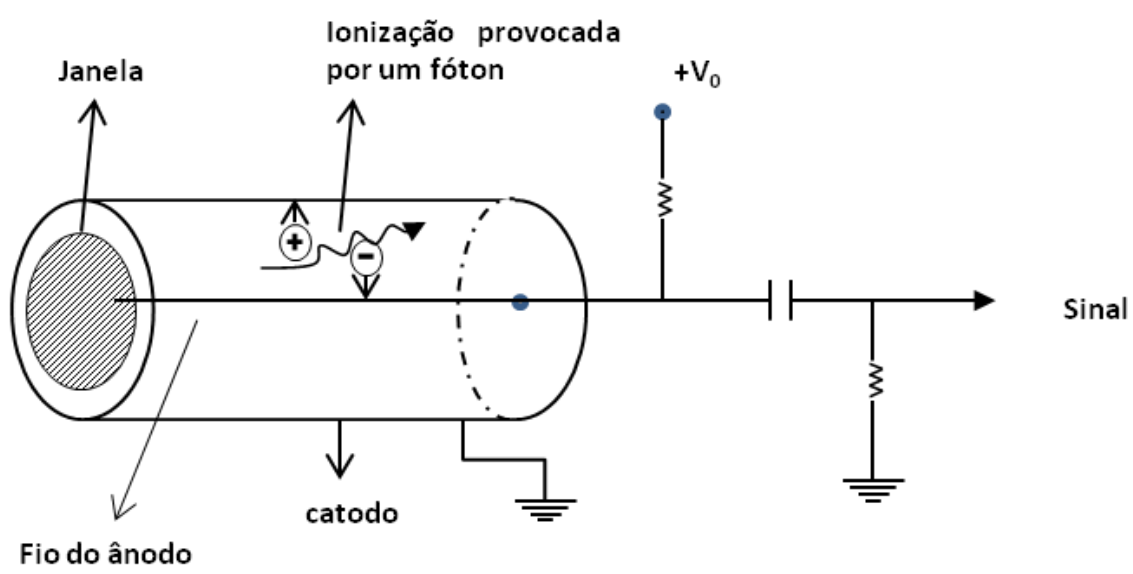

Figura 6: Componentes de uma câmara de ionização. Fonte: SANTOS, J. C. 2013.

\subsection{Feixes de fótons}

\subsubsection{Produção de raios $X$}

A radiação de freamento é produzida quando certo material, preferencialmente de número atômico alto, é bombardeado por elétrons com altas energias. Estes elétrons são liberados por um filamento percorrido por uma corrente elétrica (catodo), que se aquece e libera elétrons por efeito termiônico (JOHNS, 1983). Após serem liberados, os elétrons são acelerados e se chocam com o anodo. $\mathrm{Na}$ região onde as cargas se movimentam é feito vácuo a fim de evitar a dissipação de energia por conta das colisões com as moléculas do gás que estariam no percurso. Além destes equipamentos, também é possível gerar feixes de raios $X$ utilizando aceleradores Microtron ou aceleradores lineares de elétrons para gerar, pelo mesmo fenômeno de bremsstrahlung, feixes de fótons com energia muito maior (energia máxima igual à energia cinética dos elétrons). Para tensões típicas utilizadas em radiologia diagnóstica $(\sim 100 \mathrm{kV})$, menos de $1 \%$ da energia portada pelos elétrons é convertida em raios $X$ enquanto que os outros $99 \%$ são convertidos em calor.

Geralmente o anodo é feito de material com alto número atômico para aumentar o rendimento de radiação, ou seja, a fração da energia cinética inicial média dos elétrons convertida em energia radiante por conta do aumento da seção de choque de bremsstrahlung. 
A energia radiante deste processo é produzida devido à interação (colisões inelásticas) do elétron com o campo elétrico do núcleo do atômico. A perda de energia cinética do elétron é liberada na forma de fótons de bremsstrahlung. A direção preferencial para a emissão dos fótons do processo de bremsstrahlung varia com a energia cinética dos elétrons como é possível observar na Figura 7. Havendo um feixe de elétrons incidindo perpendicularmente ao alvo, o feixe de fótons obtido se torna cada vez mais proeminente na mesma direção do feixe de elétrons, quanto maior for a energia cinética deles. Comumente feixes utilizados em radioterapia (altas energias de elétrons) são produzidos em aceleradores na mesma direção do feixe de elétrons, enquanto que feixes diagnósticos (baixas energias) são utilizados no mesmo lado do alvo $\left(90^{\circ}\right.$ entre feixe de elétrons e de fótons).

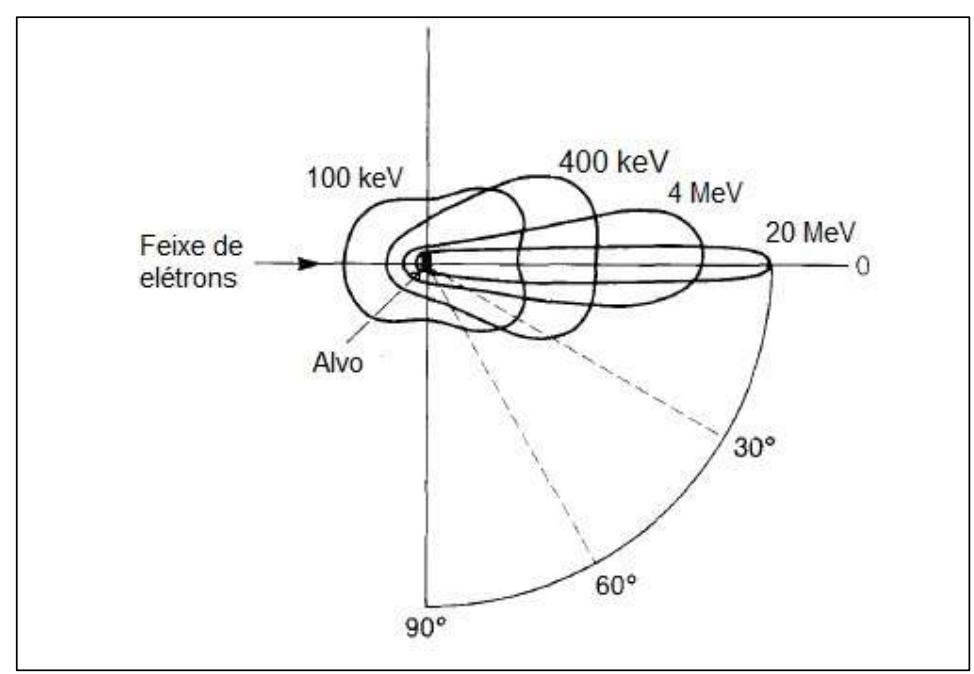

Figura 7: Distribuição angular dos fótons de bremsstrahlung para diversas energias de elétrons. Fonte: KHAN, 2003.

A Equação 19 mostra a aproximação para a razão dos poderes de freamento de radiação e de colisão que é proporcional a $T Z$, o que significa que para alvos com alto $Z$, a produção de radiação é maior. Por esse motivo, o tungstênio $(Z=74)$ é muito utilizado na geração de feixes de bremsstrahlung. Outra característica importante da utilização do tungstênio é a alta temperatura de fusão, pois grande parte da energia é dissipada no material em forma de calor (ICRU, 2012).

$$
\frac{T Z}{n}=\frac{\left(\frac{d T}{\rho d x}\right)_{r}}{\left(\frac{d T}{\rho d x}\right)_{c}}
$$


Onde

$T$ é a energia cinética inicial do elétron;

$Z$ é o número atômico do material e

$n$ é uma constante.

Somados ao espectro de bremsstrahlung, também há os raios $\mathrm{X}$ característicos que são devidos às interações entre a partícula carregada incidente (elétrons, neste caso) com os elétrons orbitais do material. Numa colisão entre estas partículas, estando a partícula incidente com energia suficiente para causar a ionização, o elétron ligado é ejetado e um outro elétron com nível de energia maior ocupa a vacância orbital. A diferença de energia dos níveis envolvidos no processo de transição eletrônica pode ser emitida na forma de um fóton característico. Os fótons emitidos através destas transições eletrônicas têm energia discreta e o espectro de suas energias é característico para cada material irradiado (ATTIX, 1986).

\subsubsection{Características de um feixe clínico}

Comumente, feixes de raios $X$ diagnósticos e de radioterapia são caracterizados pelo potencial máximo de aceleração e pelas duas primeiras camadas semirredutoras e o respectivo coeficiente de homogeneidade em materiais padrão tais como o alumínio e o cobre. Já os feixes de alta energia produzidos por aceleradores clínicos, a qualidade do feixe é definida pelo índice $\operatorname{TPR}_{20,10}$ (do inglês Tissue Phantom Ratio), que é a razão das doses absorvidas nas profundidades de 20 e $10 \mathrm{~cm}$ em um phantom de água, mantendo fixa a distância entre a fonte de radiação e o detector (em geral $100 \mathrm{~cm}$ ) e dimensão do campo de $10 \mathrm{~cm} \times 10 \mathrm{~cm}$ (IAEA TRS 398, 2000).

A planura de um feixe ( $F$, do inglês flatness) de radioterapia pode ser definida a partir das doses absorvidas máxima e mínima observadas no perfil de doses ao longo de $80 \%$ da largura da faixa central do feixe medida a 10 centímetros de profundidade (KHAN, 2003). Outra especificação define a planura de um feixe a partir da porcentagem máxima de variação de dose absorvida em $80 \%$ da largura à meia altura do perfil em um plano transversal ao eixo do feixe (AAPM, 1994). A partir da Equação 20 é possível calcular a planura do feixe. 


$$
F=100 * \frac{D_{\max }-D_{\min }}{D_{\max }+D_{\min }}
$$

Feixes gerados em aceleradores lineares geralmente devem ter a planura $F$ menor que $3 \%$ quando medida em um phantom de água a uma profundidade de 10 centímetros, distância da fonte até a superfície do phantom de 100 centímetros e maior área de campo disponível (KHAN, 2003).

Outro parâmetro importante na caracterização de um feixe é a simetria $(S)$, que é costumeiramente definida como desvio percentual máximo entre o lado esquerdo e o lado direito de um perfil de feixe tomando como limites $80 \%$ dos pontos da largura à meia altura. Pode ser definida para ambas as direções transversais e diversos tamanhos de campo (AAPM, 1994). A estimativa da simetria é calculada através da Equação (21)

$$
S=100 * \frac{\hat{\text { érea }} \text { esq }- \text { Área }}{\text { dir }}
$$

Uma especificação típica de simetria também pode ser feita comparando as áreas utilizando como referência dois pontos equidistantes em relação ao ponto central de um perfil de dose. Neste caso a diferença percentual pode ser de até $2 \%$ (AAPM, 1994).

$\mathrm{Na}$ Figura 8 estão apresentadas algumas curvas de intensidade da radiação em função do ângulo para alvos espessos de diversos materiais nos quais incide feixe de elétrons com energia de 2,35 MeV. Nesta imagem é possível ver que os feixes são produzidos com um formato não uniforme. Por conta disso, os aceleradores clínicos possuem um filtro feito com o propósito de compensar a nãouniformidade da fluência de fótons (e da dose absorvida) do campo de irradiação (chamado flatness filter ou filtro de planura).

Atualmente, a utilização sem o filtro de planura, disponível em alguns equipamentos recentes em radioterapia, mesmo sem uma maior uniformidade de campo traz as seguintes vantagens: 
- Redução do tempo de irradiação no paciente;

- Aumento da taxa de dose;

- Maior eficácia em tratamentos nos quais o paciente necessita cessar a respiração (VASSILIEV, 2006).

Conforme a energia do feixe, a planura do feixe de fótons pode variar por conta da variação da emissão de fótons com o ângulo. Em energias elevadas, o feixe fica com um formato mais pontiagudo conforme visto na Figura 7. Em estudos mais detalhados como, por exemplo, o de BUECHNER et al (1948) utilizou-se de um alvo de espesso de tungstênio e de outros materiais e mediu-se a intensidade da radiação em função do ângulo, mostrando que o feixe tem uma distribuição angular cuja região central pode ser considerada uniforme dependendo da distância entre o alvo e o material a ser irradiado.

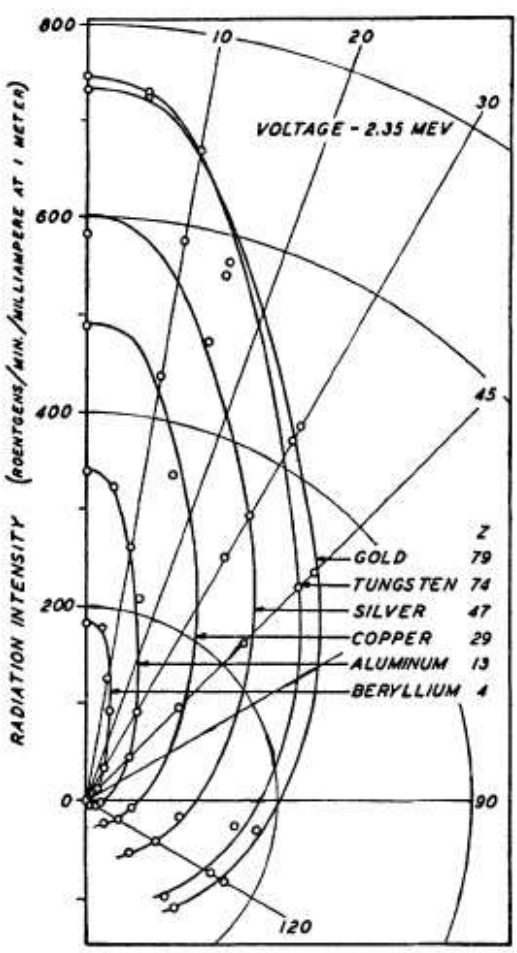

Figura 8: Variação da intensidade da radiação em função do ângulo para diversos alvos espessos. O feixe de elétrons incide a $0^{\circ}$. Fonte: W.W. BUECHNER et al,1948.

\subsection{Luminescência opticamente estimulada}

A dosimetria por OSL (do termo inglês Optically Stimullated Luminescence, Luminescência Opticamente Estimulada) consiste no emprego de materiais que têm 
a propriedade de, quando previamente irradiados, armazenarem energia absorvida da radiação em estados pontuais bastante estáveis (estados metaestáveis), energia esta que é, em parte, liberada quando o material é estimulado com luz de comprimento de onda adequado. O processo é devido à configuração eletrônica do material (em geral cristalino e isolante), que pode ser moldada pela adição de impurezas durante a produção do material e por tratamentos térmicos específicos. Quando o processo de recombinação de cargas ocorre, temos a emissão de luz que, utilizando equipamentos adequados, pode ser utilizada para determinação da dose de radiação absorvida pelo material. (MCKEEVER, 2011; YUKIHARA e MCKEEVER, 2011).

A dosimetria OSL se constitui na medição da luz emitida pelo material, em certa faixa de comprimentos de onda, durante a iluminação com fonte de luz controlada (de comprimento de onda maior). A intensidade de luz medida está relacionada com o estímulo do material e com a quantidade de radiação a que foi previamente exposto.

A luz que é aplicada para a obtenção do sinal OSL estimula o cristal, e libera elétrons ou lacunas "armadilhados" nos estados metaestáveis devidos aos defeitos dos materiais (usualmente chamados de armadilhas). Assim, torna-se possível a recombinação entre cargas para a liberação de energia em forma de fótons. Ao estado de energia onde ocorre a recombinação de cargas chama-se Centro de Recombinação.

O termo "armadilhamento" está bem difundido entre os especialistas da área, e é um jargão para um poço de potencial criado a partir dos defeitos do cristal, ou seja, um defeito localizado, no qual pode ser capturada uma carga liberada da banda de condução ou da de valência. Trata-se de um nível de energia na banda proibida daquela rede cristalina. Os defeitos envolvidos no processo OSL podem ser intrínsecos ou extrínsecos, podendo se relacionar com vacâncias de átomos da rede ou com a introdução de átomos de uma impureza adicionada ao cristal (MCKEEVER, 2011; YUKIHARA e MCKEEVER, 2011).

Entre as principais características dos materiais OSL está a forma como respondem às radiações de diversos tipos e energias. Em particular, para dosimetria de feixes de fótons e elétrons, a variação da resposta do material com a dose absorvida e com a energia da radiação (fóton ou elétron) é de grande importância para o emprego em radioterapia. Quanto mais essa resposta se aproxima à 
esperada para água, melhor o material se presta a dosimetria em radioterapia (IAEA, 2001).

Em uma modelagem mais simplificada que desconsidera decaimentos térmicos e recapturas por armadilhas, o número de elétrons armadilhados decai exponencialmente com o tempo de iluminação e depende basicamente da concentração de elétrons armadilhados $n$ e da probabilidade de transição por tempo $p$ (constante durante o tempo de medição).

$$
n(t)=n_{0} e^{-p t}
$$

Logo, neste modelo a intensidade do sinal medido é:

$$
I_{o s l}(t) \propto\left|\frac{d n}{d t}\right|=n_{0} p e^{-p t}
$$

O sinal proveniente da recombinação nos centros de armadilhamento não deve ser confundido com fotoluminescência, pois neste caso, não há necessidade de exposição à radiação ionizante e também não há condução de cargas no material (MCKEEVER, 2011; YUKIHARA e MCKEEVER, 2011).

$\mathrm{Na}$ OSL é possível medir sinais com comprimento de onda menor que o utilizado na estimulação, pois o fóton emitido pelo material depende da configuração eletrônica (transições).

Como visto na Equação 18, a razão entre os coeficientes de absorção de energia deveria dar uma boa estimativa da relação entre dose absorvida no dosímetro e a dose absorvida no tecido. No entanto, a emissão de luz pode depender de outros fatores além da energia absorvida no dosímetro tais como a distribuição e número de centros de armadilhamento e recombinação. REFT (2009) comparou a razão dos coeficientes de absorção de energia mássicos de ATTIX (1986) com a resposta relativa OSL para dosímetros de $\mathrm{Al}_{2} \mathrm{O}_{3}$ e concluiu que a razão dos coeficientes é uma boa aproximação da resposta OSL. 


\subsubsection{Modelo de estrutura de bandas e armadilhas}

As bandas de energia em um cristal são formadas pelo conjunto de níveis de energia discretos dos átomos que compõe o material, que se dividem em $(2 /+1) N$ níveis de energia, onde $N$ é o número de átomos no cristal e $/$ é o número quântico orbital.

A Figura 9 ilustra algumas disposições de níveis de energia sendo que em (b), (c) e (d) há uma separação das bandas de energia conhecida como níveis de energia proibidos, enquanto que em (a) o diagrama representa uma distribuição contínua de níveis de energia de um elétron livre.

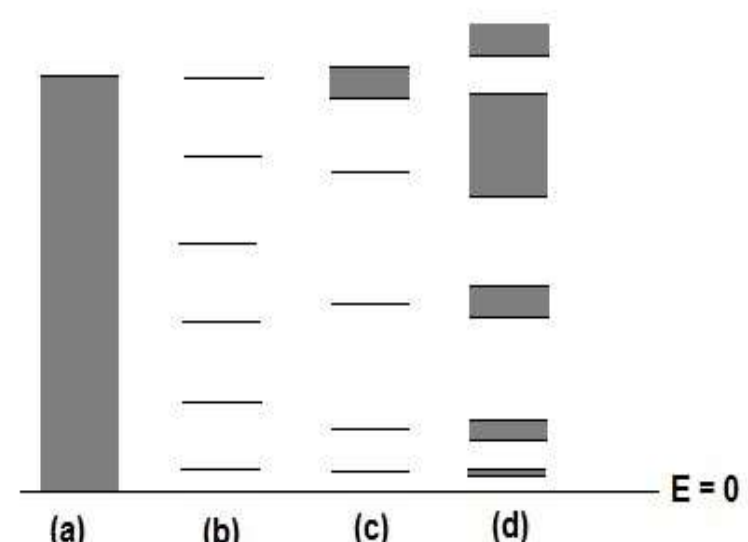

Figura 9: Disposições de níveis de energia sendo que em (a) o elétron está livre, (b) oscilador harmônico simples (c) poço de potencial e (d) sequência de poços de potencial periódicos. Adaptado de BUBE, R. H., 1960.

Em um cristal perfeito é possível criar pares elétron-lacuna, mas, mesmo assim, não é possível armazenar energia por conta da configuração eletrônica. Para que isso ocorra, deve-se criar novos níveis de energia entre as bandas. Estes níveis são os "defeitos", que são irregularidades na periodicidade da rede cristalina e são os responsáveis por "armadilhar" elétrons e lacunas que, por fim, também são responsáveis pelo sinal óptico que está relacionado com a dose absorvida no material. A Figura 10 apresenta alguns dos tipos possíveis de defeitos. 


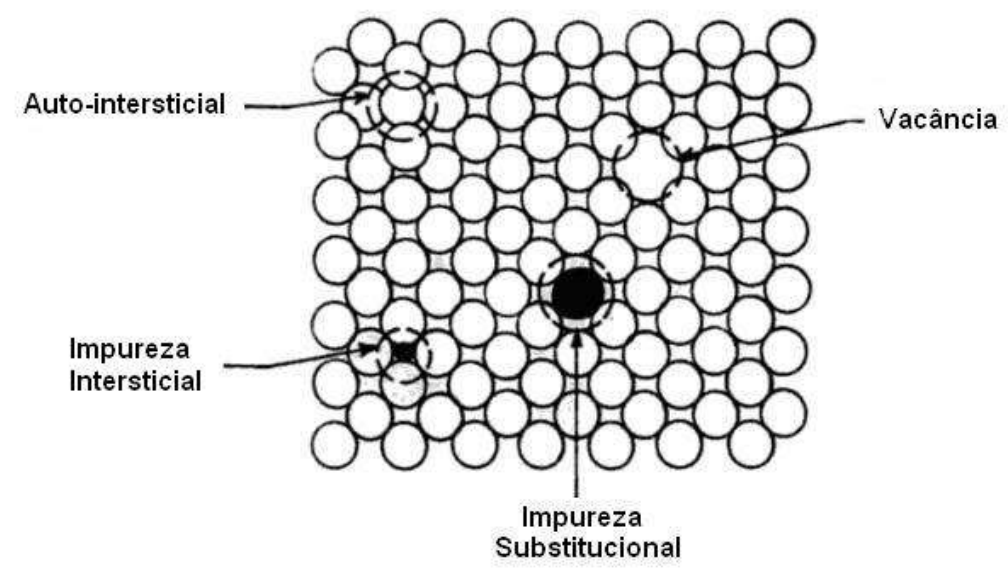

Figura 10: Tipos de defeitos em cristais. Adaptado de KEER, H. V., 1993.

Os defeitos podem ser provocados através de:

- Alterações no equilíbrio termodinâmico;

- Dopagem durante o crescimento do cristal;

- Irradiação por partículas energéticas.

\subsubsection{Armadilhamento e liberação de cargas}

Em um cristal podemos considerar que um elétron na banda de condução é uma carga livre para vagar por toda a região. $O$ defeito introduz um campo elétrico em uma região na qual abre a possibilidade de captura de uma carga livre. Se este defeito não existisse, no caso de um cristal perfeito, não haveria a possibilidade de ligação em um poço de potencial.

Depois de ligada ao poço, a carga precisa de algum tipo de estimulação para sair. Se a diferença de energia entre a armadilha e a banda for pequena (armadilhas rasas), estimulação térmica ambiente é o suficiente para liberar a carga. Quando o nível de energia é mais elevado, necessita-se de mais energia para liberar a carga, fazendo-se necessária energia térmica (temperaturas bem acima da do ambiente), óptica ou de outra espécie. A Figura 11 mostra o diagrama de níveis de energia do processo OSL. 


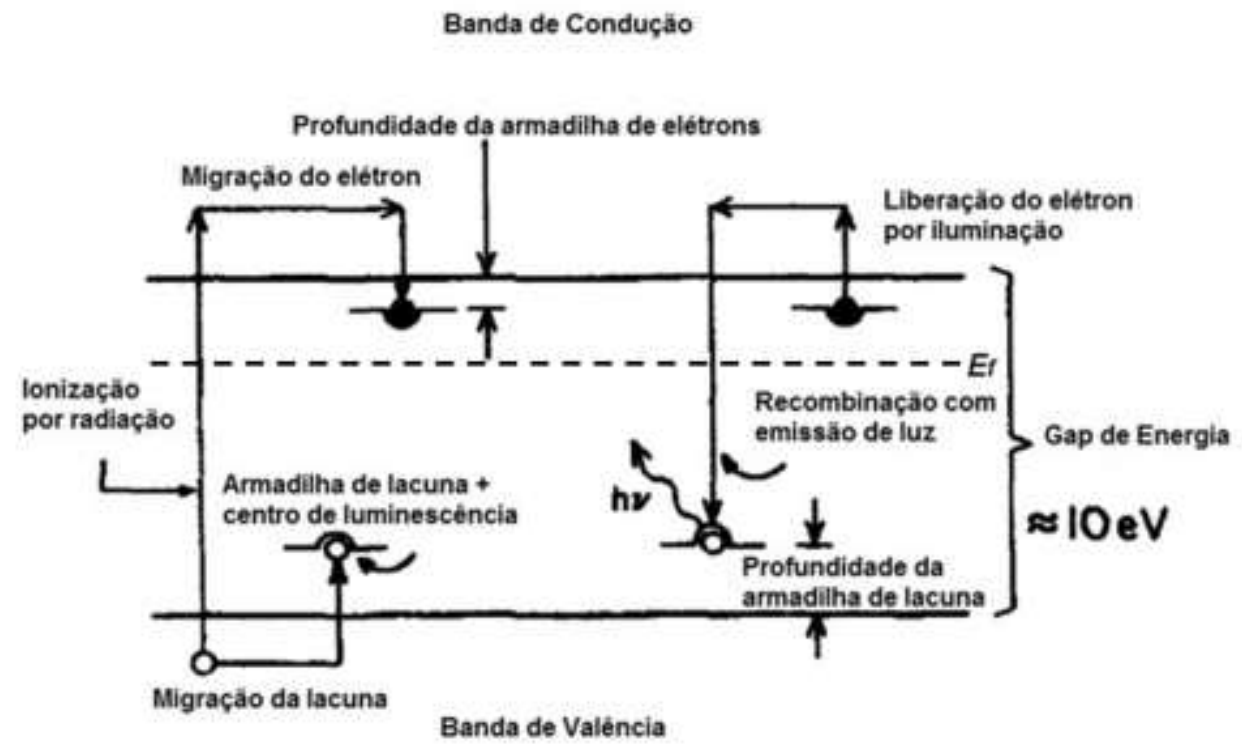

Figura 11: Diagrama de energia do processo de luminescência opticamente estimulada. Os elétrons ficam armadilhados mais próximos à banda de condução. Na parte intermediária ficam os níveis defeituosos e que são responsáveis pela recombinação elétron-lacuna e emissão OSL. Nesta região as probabilidades de captura de um elétron e de captura de uma lacuna são iguais. Os níveis mais próximos à banda de valência armadilham lacunas. Adaptado de ATTIX, 1986.

O processo se inicia com a interação da radiação com o meio produzindo ionização, ou seja, enviando elétrons para a banda de condução e gerando uma lacuna na banda de valência desde que haja energia transferida suficiente. Após liberados, os portadores de carga podem migrar para os centros de armadilhamento e ficar ligados a eles até haver energia suficiente para a liberação (estado metaestável), mas boa parte das cargas liberadas pela irradiação irá retornar às suas respectivas bandas. Na Figura 11, as armadilhas de elétrons são os defeitos mais próximos à banda de condução e acima da energia de Fermi $\boldsymbol{E}_{\boldsymbol{f}}$, enquanto que as armadilhas de lacunas estão localizadas mais próximas à banda de valência. $\mathrm{A}$ região que separa as bandas de condução e valência é a banda proibida, que contem os níveis de energia introduzidos pelos defeitos. Ao fornecer energia luminosa ao material, os elétrons armadilhados voltam à banda de condução e ao recombinarem com vacâncias em algum centro de recombinação, um fóton é liberado.

Para este modelo, há uma equação que rege a probabilidade de cargas armadilhadas em um dado defeito (armadilha) de energia $E$, ser liberada termicamente: 


$$
P=f \cdot e^{-\frac{E}{k T}}
$$

Onde:

$P$ é a probabilidade de decaimento por unidade de tempo;

$f$ é o fator de frequência;

$k$ é a constante de Boltzmann;

$E$ é a energia necessária para o desarmadilhamento, chamada de energia de ativação e

$T$ é a temperatura.

Podemos observar nesta equação que, após ser armadilhada, sempre existe uma possibilidade de a carga ser liberada termicamente, embora essa probabilidade seja, em geral, muito pequena à temperatura ambiente, razão pela qual a dosimetria OSL pode ser empregada para avaliar doses integradas em tempos longos.

\subsubsection{Modalidade de estimulação CW-OSL}

É o modo no qual a leitura do sinal OSL é feita de tal forma que a intensidade luminosa de estimulação não varia com o tempo. Considerando a modelagem mais simples na qual há apenas um centro de recombinação e uma armadilha, a área total sob a curva OSL (número de fótons emitidos) não se altera ao mudarmos a intensidade da estimulação. Só o formato da curva será alterado.

Neste método deve-se utilizar filtros ópticos para distinguir a luz de estímulo da luz proveniente do material, e também para proteger a integridade da fotomultiplicadora.

No modelo OSL de primeira ordem, como $\sigma_{\lambda}$ é a seção de choque de fotoionização (probabilidade de fotoionização por unidade de tempo por átomo) e $\varphi_{\lambda}$ é o fluxo de fótons de estimulação, a taxa de decaimento pode variar em função destes parâmetros. Na modelagem mais simples para o sinal OSL, o sinal é dado por uma exponencial decrescente como na Equação 23, sendo que a multiplicação de $\sigma_{\lambda}$ por $\varphi_{\lambda}$ é a probabilidade de transição óptica $p$ vista na Equação (25).

$$
I_{o s l}(t) \propto n_{0} \sigma_{\lambda} \varphi_{\lambda} e^{-\sigma_{\lambda} \varphi_{\lambda} t}
$$


Quanto à área sob a curva (integral de losL no tempo), é fácil perceber que, tendo um número finito de cargas armadilhadas $n_{0}$, as áreas das curvas dos sinais OSL por tempo serão iguais, mas os decaimentos serão diferentes de acordo com o fluxo de fótons utilizado para estimulação.

\subsection{Simulação do transporte de radiação por Monte Carlo}

Atualmente os sistemas de planejamento clínicos utilizam algoritmos de cálculo a partir de medidas experimentais de dose em profundidade e perfis de dose em phantom de água para a obtenção da dose. As simulações computacionais já são empregadas para obtenção de distribuições de dose mais fidedignas, e podem vir a ser, em futuro breve, uma ferramenta corriqueira para obter distribuições de dose específicas no paciente durante o tratamento.

Com o Método de Monte Carlo, ao simular uma infinidade de partículas interagindo com o meio de interesse observando as grandezas macroscópicas que estão relacionadas com o comportamento médio delas, temos que o valor esperado corresponde à solução da equação de transporte de Boltzmann (METROPOLIS e ULAM, 1949).

A sequência de eventos que ocorre com a partícula desde a geração até a absorção ou escape do material de interesse (YORIYAZ, 2009) é chamada de história da partícula. Para simular uma história se faz necessário conhecer as funções densidade de probabilidade das variáveis aleatórias que fazem parte do processo que são utilizadas em técnicas de amostragem. $O$ caminho livre médio entre os eventos, o tipo de interação, a perda de energia, alteração na direção e criação de partículas secundárias são as variáveis aleatórias que serão determinadas por distribuições de probabilidade (SALVAT et al., 1996 e SALVAT et al., 2006). A partir destas funções densidade de probabilidade e utilizando métodos de amostragem é feita a geração de histórias.

Por ser um método aleatório, o Monte Carlo necessita de um gerador de números aleatórios para alimentar o sistema que podem, por exemplo, ser um conjunto de números uniformemente distribuídos em uma faixa de valores entre $0 \mathrm{e}$ 1. Em geral, nos geradores de números aleatórios mais utilizados, se faz uso de vários métodos tais quais os métodos linear congruencial, congruencial misto e congruencial multiplicativo, sendo que os números aleatórios na verdade são 
pseudo-aleatórios, pois se trata de um algoritmo predeterminado que produz a distribuição uniforme de aleatórios. No código PENELOPE, por exemplo, o algoritmo para geração dos pseudo-aleatórios foi desenvolvido por L'ECUYER (1988).

A partícula começa sua trajetória de uma posição com uma energia definida. Simula-se o caminho livre médio através de um aleatório gerado uniformemente entre 0 e 1 que será usado como input na função densidade de probabilidade para a geração dos valores aleatórios do caminho livre médio no meio de interesse. Após a partícula alterar sua posição uma interação pode ocorrer. Os ângulos de espalhamento e a perda de energia são amostrados de acordo com suas distribuições de probabilidade.

O programa repete estes passos até o momento no qual a partícula deixa o sistema ou quando a energia chega ao valor mínimo estipulado que é chamado de energia de corte. A partir dos resultados da simulação de muitas histórias é possível obter a energia depositada pela radiação em volumes de interesse, bem como a distribuição angular e energética da radiação secundária produzida.

Existem situações nas quais a probabilidade de interação é muito pequena tornando a incerteza da grandeza a ser determinada muito elevada. Para estes casos, por exemplo, a simulação da produção de raios $\mathrm{X}$, deve-se aplicar métodos de redução de variância de modo a obter resultados mais confiáveis. Esses eventos são muito menos prováveis que os espalhamentos elásticos e inelásticos necessitando, assim, um maior tempo de simulação. Neste caso, é possível reduzir a variância forçando as interações de interesse aplicando um peso estatístico que consiste em reduzir o caminho livre médio do processo para um menor mantendo sem alterações as funções densidade de probabilidade para a perda de energia e alteração de direção. 


\section{MATERIAIS E MÉTODOS}

Os experimentos realizados neste trabalho consistiram na medição da resposta OSL do dosímetros que foram previamente irradiados em diversos feixes. Para a determinação de dose absorvida no ar foi utilizada uma câmara de ionização conectada a um eletrômetro. Devido à necessidade de se irradiar mais de um dosímetro por dose, foi estudada a uniformidade do feixe com o objetivo de definir uma região de dose uniforme. Essa varredura foi feita com a câmara de ionização acoplada a um motor controlado remotamente sendo a posição do detector monitorada por câmera de video. Como complemento para o estudo, foram feitas simulações computacionais de deposição de energias nos materiais utilizando espectros obtidos através da mescla de um modelo consagrado na literatura (TBC) com simulações em Monte Carlo com o código PENELOPE.

\subsection{Metodologia}

Foram feitas irradiações dos materiais (óxido de berilo e óxido de alumínio, nos formatos de pastilhas cerâmicas Thermalox ${ }^{\mathrm{TM}} 995$ e fitas Luxel ${ }^{\mathrm{TM}}$, respectivamente) (YUKIHARA, 2011; YUKIHARA et al, 2005; BULUR e YELTIK, 2010; SOMMER et al, 2007) com feixes de raios $X$ do acelerador Microtron e de aceleradores clínicos, e de raios $X$ e gama dos irradiadores do Laboratório de Dosimetria das Radiações e Física Médica. Para cada feixe, a irradiação foi feita com um conjunto de doses absorvidas - sete valores na faixa de centenas de mGy até aproximadamente 2 Gy, faixa de utilização em radioterapia.

Foram estudadas:

- Curvas de emissão OSL para os materiais analisados;

- Dependência energética;

- Simulações em Monte Carlo para a energia depositada nos materiais analisados.

Para a avaliação da dependência energética da resposta OSL, foram feitas análises gráficas da resposta OSL em função da dose absorvida para cada um dos 
feixes, e comparados os parâmetros das curvas (em geral lineares) obtidas em ajustes por mínimos quadrados. Foi feito também um estudo qualitativo das variações no formato das curvas de emissão OSL com mudanças de dose absorvida e energia da radiação.

Os materiais dosimétricos e os feixes foram simulados com o código PENELOPE para a obtenção dos valores esperados de deposição de energia para comparar com a dependência energética experimental.

O PENELOPE é um código de computador desenvolvido a fim de simular a interação de fótons, pósitrons e elétrons com a matéria desde geometrias simples até casos mais detalhados.

O equipamento utilizado para as avaliações OSL foi o Risø- TL/OSL DA-20 (Risø National Laboratory, Denmark) (DTU, 2014), empregando iluminação com LEDs na faixa do azul em modo contínuo (CW) e coleta os sinais OSL em um tubo fotomultiplicador com filtros ópticos acoplados (Hoya U-340).

\subsection{Dosímetros utilizados}

\subsection{1 $\mathrm{Al}_{2} \mathrm{O}_{3}: \mathrm{C}$}

O óxido de alumínio é um material com densidade de $3,96 \mathrm{~g} / \mathrm{cm}^{3}$ e número atômico efetivo igual a 10,2. Essas características não remetem a materiais tecidoequivalentes, porém, por conta destas peculiaridades, tem sensibilidade maior para fótons de energia baixa e pode ser utilizado para discriminar se os fótons utilizados na irradiação deste material são de baixa ou alta energia (AKSELROD et al, 1998)

A utilização dos dosímetros de $\mathrm{Al}_{2} \mathrm{O}_{3}: \mathrm{C}$ aplicando a técnica OSL conta com uma sensibilidade altíssima comparando-se com outros materiais utilizados com mesma técnica, tornando possível utilizar dimensões pequenas de material detector, melhorando, assim, a resolução espacial (YUKIHARA et al, 2005). A Figura 12 ilustra a curva de emissão OSL, em modo CW, para este material após irradiação.

Outras características importantes são:

- Baixo fading (decréscimo do sinal com o tempo desde que o dosímetro seja armazenado em temperatura ambiente e sem exposição à luz);

- Ampla faixa de utilização (de $10^{-4}$ a $10 \mathrm{~Gy}$ ) (AKSELROD et al, 1993). 
Este material tem duas bandas de emissão OSL centradas em aproximadamente $330 \mathrm{~nm}$ e $420 \mathrm{~nm}$, cujos tempo de vida são de $7 \mathrm{~ns}$ e $35 \mathrm{~ms}$ respectivamente. Essas duas bandas se devem aos defeitos obtidos por vacâncias de oxigênio ocupadas por elétrons que são conhecidas por Centros $\mathrm{F} \mathrm{e} \mathrm{F}^{+}$. Estes defeitos podem ser identificados por uma elevada absorção nas bandas centradas em 205, 230 e 255 nm (AKSELROD et al, 1998).

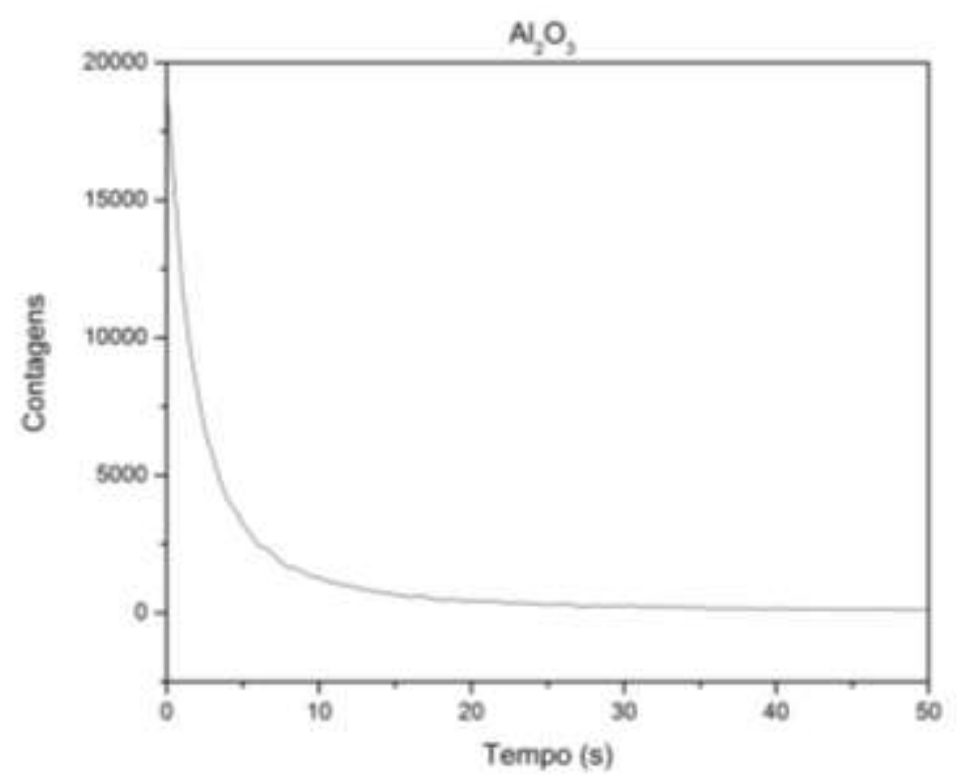

Figura 12: curva de emissão OSL em CW: decaimento do sinal OSL com o tempo ao aplicar luz de estimulação com intensidade constante.

Os dosímetros utilizados neste trabalho foram cortados em discos com $0,5 \mathrm{~cm}$ de diâmetro e espessura de 0,2 $\mathrm{mm}$ a partir de uma fita de Luxel ${ }^{\mathrm{TM}}$ (Landauer Inc.) que consiste em um filme polimérico como suporte para $\mathrm{Al}_{2} \mathrm{O}_{3}: \mathrm{C}$ em pó, sendo que, não há informações sobre o material que compõe o filme polimérico e a quantidade de impurezas no óxido de alumínio.

\subsection{2 $\mathrm{BeO}$}

O óxido de berílio é um material muito utilizado para dosimetria TL e OSL, tem número atômico efetivo similar ao da água $\left(Z_{\text {eff }}=7,2\right)$, sendo assim considerado um ótimo material tecido-equivalente (YUKIHARA e MCKEEVER, 2011) visto que o número atômico efetivo do tecido humano é aproximadamente igual a 7,6 (YUKIHARA, 2011), ou seja, quando um dosímetro feito a partir deste material é 
irradiado com feixes de energias diferentes, espera-se que o valor das correções a serem aplicadas para obter dose absorvida em tecido sejam pequenas. Neste trabalho foram utilizados detectores Thermalox ${ }^{\text {TM }} 995$ (Brush Wellman Inc., USA) compostos de 99,5 \% de óxido de Berílio (não há informação do fabricante sobre os outros $0,5 \%$ que compõe o material) com as seguintes características: 4,7 x 4,7 x $0,5 \mathrm{~mm}$ e massa aproximada igual a $32 \mathrm{mg}$, densidade igual a 2,85 g/ $\mathrm{cm}^{3}$ e tamanho de grão de $15 \mu \mathrm{m}$. A Figura 13 ilustra a curva de emissão OSL de um dosímetro de $\mathrm{BeO}$ estimulado com luz de intensidade constante.

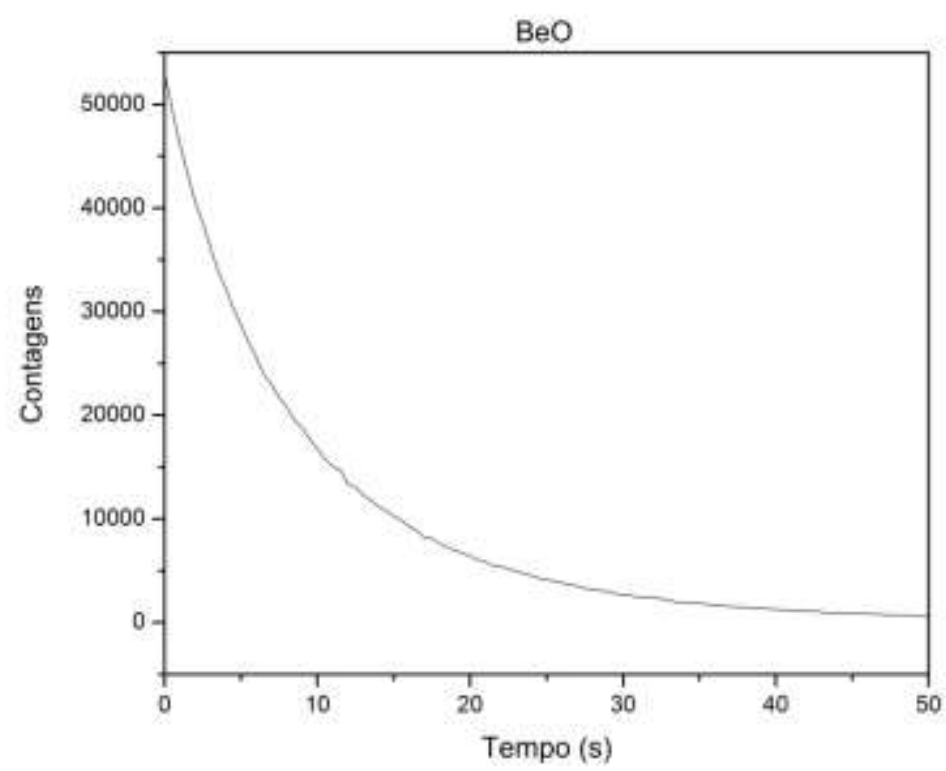

Figura 13: Curva de emissão OSL em CW para os dosímetro de $\mathrm{BeO}$ quando irradiado no feixe com energia de $1,9 \mathrm{MeV}$ do Microtron.

Este material apresenta resposta linear na faixa de $5 \mu$ Gy a 5 Gy (YUKIHARA e MCKEEVER, 2011) e pequena perda de sinal com o tempo (fading). Segundo MCKEEVER et al (1995) o espectro de emissão OSL do BeO é similar os de emissão termoluminescente e tem banda centrada em $335 \mathrm{~nm}$.

\subsubsection{Bleaching}

Bleaching é o processo de limpeza de sinal residual dos dosímetros antes da utilização. Neste tratamento óptico, os dosímetros foram iluminados por um conjunto de lâmpadas brancas com potência radiante de $55 \mathrm{~W}$ cada durante 24 horas. Foi tomado o cuidado de iluminar cada face dos detectores por metade do tempo para garantir a eliminação de qualquer sinal remanescente. Para a comprovação do 
completo esvaziamento, a cada conjunto irradiado, alguns dosímetros foram segregados para leitura sem irradiar.

Após o bleaching os dosímetros foram sempre embalados em pacotes de PVC vedados à luz, nos quais foram irradiados e permaneceram até ocorrer a leitura OSL.

A Figura 14 mostra uma embalagem típica utilizada para acomodar os dosímetros que, além de proteger mecanicamente, também evita a iluminação espúria.

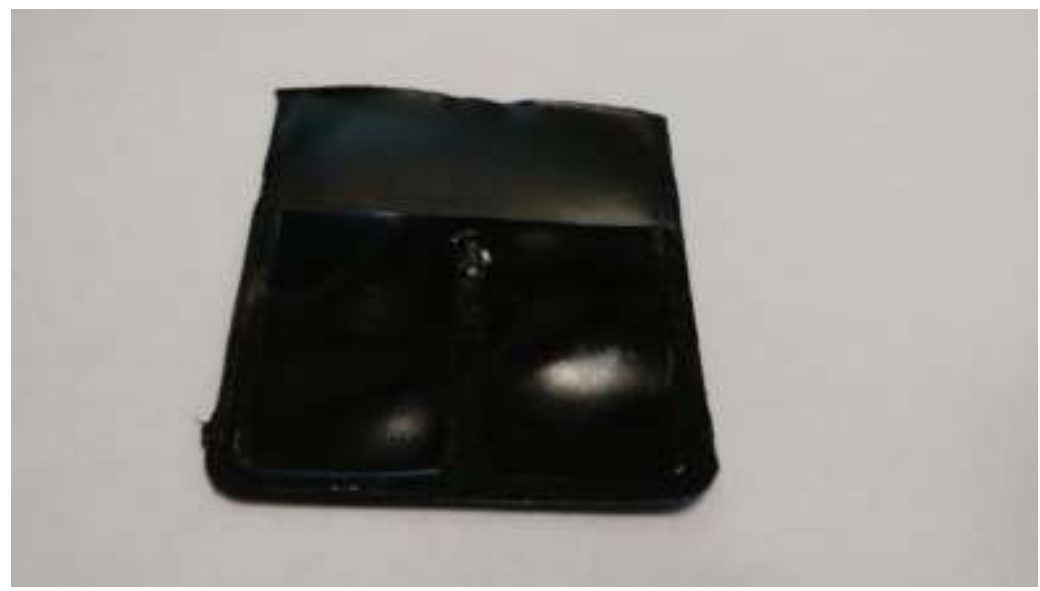

Figura 14: Embalagem para dosímetros de cor preta cuja finalidade é a proteção contra iluminação espúria.

\subsection{Irradiadores}

\subsubsection{Unidade de ${ }^{60} \mathrm{Co}$}

Para a irradiação com raios gama do ${ }^{60} \mathrm{Co}$ foi usado um antigo equipamento de radioterapia, instalado no Laboratório de Dosimetria das Radiações e Física Médica, cuja fonte radioativa tem abertura controlada remotamente. O campo de irradiação foi conformado a partir de colimadores reguláveis para a irradiação mantendo os dosímetros distando a 1,20 m do foco.

O irradiador utilizado foi o Theratron 80 que é composto por uma fonte de ${ }^{60} \mathrm{Co}$ com atividade de $6,02 \times 10^{13} \mathrm{~Bq}$ em 04/06/2015 (MALTHEZ, 2015), de pequenas dimensões, armazenada dentro de um cabeçote de aço fundido preenchido com chumbo. Os fótons são colimados por um conjunto de colimadores móveis reguláveis que conformam o campo de radiação. Há um sistema pneumático cuja 
função é liberar com segurança a fonte para a irradiação. A Figura 15 mostra o irradiador.

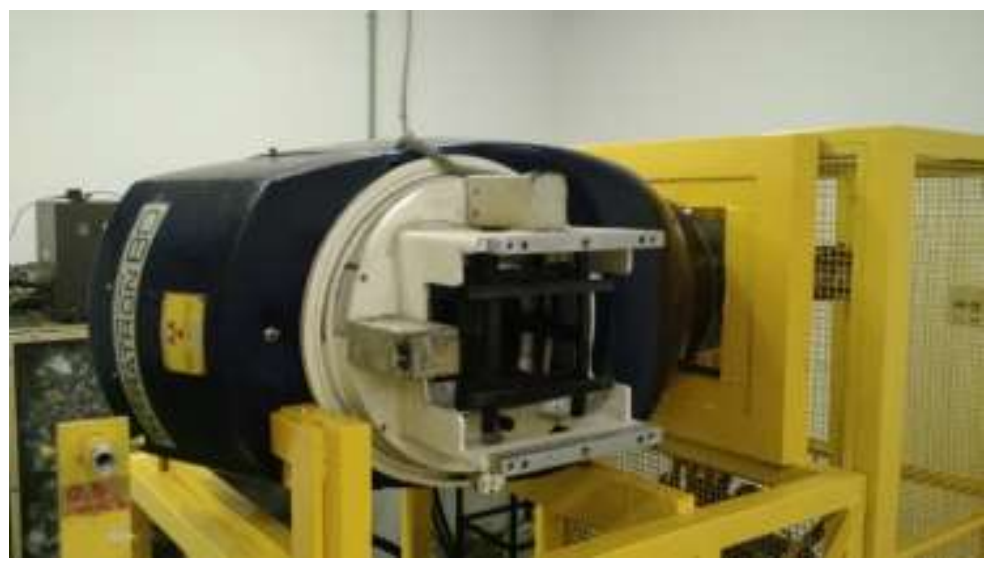

Figura 15: Irradiador Theratron 80 utilizado na irradiação com feixes gama de ${ }^{60} \mathrm{Co}$.

O processo de emissão de radiação gama se dá pelo decaimento beta menos do ${ }^{60} \mathrm{Co}$ em ${ }^{60} \mathrm{Ni}$. Após este processo o ${ }^{60} \mathrm{Ni}$ excitado decai emitindo dois fótons com energias de 1,17 e 1,33 MeV. (NUDAT)

\subsubsection{Unidade de ${ }^{137} \mathrm{Cs}$}

$\mathrm{Na}$ irradiação com raios gama do ${ }^{137} \mathrm{Cs}$ foi utilizado o irradiador radioterapêutico Caesatron Model-e que também se encontra no Laboratório de Dosimetria das Radiações e Física Médica e está apresentado na Figura 16. O sistema de abertura com mola é acionado remotamente; possui colimadores cuja abertura pode ser alterada.

A taxa de dose absorvida no ar medida durante as irradiações posicionando os dosímetros em um suporte feito de madeira distando a $49 \mathrm{~cm}$ do foco foi de $1,550 \mathrm{mGy} / \mathrm{s}$ e o campo de irradiação nesta distância foi calculado como suficiente para cobrir todos os dosímetros expostos. A atividade da fonte de ${ }^{137} \mathrm{Cs}$ avaliada em 04/06/2015 foi de $1,25 \times 10^{13} \mathrm{~Bq}$ (MALTHEZ, 2015). 


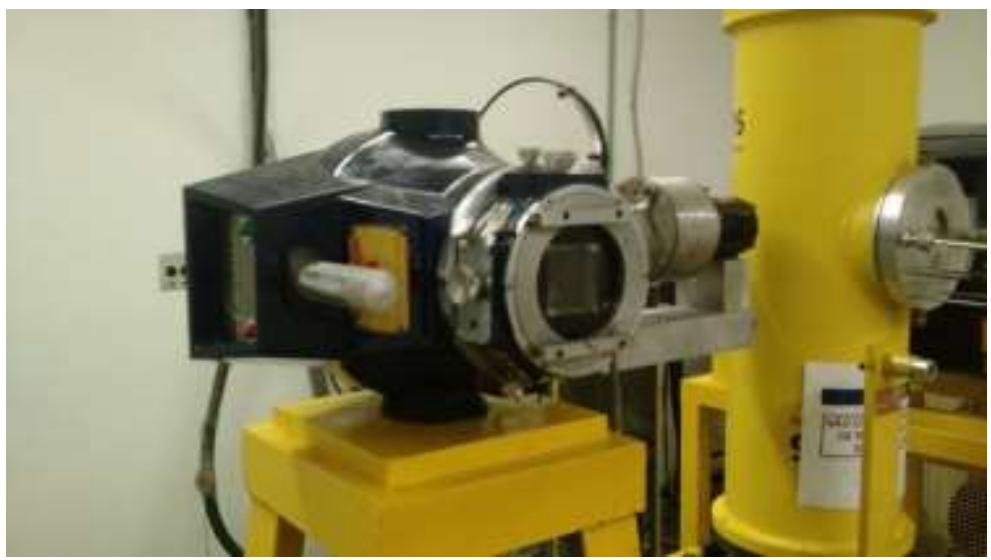

Figura 16: Irradiador Cs-137.

O fóton de $662 \mathrm{keV}$ emitido pela fonte de ${ }_{55}^{137} \mathrm{Cs}$ ocorre pelo decaimento beta menos para o ${ }_{56}^{137 \mathrm{Ba}}$ (estado metaestável) que, por fim, emite o fóton e decai para o ${ }_{56}^{137} \mathrm{Ba}$.

\subsubsection{Equipamento de raios- $X$}

Para a irradiação com feixes de raios $X$ de baixa energia o equipamento de uso industrial cujo fabricante é Philips, modelo MG-450 foi utilizado e que está locado nas dependências do Grupo de Dosimetria das Radiações e Física Médica do Instituto de Física da USP. A Figura 17 mostra o equipamento utilizado.

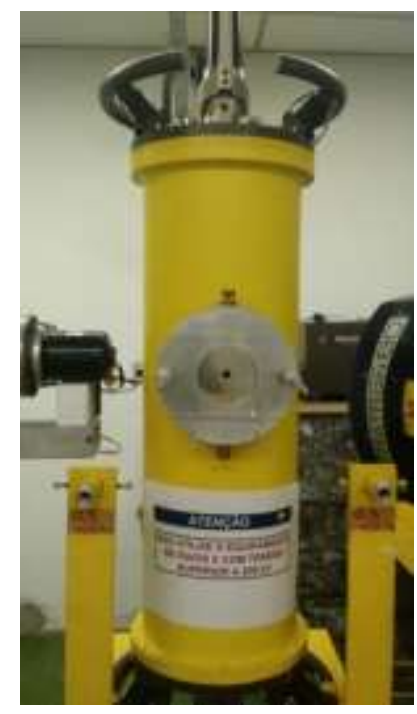

Figura 17: Equipamento de raios X do Grupo de Dosimetria das Radiações e Física Médica. 
Este equipamento opera com tensões entre 20 e $420 \mathrm{kV}$, corrente ajustável entre 0,05 e $15 \mathrm{~mA}$, possui anodo feito de tungstênio e filtração inerente do tubo igual a 2,2 $\mathrm{mm}$ de Be.

As irradiações foram feitas com a colocação de combinações de placas de alumínio, estanho e cobre na saída do feixe a fim de filtrar a contribuição de baixa energia e padronizar os feixes de acordo com a norma ABNT NBR ISO 4037-1. Nesta norma estão as características de tensão e filtração que fornecem as camadas semirredutoras e a energia média. Foi utilizando um colimador feito de chumbo recoberto por aço inox com orifício com diâmetro de $2,5 \mathrm{~cm}$. À frente deste colimador foram presas as placas metálicas responsáveis pela conformação do espectro de raios $X$. A ordem das placas foi mantida de acordo com a recomendação: primeiro o material com número atômico maior (mais próximo ao ponto focal do feixe), e por último a placa de alumínio (número atômico menor). Na Tabela 1 temos os valores de tensão, energia média, camada semirredutora, filtrações adicionais e resolução para as qualidades de radiação estipulados pela norma. Nessa tabela a resolução espectral é dada pela razão entre largura à meia altura do espectro e a energia mais frequente (apenas do espectro de bremsstrahlung) e deve, segundo a norma, ter valores entre 48 e 57\%.

Tabela 1: Características requeridas da série de espectros largos segundo a norma ABNT NBR ISO 4037-1.

\begin{tabular}{|c|c|c|c|c|c|c|c|}
\hline & $\begin{array}{c}\text { Energia } \\
\text { média, } \\
\bar{E} \\
\mathrm{keV}\end{array}$ & $\begin{array}{c}\text { Resolução, } \\
R_{E} \\
\%\end{array}$ & $\begin{array}{c}\text { Tensāo } \\
\text { no tubo a } \\
\text { kV }\end{array}$ & $\begin{array}{l}\text { Filtraç: } \\
\text { Sn }\end{array}$ & $\begin{array}{l}\text { adicional }{ }^{\mathrm{b}} \\
\mathrm{Cu}\end{array}$ & $\begin{array}{c}1^{\mathrm{a}} \mathrm{HVL} \\
\mathrm{Cu}^{\mathrm{c}} \\
\mathrm{mm}\end{array}$ & $\begin{array}{c}2^{\mathrm{a}} \mathrm{HVL} \\
\mathrm{Cu}^{\mathrm{c}} \\
\mathrm{mm}\end{array}$ \\
\hline & 45 & 48 & 60 & & 0,3 & 0,18 & 0,21 \\
\hline & 57 & 55 & 80 & & 0,5 & 0,35 & 0,44 \\
\hline & 79 & 51 & 110 & & 2,0 & 0,96 & 1,11 \\
\hline & 104 & 56 & 150 & 1,0 & & 1,86 & 2,10 \\
\hline & 137 & 57 & 200 & 2,0 & & 3,08 & 3,31 \\
\hline & 173 & 56 & 250 & 4,0 & & 4,22 & 4,40 \\
\hline & 208 & 57 & 300 & 6,5 & & 5,20 & 5,34 \\
\hline b & \multicolumn{7}{|c|}{$\begin{array}{l}\text { A filtração total consiste, em cada caso, na filtração adicional mais a filtração inerente, ajustada para } \\
4 \text { mm de aluminio, (ver } 4.2 .3 \text { ). }\end{array}$} \\
\hline c & \multicolumn{7}{|c|}{ As HVL sāo medidas a $1 \mathrm{~m}$ do ponto focal. } \\
\hline
\end{tabular}


Neste trabalho foram utilizados os feixes com tensões no tubo de 150 e 200 kV com a filtração adicional conforme indicada pela norma.

A filtração inerente de berílio do tubo de raios $X$ foi considerada como desprezível de acordo com o trabalho feito por Guimarães (2005) e, portanto, uma placa com $4 \mathrm{~mm}$ de Al foi acrescentada em todos os casos, além da filtração adicional descrita na Tabela 1.

\subsubsection{Acelerador Microtron}

O acelerador tipo Microtron, que está localizado no Laboratório do Acelerador Linear (LAL) no Instituto de Física da Universidade de São Paulo, foi utilizado para a produção dos feixes de fótons de raios X. O Microtron foi projetado para produzir feixes de elétrons com energia máxima de $31 \mathrm{MeV}$ e contar com dois estágios de aceleração, o primeiro cuja finalidade é aumentar a energia do feixe até aproximadamente $5 \mathrm{MeV}$ e o segundo, que é o acelerador principal, que forneceria um feixe com energia de $31 \mathrm{MeV}$.

O Microtron utiliza-se de cavidades aceleradoras cujas extremidades estão conectadas a eletroímãs defletores. Com isso, o feixe pode passar diversas vezes pelas cavidades, aumentando o ganho de energia e maximizando o espaço ocupado por um acelerador linear. O diagrama dos componentes de um acelerador Microtron race-track, que é o caso do Microtron do LAL-IFUSP, se encontra na Figura 18.

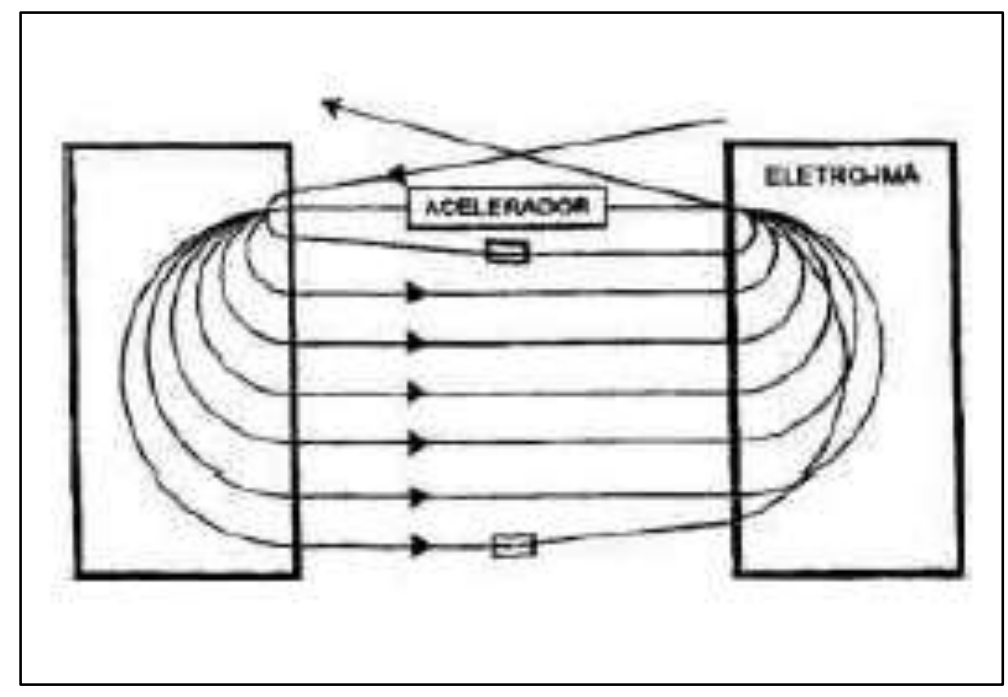

Figura 18: Diagrama de um microtron tipo race-track. Fonte: RIOS, P. B., 2002. 
O feixe de elétrons é provido por uma válvula triodo, cujo potencial de aceleração é igual a $100 \mathrm{kV}$. No catodo desta válvula os elétrons são ejetados por efeito termiônico e ao aplicar a tensão de aceleração entre a grade e o ânodo, os elétrons são acelerados até a saída do canhão. Após esse primeiro estágio, os elétrons passam pelos sistemas de chopper e buncher cuja função é produzir um conjunto de elétrons com fase semelhante (empacotamento) nas cavidades onde estarão sujeitos à aceleração síncrona devido à radiofrequência (RF) proveniente de uma válvula Klystron com frequência de $2,45 \mathrm{GHz}$ (Laboratório do Acelerador Linear do IFUSP). Após passar por este estágio de aceleração o feixe é obtido com energia próxima a 1,9 MeV.

Ao passar por essa etapa, o feixe é direcionado no Microtron booster, que é composto por conjunto de eletroímãs, cuja função é manter a recirculação do feixe. Os quadrupolos utilizados neste sistema são responsáveis por focalizar ou desfocalizar o feixe. Já os dipolos são utilizados na mudança de direção das partículas carregadas.

A Figura 19 mostra as partes que compõem o acelerador Microtron no estágio de desenvolvimento atual que conta com três câmaras para irradiação com elétrons de energias $100 \mathrm{keV}, 1,9 \mathrm{MeV}$ e 5,0 MeV. Neste trabalho, utilizamos as energias de 1,9 e $5,0 \mathrm{MeV}$.

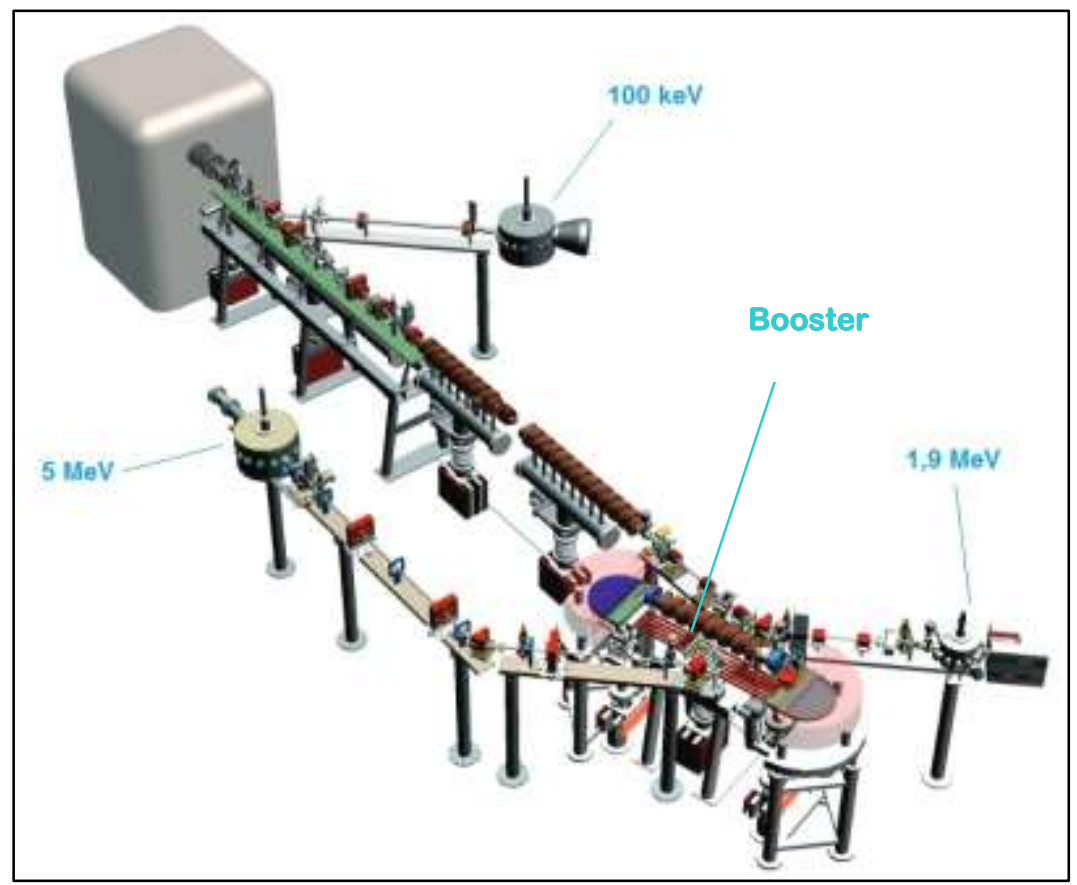

Figura 19: Componentes do acelerador Microtron. Fonte: site LAL-IFUSP 
Os alvos para produção de raios $\mathrm{X}$ por bremsstrahlung foram posicionados a $10 \mathrm{~mm}$ da parte externa das janelas de alumínio das câmaras de irradiação nas saídas das linhas de 1,9 MeV e 5,0 MeV através de suporte mecânico desenvolvido para tal finalidade (Figura 20). Esse arranjo com alvo externo à câmara facilita na operação do sistema por não se fazer necessário desfazer e refazer o vácuo. As janelas de alumínio isolam a câmara do ambiente externo, tem formato levemente abaulado por conta do vácuo feito na câmara e espessura de $50 \mu \mathrm{m}$ na linha de 1,9 MeV e 1,0 mm na linha de 5,0 MeV. Devido à espessura e à composição do material das janelas (número atômico baixo), não há alteração na produção de raios $X$. Há também a vantagem de espalhar o feixe de elétrons antes da colisão com o alvo para produção de raios $\mathrm{X}$, proporcionando assim, um feixe de bremsstrahlung mais aberto e menor aquecimento do alvo. Na Tabela 2 estão apresentadas algumas características do acelerador.

Tabela 2: Características do acelerador. Fonte: LAL-IFUSP.

\begin{tabular}{|c|c|}
\hline \multicolumn{2}{|c|}{ Linha de $100 \mathrm{keV}$} \\
\hline Energia de operação & 10 a $100 \mathrm{keV}$ \\
\hline Faixa de corrente & $1 \mathrm{nA}$ a $100 \mu \mathrm{A}$ \\
\hline Diâmetro do feixe & menor que 2 mm \\
\hline \multicolumn{2}{|c|}{ Linha de 1,9 MeV } \\
\hline Energia de operação & 0,9 a 1,9 MeV, cw (pulsado a 2,45 GHz) \\
\hline Faixa de corrente & $1 \mathrm{nA}$ a $1 \mu \mathrm{A}$ \\
\hline Diâmetro do feixe & $\sim 2 \mathrm{~mm}$ \\
\hline \multicolumn{2}{|c|}{ Linha de 5,0 MeV (Booster) } \\
\hline Energia de operação & $5,0 \mathrm{MeV}$ \\
\hline Corrente máxima & $2 \mu \mathrm{A}$ \\
\hline Diâmetro do feixe & $\sim 2 \mathrm{~mm}$ \\
\hline
\end{tabular}

\subsubsection{Características do alvo}

Para a geração dos fótons de raios $X$ a partir de elétrons acelerados no Microtron foram utilizados alvos compostos por liga de tungstênio, níquel e cobre nas proporções de $97 \%, 1,5 \%$ e 1,5\% respectivamente com diâmetro de uma polegada e espessuras de $1 \mathrm{~mm}$ e $2 \mathrm{~mm}$ produzidos pela empresa Brassinter cujas 
características estão na Tabela 3, e cuja montagem ao suporte feito de alumínio pode ser vista na Figura 20. Essas espessuras foram dimensionadas a partir do valor do alcance CDSA tabelados pelo NIST (Estar) para elétrons com as energias cinéticas utilizadas no acelerador Microtron. CSDA é a sigla para continuous slowing-down approximation que é uma aproximação que considera a perda de energia contínua em todo o percurso dos elétrons no meio (BERGER e SELTZER, 1983). Esta aproximação desconsidera espalhamentos múltiplos. A incidência do feixe no alvo foi perpendicular e os fótons de raios $X$ produzidos, por conta da faixa de energia utilizada, predominam na mesma direção do feixe de elétrons como mostrado na Figura 7.

Tabela 3: Características do alvo feito a partir da liga composta de tungstênio, cobre e níquel.

\begin{tabular}{cc}
\hline Liga & NC2007 \\
\hline Composição $(\%)$ & $\mathrm{W}=97 \%, \mathrm{Ni}=1,5 \%$ e Cu $1,5 \%$. \\
Densidade $\left(\mathrm{g} / \mathrm{cm}^{3}\right)$ & 18,5 \\
Dureza $(\mathrm{HRC})$ & $28-30$ \\
Limite de resistência à tração $\left(\mathrm{N} / \mathrm{mm}^{2}\right)$ & 830 \\
Alongamento $(\%)$ & 6 \\
Módulo de elasticidade $\left(\mathrm{kN} / \mathrm{mm}^{2}\right)$ & 340 \\
Coeficiente de dilatação térmica $\left(10^{-6} /{ }^{\circ} \mathrm{C}\right)$ & 4,80 \\
Condutividade térmica $(\mathrm{CGS})$ & 0,260 \\
Condutividade elétrica $(\% \mid \mathrm{ACS})$ & 16 \\
Propriedades magnéticas & Não magnético
\end{tabular}

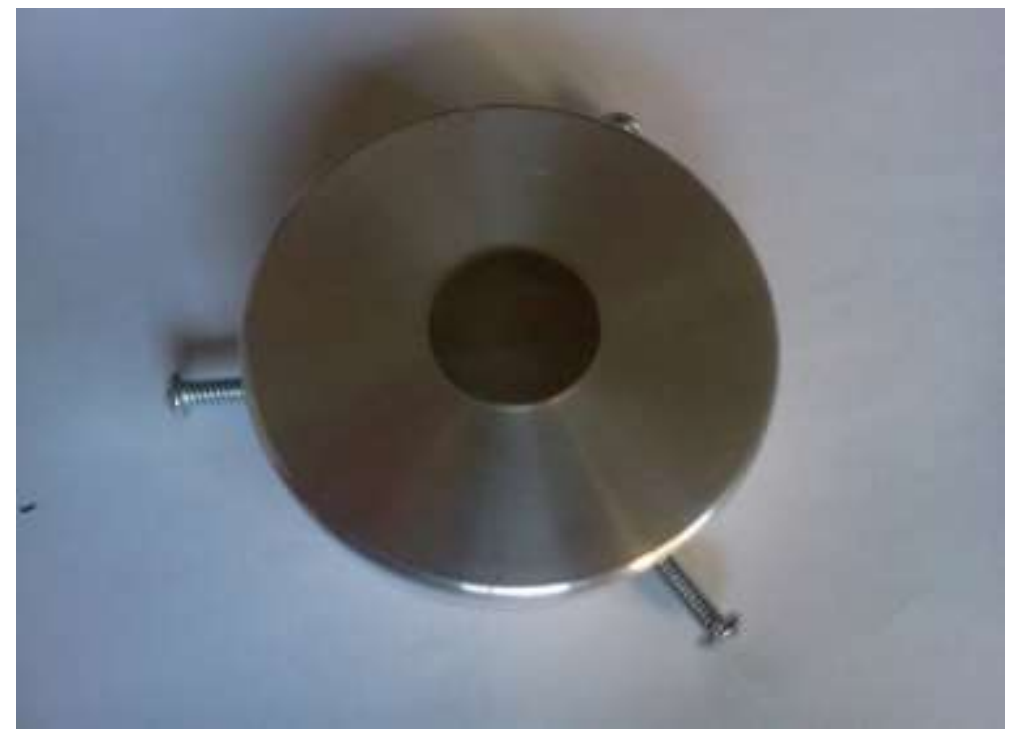

Figura 20: Suporte com alvo acoplado feito a partir de liga tungstênio, cobre e níquel utilizado para a produção de fótons de bremsstrahlung. 


\subsubsection{Aceleradores Clínicos}

Os aceleradores clínicos utilizados foram fabricados pela empresa Varian, modelos Clinac 6EX e iX. Foram utilizados os feixes de raios $\mathrm{X}$ gerados com elétrons $6 \mathrm{MeV}$ e $15 \mathrm{MeV}$ e taxas de dose absorvida na água de $100 \mathrm{mGy} / \mathrm{s}$ (600 UM/min) na profundidade de dose máxima. Esses equipamentos estão localizados no Hospital $\mathrm{A}$. C. Camargo. A Figura 21 mostra os aceleradores utilizados.
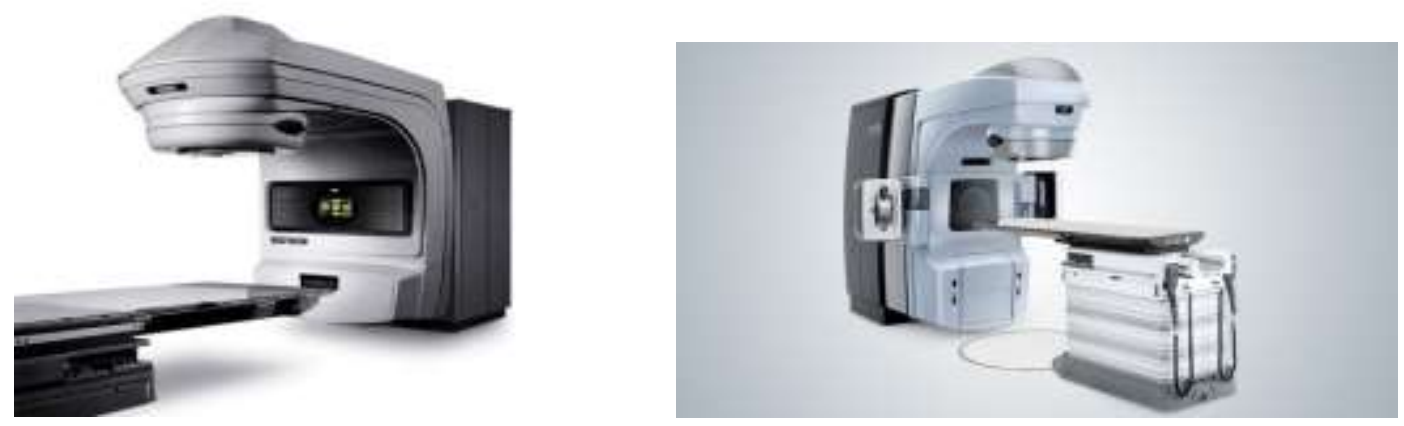

Figura 21: Aceleradores Clinac 6EX e Clinac iX.

A irradiação foi feita posicionando o conjunto de dosímetros a um metro de distância do foco $(S S D=100 \mathrm{~cm}$ ) cobertos por placas de build-up feitas de PMMA com espessuras de $1,5 \mathrm{~cm}$ para o feixe de $6 \mathrm{MeV}$ e 2,6 cm para o de $15 \mathrm{MeV}$ sobre um phantom modelo RW3 Scanditronix Wellhoffer com espessura de $15 \mathrm{~cm}$ e dimensão do campo de irradiação de $15 \times 15 \mathrm{~cm}$. As doses absorvidas em água, fornecidas pelos físicos médicos do hospital, foram corrigidas para doses absorvidas no ar aplicando a razão dos coeficientes de absorção de energia mássicos (IAEA TRS 398, 2000).

O fator de calibração $N_{D, w}$ tem valor de 53,04 mGy/nC com incerteza de 2,55\%. A incerteza total para dose absorvida no ar considerando outros parâmetros como a incerteza da PDP e do fator de rendimento não ultrapassou $3 \%$.

\subsection{Sistema de dosimetria}

O equipamento utilizado para fazer a medição da dose absorvida no ar foi constituído de uma câmara de ionização tipo Farmer com volume interno de $0,6 \mathrm{~cm}^{3}$, fabricante Nuclear Enterprises LTD., modelo 2571 e eletrômetro Fabricante PTW e modelo Unidos E, com tensão contínua aplicada à câmara de $250 \mathrm{~V}$. Este conjunto foi calibrado no IPEN em setembro de 2016 utilizando método de substituição a um padrão rastreável ao Laboratório Nacional de Metrologia das Radiações lonizantes. Na maioria dos feixes a câmara foi utilizada a capa de build-up original cuja função é 
manter o equilíbrio eletrônico (e proteger a câmara contra choques mecânicos). Esta capa foi desenhada pelo fabricante para utilização em feixes de fótons até $2 \mathrm{MeV}$ de energia, é constituída de Delrinß e tem espessura de $3,87 \mathrm{~mm}$. Para irradiação no feixe com energia máxima de 5,0 MeV necessitou-se a confecção de uma nova capa de build-up. Ela foi feita em PMMA com dimensões grandes o suficiente para manter o equilíbrio eletrônico. A capa de build-up apresentada na Figura 22 tem base quadrada e dimensões $5 \times 5 \times 8 \mathrm{~cm}$ e orifício central de $1 \mathrm{~cm}$ para inserção da câmara.

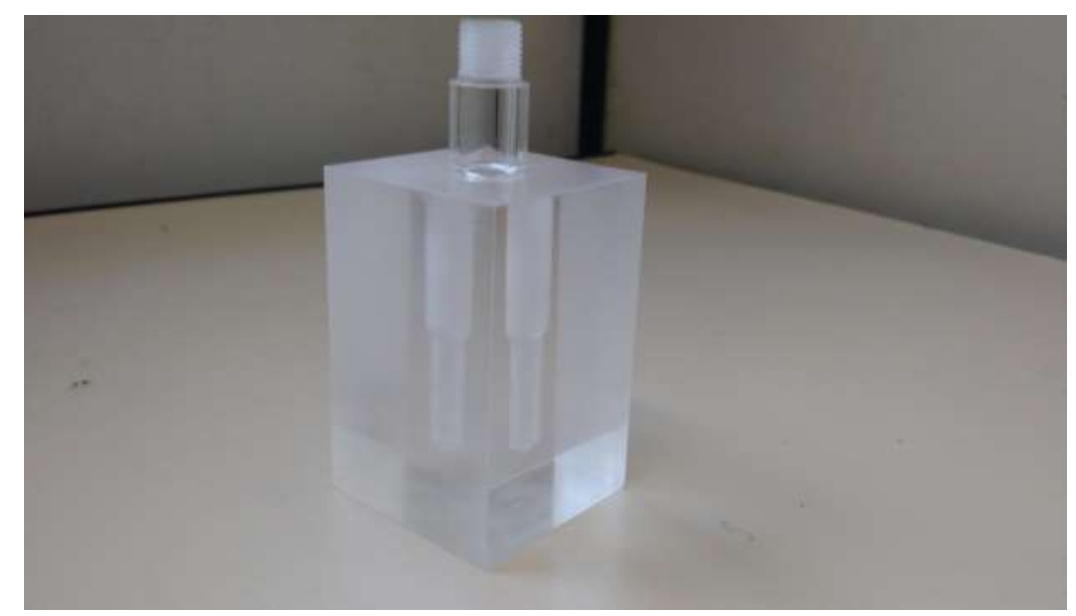

Figura 22: Capa de build-up de PMMA com suporte para câmara de ionização.

A Figura 23 mostra a câmara inserida na capa de build-up até $2 \mathrm{MeV}$ e o eletrômetro utilizado.

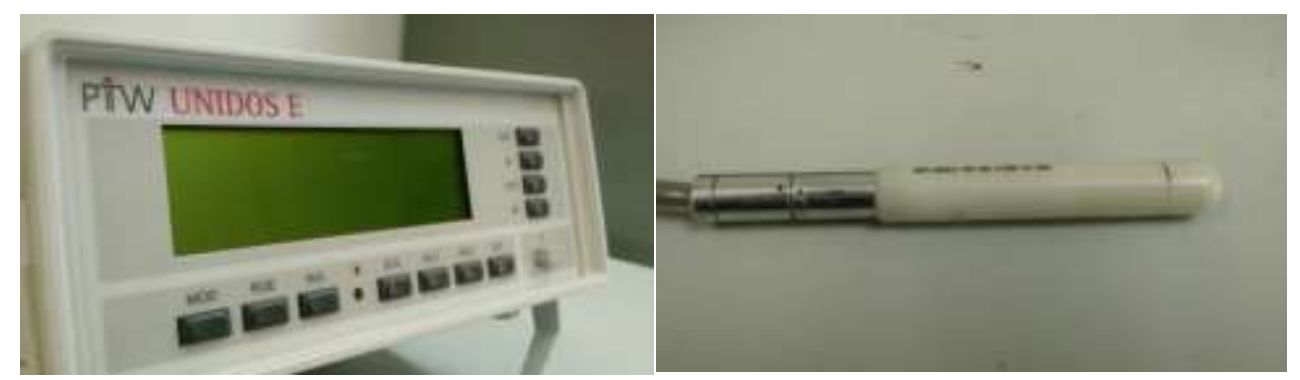

Figura 23: Eletrômetro UNIDOS E e câmara de ionização Farmer utilizadas nas medições.

Este conjunto foi utilizado conectado a um computador com programa desenvolvido para registrar a taxa de dose absorvida a cada segundo para a medição da dose absorvida no ar que foi entregue aos dosímetros em todas as medidas. 
Com o valor registrado pela câmara de ionização nas medições feitas, foram aplicadas as correções necessárias para a estimativa do valor de dose absorvida para os feixes de diversas qualidades aplicando-se a seguinte equação:

$$
D_{C o}=M N_{k} k_{Q, C o} F
$$

Onde:

Mé a leitura no visor do eletrômetro em coulomb;

$N_{k}$ é o fator de calibração da câmara em termos do kerma no ar com relação à carga medida obtido no certificado de calibração feito por laboratório secundário de metrologia do Instituto de Pesquisas Energéticas e Nucleares (IPEN) cujo valor é de 41,01 mGy/nC com incerteza de 1,7\%.

$K_{Q, \text { Co }}$ é o fator de correção do feixe utilizado quando a medição for feita com feixe de qualidade $Q$, diferente da utilizada na calibração, que no caso é ${ }^{60} \mathrm{Co}$.

Há também mais uma correção empregada devido à variação da temperatura ambiente e da pressão atmosférica no momento da medida que é dada por:

$$
F=\frac{P_{0}}{P} \frac{(T+273,15)}{T_{0}}
$$

Onde $P_{0}$ e $T_{0}$ são a pressão atmosférica e a temperatura obtidas no certificado de calibração da câmara e $P$ e $T$ são a pressão e a temperatura no momento da medição.

As incertezas para as doses absorvidas no ar nas irradiações nos feixes utilizados neste trabalho (exceto dos aceleradores clínicos) foram menores que $2 \%$.

\subsection{Simulações em Monte Carlo}

\subsubsection{Características gerais e materiais simulados}

Para as simulações feitas, alguns parâmetros podem alterar a precisão e o tempo gasto na simulação, dentre eles temos a energia de corte, valor limiar no qual se considera que a partícula depositou toda sua energia no meio. $O$ valor escolhido para a energia de corte para fótons foi de $1 \mathrm{keV}$ enquanto para elétrons foi igual a $10 \mathrm{keV}$ por considerar pouco significativas simulações de partículas com energia 
menor que a escolhida para o espectro de bremsstrahlung e para economizar tempo de máquina. O número de histórias simuladas tiveram valores entre $10^{6}$ e $10^{9}$ enquanto que as incertezas da deposição de energia nos materiais não excederam $2 \%$.

A faixa de energia possível de simular varia desde alguns eV (com precisão limitada) até $\mathrm{GeV}$, cobrindo toda a faixa de energia utilizada pela radioterapia atual. Segundo os desenvolvedores do programa, pode haver imprecisões na utilização em energia menor que $1 \mathrm{keV}$ por conta de seções de choque diferenciais para efeito fotoelétrico que, em valores de energia pequenos, tendem a ser mais incertos (SALVAT, 2006). Porém, neste trabalho as energias utilizadas foram bem maiores por conta dos potenciais máximos dos feixes e dos filtros utilizados, minimizando, assim, possíveis erros por conta das seções de choque.

Utilizando-se do programa MATERIAL, geraram-se 0 alvo e as demais substâncias utilizadas neste trabalho. Este programa auxiliar ao PENELOPE utiliza uma base de dados com as características dos materiais sendo possível até compor materiais que não se encontram na lista dos 280 já incluídos. O usuário deve incluir a composição química, densidade ou usar um dos materiais pré-preparados. Para compostos e misturas uma aproximação é feita para definir as seções de choque somando-se ponderadamente pelo índice estequiométrico as seções de choque atômica das substâncias que compõem o material.

$O$ alvo utilizado nas irradiações no acelerador Microtron para gerar raios $X$ foi composto da liga apresentada na Tabela 3, e repetida na Tabela 4. Essas proporções foram utilizadas para a geração de raios $\mathrm{X}$. 
Tabela 4: Características dos materiais utilizados nas simulações. $O$ alvo composto pela liga de tungstênio, cobre e níquel é apresentado em proporções mássicas, diferentemente dos outros materiais cujas proporções foram dadas em relação ao número de elementos.

\begin{tabular}{ccc}
\hline Material & Densidade $\left(\mathbf{g} / \mathbf{c m}^{3}\right)$ & Composição \\
\hline Alvo & 18,5 & $97 \% \mathrm{~W}, 1,5 \% \mathrm{Cu}$ e $1,5 \% \mathrm{Ni}$ (massa) \\
$\mathrm{Ar}$ & $1,20 \times 10^{-3}$ & $0,015 \% \mathrm{C}, 78,44 \% \mathrm{~N}, 21,07 \%$ O e $0,467 \% \mathrm{Ar}$ \\
$\mathrm{BeO}$ & 3,01 & $50 \% \mathrm{Be} \mathrm{e} 50 \% \mathrm{O}$ \\
$\mathrm{Al}_{2} \mathrm{O}_{3}$ & 3,97 & $40 \% \mathrm{Al}$ e $60 \% \mathrm{O}$ \\
$\mathrm{PVC}$ & 1,30 & $50 \% \mathrm{H}, 33,33 \% \mathrm{C}$ e $16,67 \% \mathrm{Cl}$ \\
$\mathrm{PMMA}$ & 1,19 & $53,33 \% \mathrm{H}, 33,33 \% \mathrm{C} \mathrm{e} 13,33 \% \mathrm{O}$ \\
Cobre & 8,96 & $100 \% \mathrm{Cu}$ \\
Estanho & 7,31 & $100 \% \mathrm{Sn}$ \\
Água & 1,00 & $66,67 \% \mathrm{H} \mathrm{e} 33,33 \mathrm{O}$ \\
Alumínio & 2,6989 & $100 \% \mathrm{Al}$ \\
Berílio & 1,85 & $100 \% \mathrm{Be}$ \\
Tungstênio & 19,3 & $100 \% \mathrm{~W}$ \\
\hline
\end{tabular}

Com o método de Monte Carlo, foi simulada a geração de raios $X$ pelo feixe de elétrons do Microtron no alvo. Para os feixes de fótons gerados em aceleradores clínicos foram utilizados dados da literatura para o espectro. Já os feixes de raios $X$ de baixa energia tiveram seu espectro obtido a partir de um modelo semiempírico, seguido de simulações das interações desse feixe com os filtros metálicos empregando o código PENELOPE.

Para todas as situações, foram simuladas por Monte Carlo as interações dos feixes de fótons com os materiais dos dosímetros (Tabela 4) devidamente embalados para calcular a energia depositada em cada um.

\subsubsection{Fator de dependência energética simulado}

Para verificar a dependência energética dos dosímetros utilizados, foi calculado o fator de dependência energética, que consiste na relação das doses absorvidas simuladas no dosímetro e no meio de referência (ar) para dois feixes diferentes sendo que um deles deve ser a referência, que, para este estudo foi o de raios gama do Co-60. 


$$
f_{C o}^{x}=\frac{\left(\frac{D_{\text {mat }}}{D_{a r}}\right)_{x}}{\left(\frac{D_{\text {mat }}}{D_{a r}}\right)_{C o}}
$$

onde

$\left(\frac{D_{\text {mat }}}{D_{a r}}\right)_{x}$ é a relação entre doses absorvidas simuladas no material e no ar para o feixe com energia $\boldsymbol{x} e$

$\left(\frac{D_{m a t}}{D_{a r}}\right)_{C o}$ é a mesma relação que a anterior, porém para a irradiação simulada com feixe proveniente de uma fonte de Co-60.

Caso o fator de dependência energética se aproxime da unidade, a resposta do dosímetro independe da energia do feixe incidente.

A geometria dos detectores de óxido de alumínio no qual a deposição da dose absorvida foi simulada consiste em um cilindro posicionado entre duas placas que simulam a embalagem feita em PVC que são presas a outra placa de PMMA que foi utilizada como suporte. Para os feixes que necessitavam de material a frente dos dosímetros para manter o equilíbrio eletrônico, foi adicionada mais uma placa de PMMA com dimensões iguais às utilizadas experimentalmente. Os detectores de $\mathrm{Al}_{2} \mathrm{O}_{3}$ e $\mathrm{BeO}$ foram simulados com dimensões iguais às dos dosímetros utilizados experimentalmente conforme a Figura 24 , onde $L$ é a distância utilizada em cada caso experimental.

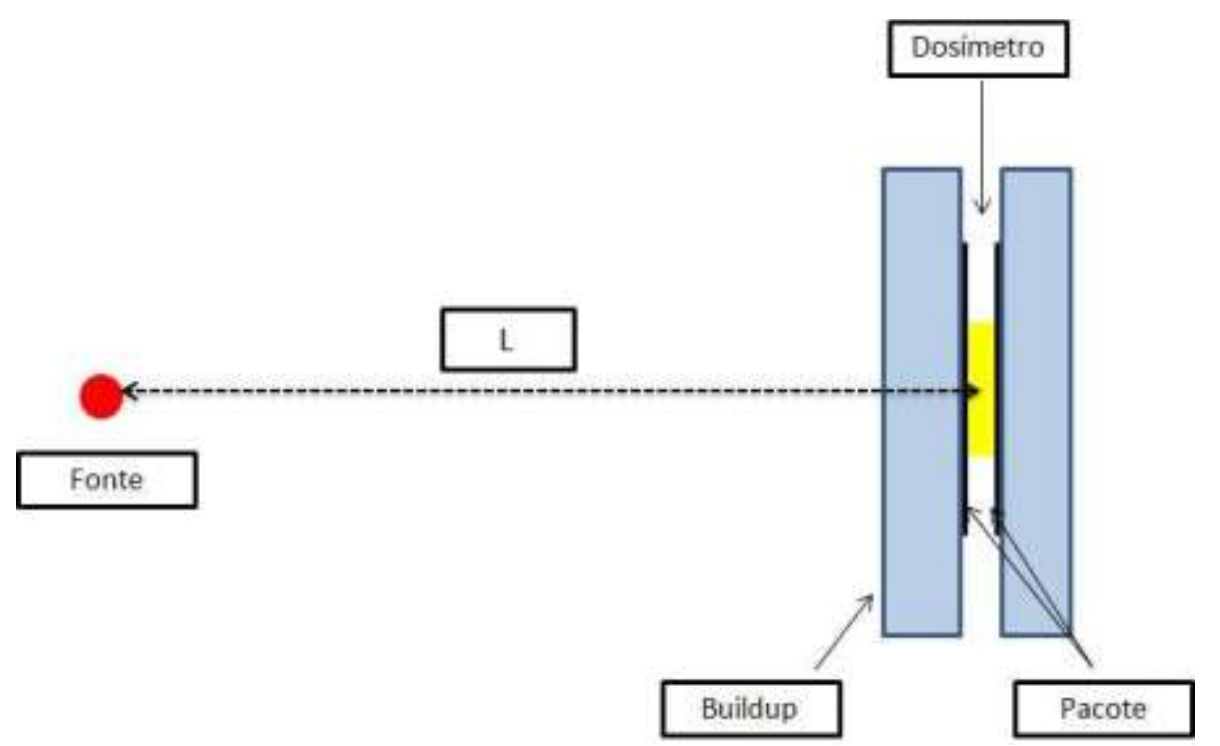

Figura 24: Geometria utilizada nas simulações. D representa a distância utilizada na situação experimental. 


\subsubsection{Espectros}

Para os feixes clínicos, devido à dificuldade em obter a geometria completa dos componentes dos aceleradores, foram utilizados os espectros obtidos por SHEIKH-BAGHERI, D. e ROGERS, D. W. O. (2002) mantendo os parâmetros geométricos idênticos à situação experimental. A Figura 25 ilustra estes espectros. No caso do acelerador Microtron, como toda geometria era conhecida, foi simulado desde a colisão do feixe de elétrons com o alvo até a interação dos fótons com os dosímetros, não se recorreu a espectro obtido em literatura, e todo o processo de geração de raios $X$ foi simulado com o código PENELOPE. Devido à baixa probabilidade de interação foi utilizado o método de redução de variância (chamado de Interaction Forcing no código PENELOPE) com o peso estatístico igual a 50 de modo a aumentar a confiabilidade estatística.

Para a validação dos espectros dos aceleradores clínicos, foram feitas simulações da deposição de energia em profundidade em um phantom composto de água, para comparação com as curvas experimentais equivalentes.
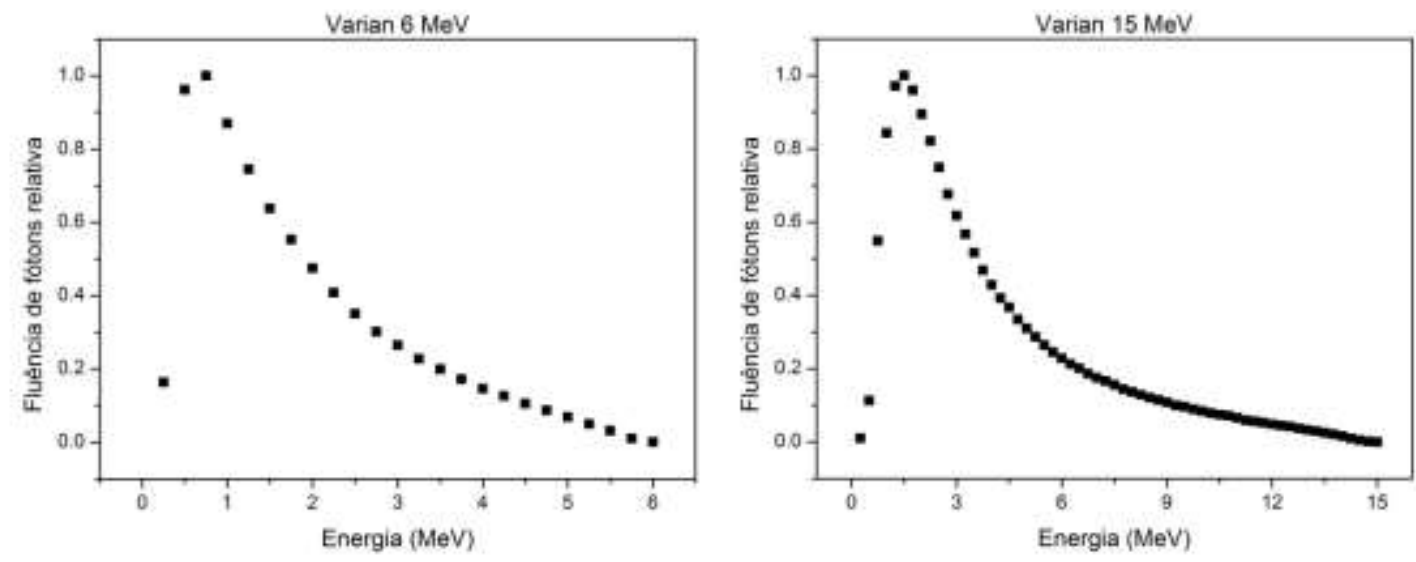

Figura 25: Espectro de energia dos fótons de raios X de aceleradores clínicos de $6 \mathrm{MeV}$ e $15 \mathrm{MeV}$.

Já os espectros de feixes de raios $X$ convencional de espectro largo foram obtidos em duas partes: primeiro foi feita a geração do espectro através de programa desenvolvido utilizando o modelo TBC (TUCKER, 1991) e as implementações neste modelo propostas por (COSTA, 2007) com os parâmetros do equipamento de raios $X$ utilizado nas irradiações experimentais (tensão e corrente $e$ a filtração inerente de berílio). Esse primeiro espectro pelo modelo TBC (Figura 26) 
foi utilizado como entrada de simulação em Monte Carlo, incidindo nos materiais (filtros) especificados na norma ABNT NBR ISO 4037-1 (Tabela 1).

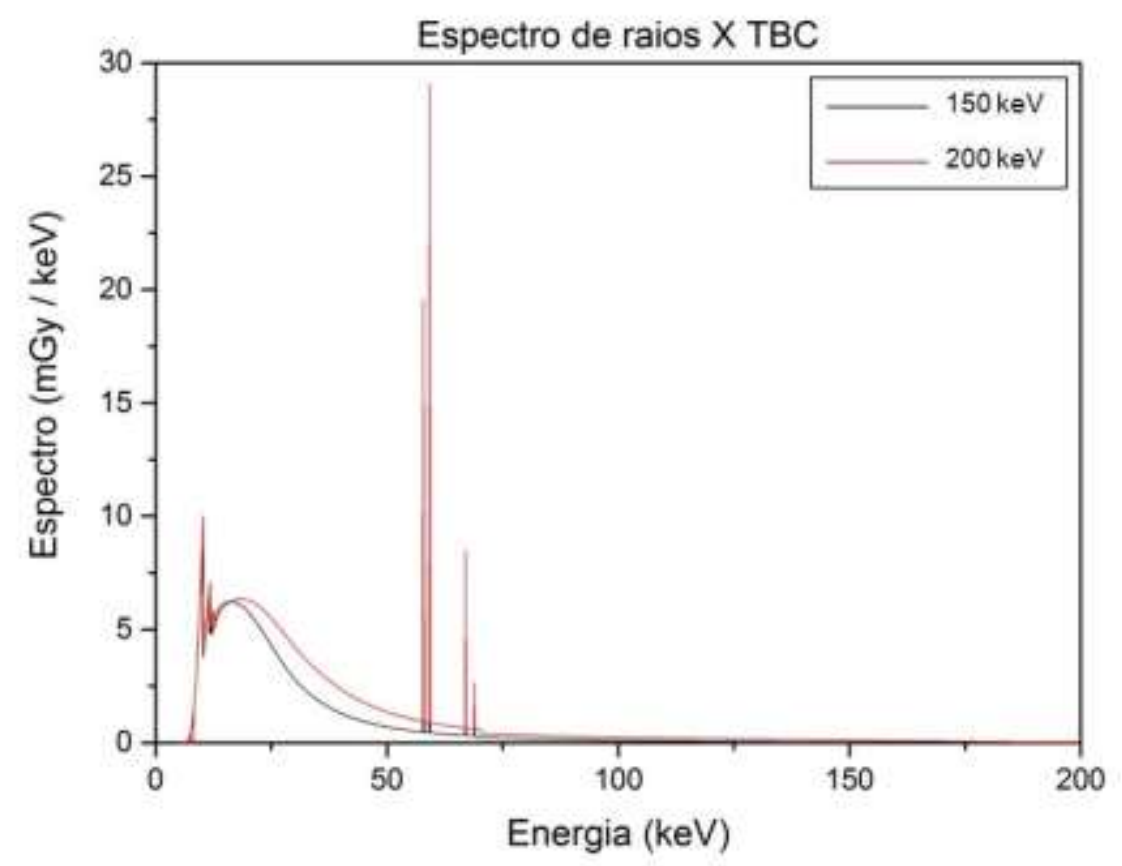

Figura 26: Espectros calculados pelo modelo TBC para as energias máximas de 150 e $200 \mathrm{keV}$.

A Figura 27 ilustra a geometria utilizada para a simulação dos espectros do Microtron e dos feixes de raios $X$ convencional com espectro largo. A seta em vermelho simboliza a direção do feixe de interesse, que para o Microtron são elétrons e para o equipamento de raios $X$ convencional é o espectro de fótons obtido pelo modelo TBC. No feixe do acelerador Microtron a placa azul representa a janela de alumínio com a espessuras de $50 \mu \mathrm{m}$ ou $1 \mathrm{~mm}$ (que são as espessuras utilizadas no experimento) enquanto que a laranja são as placas da liga composta de tungstênio, cobre e níquel com espessuras de 1 ou $2 \mathrm{~mm}$ que foram utilizadas nos feixes de 1,9 MeV e 5,0 MeV respectivamente. Nos feixes de espectro largo, os materiais de cor azul e laranja são os filtros com materiais estipulados pela norma. $O$ material de cor roxa, para todos os casos, simboliza o detector de fótons utilizado para a aquisição do espectro com aproximadamente 100 bins distribuídos para as faixas de energia utilizada. 


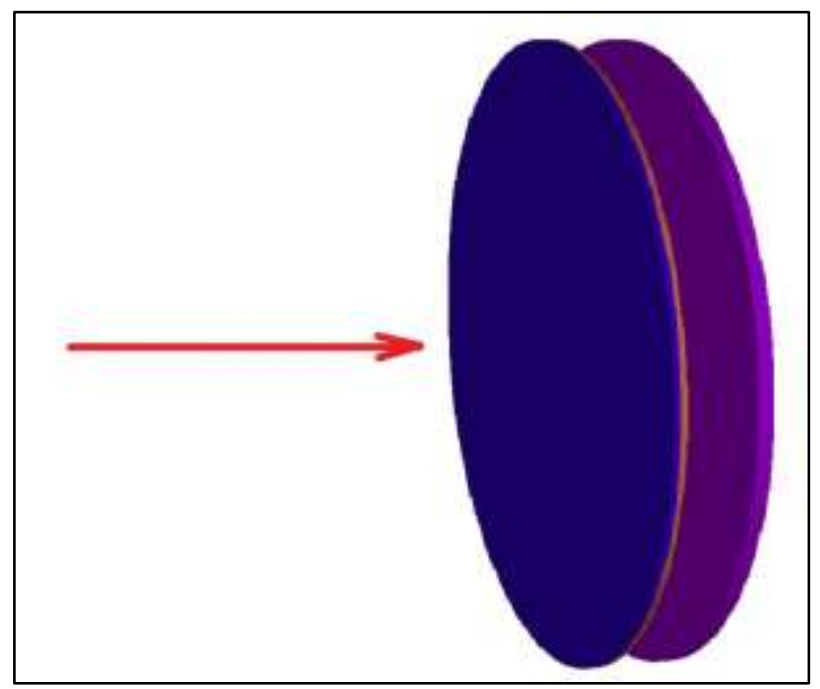

Figura 27: Geometria de obtenção dos espectros.

A validação do feixe de espectro largo foi feita comparando-se os valores obtidos por simulações da camada semirredutora, energia média e coeficiente de homogeneidade com os valores da norma.

As camadas semirredutoras foram obtidas ao simular a transmissão dos feixes de fótons com espectro largo simulados, por placas de cobre com espessuras variadas. Com os espectros de energia do feixe transmitido foi calculado o kerma de colisão no ar para cada espessura de placa. A CSR foi calculada através de ajustes exponenciais de primeira ordem mais constante.

\subsection{Leitura do sinal OSL}

O processo de leitura dos dosímetros foi feito em duas etapas: a primeira consistiu na leitura individual de cada dosímetro pré-irradiado aplicando-se luz de estimulação até a extinção do sinal. Após essa etapa, cada dosímetro foi irradiado com dose padrão de uma fonte beta do equipamento Risø e lido novamente. As duas leituras OSL obtidas dessa maneira foram empregadas para realizar a normalização por sinal padrão.

A normalização do sinal OSL é a utilização da razão das contagens de fótons emitidos por um dosímetro quando irradiado no feixe de interesse e em um feixe padrão. Esse processo tem por objetivo minimizar imprecisões por conta de possíveis diferenças de sensibilidade, massa e variações do sistema de medição. Esse método já se mostrou bastante satisfatório na redução de incertezas como visto em YUKIHARA et al (2005). 


\subsubsection{Leitor OSL}

A leitura dos dosímetros foi feita utilizando-se do equipamento Risø (Figura 28). Neste equipamento há um sistema giratório que alterna a posição dos dosímetros durante o processo de irradiação ou medição, sem a necessidade de manipulação individual, que poderia expô-los à luz externa. Utilizando-se um conjunto com filtros e colimadores ópticos, maximiza-se o sinal lido e preserva-se a integridade da fotomultiplicadora. Este equipamento detecta a luz vinda dos materiais estimulados opticamente aplicando-se uma luz azul proveniente de um conjunto de LEDs cujo pico de emissão tem o valor de aproximadamente $470 \mathrm{~nm}$ (Figura 29), com FWHM de $20 \mathrm{~nm}$ em modo de iluminação com potência constante (CW-OSL). Neste trabalho foi usado o colimador circular com orifício com diâmetro de $2 \mathrm{~mm}$ e o filtro U340 cuja função é proteger a fotomultiplicadora da luz de estímulo e permitir a passagem da luz emitida pelos dosímetros OSL.

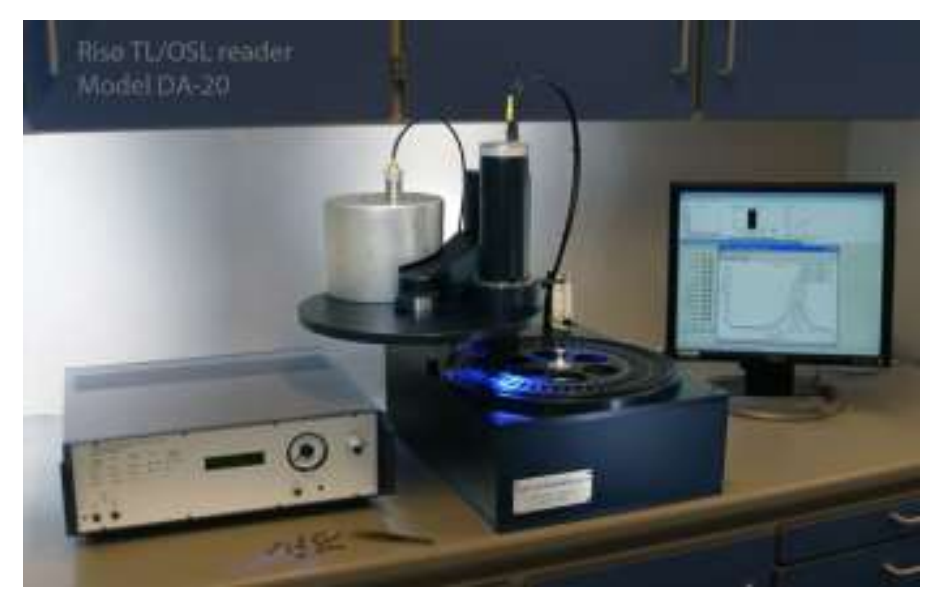

Figura 28: Leitor OSL RIS $\varnothing-$ TL/OSL DA-20 (RIS $\varnothing$ National Laboratory, Denmark).

O cluster de LEDs azuis tem potência óptica de $80 \mathrm{~W} / \mathrm{cm}^{2}$, e foi utilizada $90 \%$ da potência total durante as medições. 


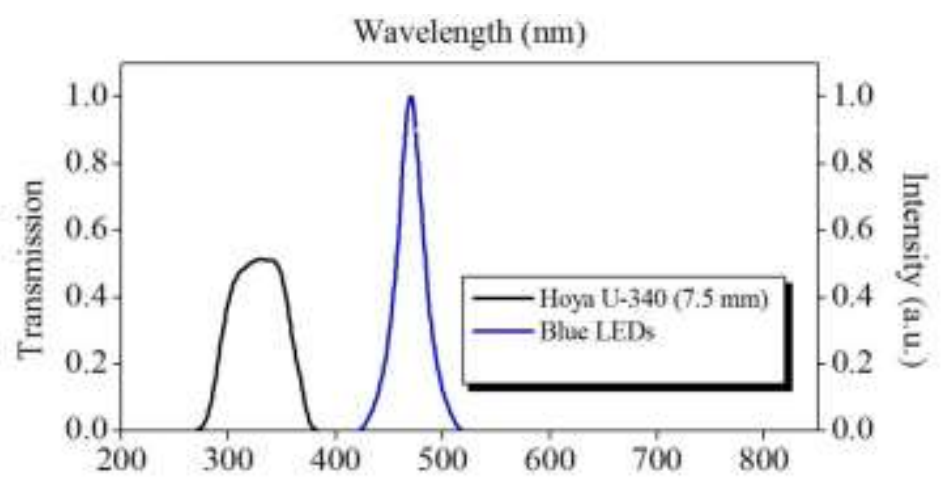

Figura 29: Espectro de transmissão do filtro U-340 e espectro de intensidade de luz emitida do conjunto de LEDs do equipamento Risø (Risø National Laboratory, Denmark).

O processo de medição consistiu em posicionar o conjunto de dosímetros irradiados com o feixe de interesse no carrossel porta-amostras, fazer a estimulação com luz azul durante $600 \mathrm{~s}$ com aquisição simultânea do sinal OSL. Esse tempo de estímulo deve ser o suficiente para esvaziar as cargas armadilhadas. Depois dessa primeira leitura, os dosímetros foram irradiados com feixe beta durante $2 \mathrm{~s}$ e, por fim, foram novamente medidos durante $600 \mathrm{~s}$ para adquirir o sinal de referência. A resposta OSL normalizada é o valor relativo ao sinal OSL para estes $2 \mathrm{~s}$ de irradiação beta. Os dosímetros não foram retirados de dentro do carrossel com o objetivo de não promover o desamardilhamento de cargas por iluminação espúria, tampouco modificar a posição dos dosímetros nos suportes, o que poderia alterar a leitura. Para o sinal de fundo, foram utilizados os dados dos últimos 50 dos $600 \mathrm{~s}$ de aplicação de luz de estimulação. Este sinal residual foi descontado de todas as medidas de emissão OSL em função do tempo de estímulo.

Nas curvas de emissão OSL foi utilizado o sinal inicial para a normalização utilizando a razão entre os sinais OSL pós-irradiação nos feixes de fótons e o sinal emitido após a irradiação com beta.

\subsection{Homogeneidade do feixe}

Comumente, os feixes gerados em aceleradores clínicos tem perfil de intensidade plano por conta do filtro de planura que é colocado na saída do feixe primário. Quando não há este filtro o perfil fica com formato que se assemelha a um sino. Por conta do uso do feixe de bremsstrahlung sem filtro de planura para o acelerador Microtron, foi desenvolvido um sistema de movimentação da câmara de ionização a fim de estudar a homogeneidade de doses do feixe de raios $\mathrm{X}$ produzido 
com os elétrons acelerados pelo Microtron e pelo equipamento de raios $X$ convencional com os filtros para obtenção do espectro largo. O sistema (Figura 30) consiste em um carrinho cuja função é mover unidimensionalmente o sensor (câmara) com velocidade controlada em uma barra rosqueada. A câmara foi posicionada a $50 \mathrm{~cm}$ do alvo (liga de W, Cu e Ni) no Microtron e $50 \mathrm{~cm}$ do foco no equipamento de raios $X$ convencional, e o carrinho foi deslocado em toda extensão, parando em diversas posições para coletar a média da taxa de dose convertida a partir da carga medida durante $30 \mathrm{~s}$ em cada posição, de forma a obtermos o perfil do feixe. Depois o processo foi repetido variando a altura em relação ao solo de todo o sistema de modo a obter uma matriz de homogeneidade. Também foi medida a corrente do acelerador a fim de normalizar a taxa de dose para um valor que independa da variação da corrente do acelerador.

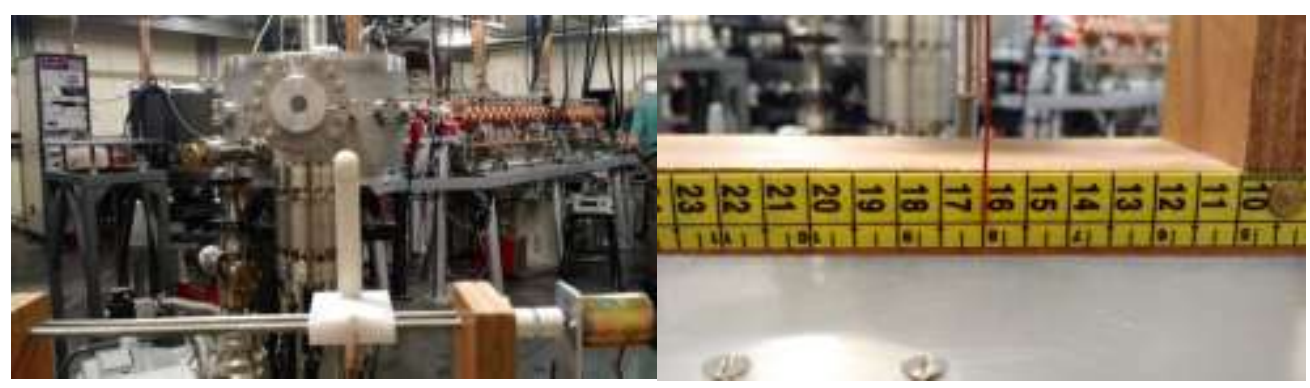

Figura 30: Sistema de movimentação da câmara de ionização. A foto à esquerda mostra a câmara de ionização fixa no suporte enquanto é movimentada em uma barra rosqueada. A graduação onde se monitorou a posição da câmara está na foto à direita.

Todo esse sistema fora controlado remotamente utilizando-se de câmeras de vídeo para a verificação da posição. Com isso, determinou-se uma área de irradiação que poderia ser considerada homogênea.

\subsection{Parâmetros de irradiação}

Os parâmetros de irradiação (Tabela 5) foram definidos ponderando caso a caso, o melhor posicionamento dos dosímetros, taxa de dose absorvida e espessura da camada de build-up. 
Tabela 5: Parâmetros de irradiação.

\begin{tabular}{clccc}
\hline Feixe & Tipo & $\begin{array}{c}\text { Distância foco- } \\
\text { dosímetros (cm) }\end{array}$ & $\begin{array}{c}\text { Espessura da } \\
\text { camada de } \\
\text { build-up (cm) }\end{array}$ & $\begin{array}{c}\text { Taxa de dose } \\
\text { (mGy/s) }\end{array}$ \\
\hline W150 & Horiz. & 50 & - & 0,860 \\
W200 & Horiz. & 50 & - & 1,460 \\
${ }^{137} \mathrm{Cs}$ & Horiz. & 49 & 0,5 & 1,550 \\
${ }^{60} \mathrm{Co}$ & Horiz. & 120 & 0,5 & 1,060 \\
Microtron 1,9 MeV & Horiz. & 50 & 0,5 & $<1$ \\
Microtron 5,0 MeV & Horiz. & 50 & 1,5 & $<1$ \\
Varian 6 MeV & Vert. & 100 & 1,5 & 100 \\
Varian 15 MeV & Vert. & 100 & 2,5 & 100 \\
\hline
\end{tabular}

\subsection{Análise de dados}

A análise dos dados foi feita utilizando o sinal inicial das medidas OSL para cada dose e descontando o sinal residual como indicado em 3.6.1. A resposta OSL normalizada foi definida como a razão do sinal inicial dos dosímetros no feixe de fótons e no feixe beta. Feita essa razão, obteve-se a média para o conjunto de dosímetros irradiados com mesma dose para plotar o gráfico da resposta OSL normalizada em função da dose absorvida para cada um dos feixes utilizados neste trabalho. Através destas curvas foram feitos ajustes lineares para a obtenção dos coeficientes angulares para cada um dos feixes. Com esses coeficientes, foram calculados os fatores de dependência energética experimentais para cada dosímetro utilizando a Equação 29, onde $C_{x}$ e $C_{C o}$ são os coeficientes angulares das retas ajustadas para o feixe com energia $x$ e para o feixe do Co-60 respectivamente.

$$
f_{C o}^{x}=\frac{C_{x}}{C_{C o}}
$$




\section{RESULTADOS}

\subsection{Método de redução de incerteza para o conjunto de dosímetros}

Irradiando-se com feixe provido pela máquina de radioterapia $\left({ }^{60} \mathrm{Co}\right)$ com uma dose de 166,8 mGy, a OSL dos dosímetros foi lida no equipamento Risø por $600 \mathrm{~s}$. Após esta leitura, os dosímetros foram reirradiados, no próprio carrossel, sem retirálos das posições iniciais, com a fonte beta $(\mathrm{Sr} / \mathrm{Y}-90)$ durante $2 \mathrm{~s}$ e medidos novamente a fim de comparar a distribuição de respostas no lote. Na Tabela 6 temos os dados da dispersão do conjunto de amostras, dada pelo coeficiente de variação (CV - desvio padrão dividido pelo valor médio) de cada amostra de leituras.

Tabela 6: Dispersões (representadas pelo coeficiente de variação) da resposta OSL dos dosímetros sem nenhum tipo de seleção ou normalização.

\begin{tabular}{ccc}
\hline Material & Quantidade & $\begin{array}{c}\text { Coeficiente de Variação } \\
\text { (\%) }\end{array}$ \\
\hline $\mathrm{Al}_{2} \mathrm{O}_{3}(\mathrm{Co}-60)$ & 48 & 9,4 \\
$\mathrm{Al}_{2} \mathrm{O}_{3}(\mathrm{Sr} / \mathrm{Y}-90)$ & 48 & 8,8 \\
$\mathrm{BeO}(\mathrm{Co}-60)$ & 48 & 14,1 \\
$\mathrm{BeO}(\mathrm{Sr} / \mathrm{Y}-90)$ & 48 & 14,4 \\
\hline
\end{tabular}

No $\mathrm{Al}_{2} \mathrm{O}_{3}$, tanto a irradiação com fótons provenientes do ${ }^{60} \mathrm{Co}$ quanto o feixe da fonte beta, o desvio padrão foi de aproximadamente $9 \%$ do valor médio. Para o $\mathrm{BeO}$ utilizando os mesmos feixes de irradiação, foram obtidos desvios padrões próximos a 14\%. Uma das formas de reduzir a incerteza do lote de dosímetros é fazer uma seleção de um subconjunto, por resposta, de forma a ter um conjunto menor, mas mais homogêneo. Um dos grandes inconvenientes do processo de seleção é o fato de confiar na repetitividade das amostras. Observando a dispersão, não é possível predizer que, um dosímetro cuja medida se enquadrou em alguma posição arbitrária em relação à média, sempre estará contido na mesma posição no conjunto de medidas. Outra forma de utilização da leitura dos dosímetros seria dispor de todo o conjunto, porém fazer a normalização com uma segunda irradiação. Mas será que a normalização reduz a incerteza? Ou seja, uma normalização por irradiação padronizada pode aumentar a chance de produzir dados mais confiáveis? 
A Tabela 7 ilustra uma redução significativa na incerteza obtida para os valores normalizados. Utilizando a razão entre os sinais, consegue-se reduzir a incerteza e, consequentemente, aumentar a confiabilidade no grupo de dosímetros sem dispender do trabalho de fazer a seleção e manter selecionado o grupo, e confiar que, na repetição de medidas, os valores para um dado dosímetro permanecerão na mesma posição relativa.

Tabela 7: Resposta OSL após normalização com irradiação por fonte beta durante $2 \mathrm{~s}$.

\begin{tabular}{ccc}
\hline Material & Quantidade & Dispersão (\%) \\
\hline $\mathrm{Al}_{2} \mathrm{O}_{3}$ & 48 & 4,3 \\
$\mathrm{BeO}$ & 48 & 4,8 \\
\hline
\end{tabular}

Na Figura 31 estão os histogramas que ilustram a redução da dispersão do lote de dosímetros ao utilizar a razão entre o sinal OSL e o sinal de referência. Para o $\mathrm{Al}_{2} \mathrm{O}_{3}$ a redução no $\mathrm{CV}$ foi de mais de $50 \%$ e para o $\mathrm{BeO}$, o $\mathrm{CV}$ se reduziu para um terço do valor anterior.
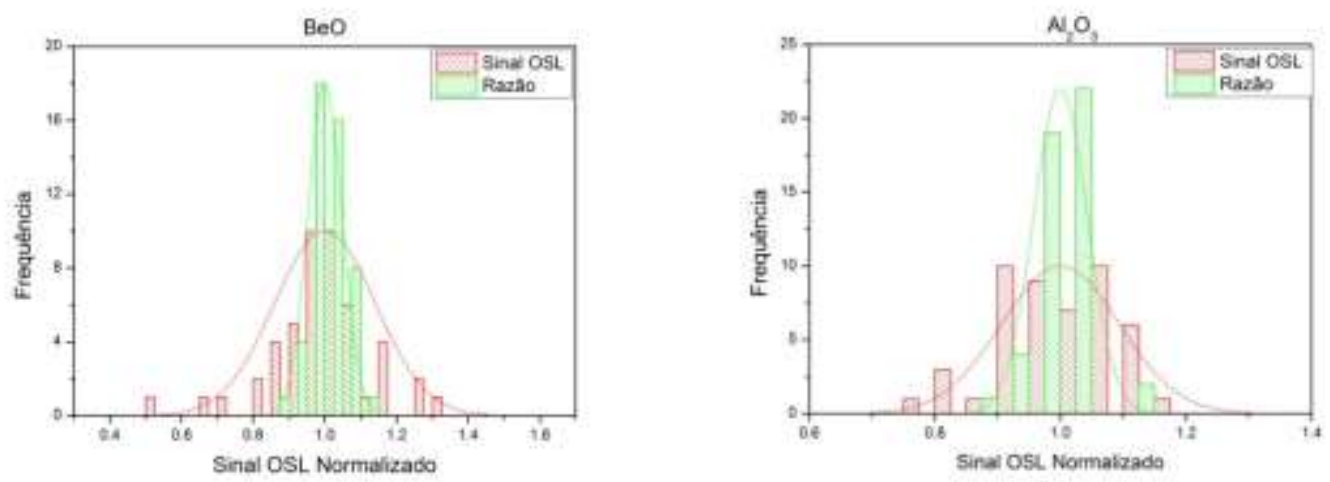

Figura 31: Histogramas do sinal OSL após a irradiação no feixe de Co-60 e do sinal normalizado pela dose de referência do feixe beta para os conjuntos de $\mathrm{Al}_{2} \mathrm{O}_{3}$ e $\mathrm{BeO}$. A abcissa dos gráficos foi normalizada pelo valor médio de cada distribuição.

\subsection{Estudo da homogeneidade dos feixes}

A fim de garantir uma região para irradiação cuja variação de dose absorvida seja a menor possível, foi feito um levantamento da intensidade do feixe nas diversas energias utilizadas.

A Figura 32 apresenta os perfis da razão entre taxa de dose medida pelo conjunto câmara mais eletrômetro e corrente acelerador Microtron para os feixes de 1,9 MeV e 5,0 MeV, utilizando o dispositivo desenvolvido para esta finalidade. $\mathrm{Na}$ 
Figura 33 são apresentadas as varreduras feitas com distância foco-câmara de 50 $\mathrm{cm}$ para os feixes de raios $X$ convencional com espectro largo com potencial máximo igual a 150 e $200 \mathrm{kV}$. Em todos os casos foi feita a normalização pelos valores no ponto central.
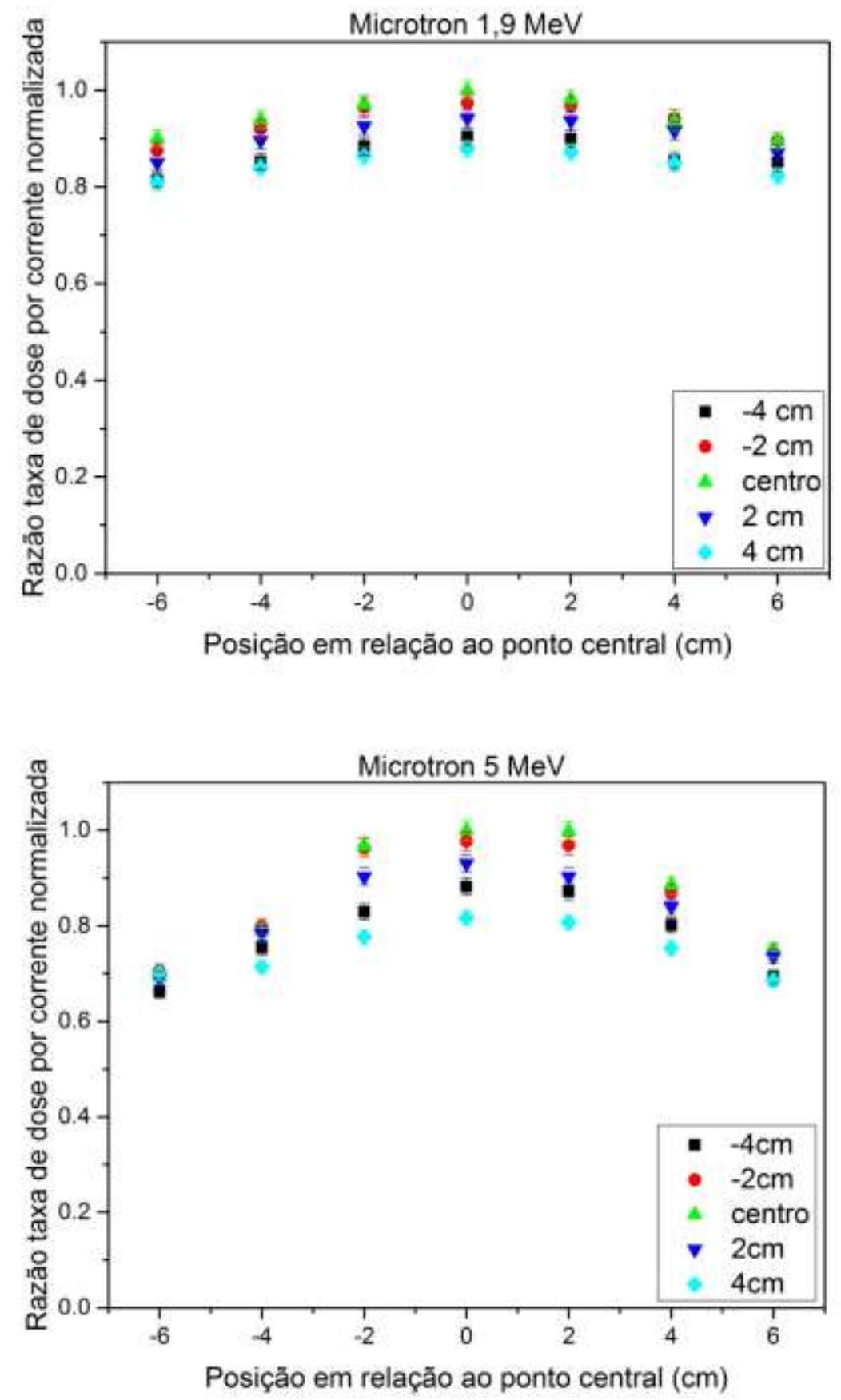

Figura 32: Razão taxa de dose absorvida por corrente obtida por varredura com câmara de ionização para o feixe de raios $X$ produzido por elétrons com energia de 1,9 MeV e 5,0 MeV. Na legenda estão os deslocamentos verticais em relação ao ponto central a $50 \mathrm{~cm}$ do alvo. As correntes utilizadas foram da ordem de $1 \mu \mathrm{A}$ e $10 \mu \mathrm{A}$ respectivamente. 

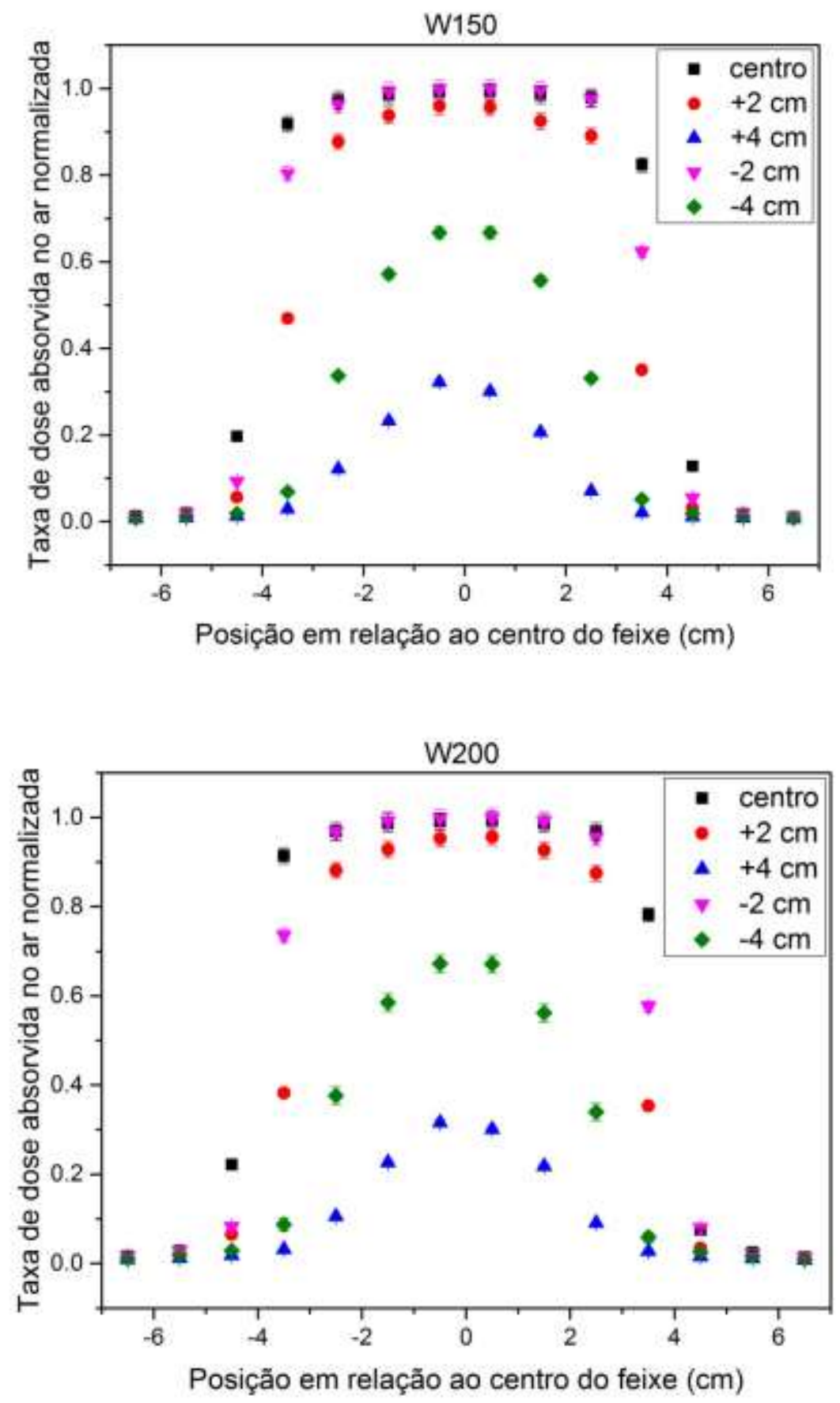

Figura 33: Varredura do feixe de espectro largo com potencial máximo 150 e $200 \mathrm{kV}$ respectivamente, variandose as alturas de modo a determinar a região de irradiação. A corrente foi mantida em $15 \mathrm{~mA}$ durante a varredura.

Observando o comportamento dos pontos das varreduras tanto do acelerador Microtron quanto do equipamento de raios $\mathrm{X}$ convencional, foi possível definir uma região próxima ao centro do feixe na qual a dose absorvida seria uniforme dentro da incerteza. Nos feixes de raios $\mathrm{X}$ convencional com espectro largo, a região definida tem dimensões de $\pm 2,5 \mathrm{~cm}$ na horizontal e entre o centro do feixe e $-2,0 \mathrm{~cm}$ na 
vertical. Já para o feixe do Microtron com 1,9 e 5,0 MeV de energia máxima, a área de irradiação foi definida em $\pm 2,0 \mathrm{~cm}$ na horizontal e entre o centro do feixe e $2,0 \mathrm{~cm}$ na vertical.

A planura do feixe foi avaliada de forma distinta para os feixes. No caso dos feixes de raios $X$ convencional com espectro largo a análise foi feita conforme a Equação 20 limitando a $80 \%$ da região central do feixe. Já para o feixe do acelerador Microtron, por não haver colimação para limitar a largura do feixe, o cálculo da planura foi feito utilizando a região empregada para a irradiação. $\mathrm{Na}$ Tabela 8 estão apresentados os valores de planura. O sinal positivo (+) indica um deslocamento vertical acima do ponto central, enquanto que o sinal negativo (-) indica deslocamento vertical abaixo. Para os feixes de raios $X$ convencional de espectro largo e do Microtron, o deslocamento foi de $\pm 2 \mathrm{~cm}$. Para os feixes clínicos, foram cedidos pela equipe do hospital os valores de planura. Os valores de $\mathrm{F}$ para os feixes de $6 \mathrm{MeV}$ e $15 \mathrm{MeV}$ dos aceleradores Clinac 6eX e iX, foram de 0,30 e 0,16\% respectivamente. Esses dados evidenciam uma variação de doses absorvidas em água muito baixa em todo o plano de irradiação. Isso se deve ao uso do filtro de planura.

Tabela 8: Planura dos feixes na região central e deslocado acima (+) e abaixo (-)

\begin{tabular}{cccc}
\hline Feixe & Planura centro (\%) & Planura + (\%) & Planura - (\%) \\
\hline $1,9 \mathrm{MeV}$ & 1,4 & 0,9 & 0,4 \\
$5,0 \mathrm{MeV}$ & 1,7 & 1,5 & 0,7 \\
W150 & 0,8 & 4,4 & 0,1 \\
W200 & 1,3 & 4,5 & 2,2 \\
\hline
\end{tabular}

Outra análise feita foi o cálculo da simetria dos feixes. Este parâmetro foi avaliado integrando-se as áreas à direita e à esquerda do centro do feixe de todas as curvas medidas (Figuras 32 e 33). A Tabela 9 mostra que a porcentagem máxima de variação encontrada (simetria) foi de $3,5 \%$ no feixe de espectro largo com energia máxima de $200 \mathrm{keV}$. 
Tabela 9: Valores da simetria dos feixes de espectro largo, Microtron e aceleradores clínicos.

\begin{tabular}{cccc}
\hline Feixe & $\begin{array}{c}\text { Area normalizada } \\
\text { à esquerda }\end{array}$ & $\begin{array}{c}\text { Area normalizada } \\
\text { à direita }\end{array}$ & Simetria (\%) \\
\hline $1,9 \mathrm{MeV}$ & 0,4997 & 0,5003 & $-0,1$ \\
$5,0 \mathrm{MeV}$ & 0,4856 & 0,5144 & $-2,9$ \\
$\mathrm{~W} 150$ & 0,5099 & 0,4901 & 2,0 \\
$\mathrm{~W} 200$ & 0,5177 & 0,4823 & 3,5 \\
$6 \mathrm{MeV}$ & 0,49965 & 0,50035 & $-0,07$ \\
$15 \mathrm{MeV}$ & 0,49385 & 0,50615 & $-1,23$ \\
\hline
\end{tabular}

\subsection{Resposta OSL dos dosímetros constituídos de $\mathrm{Al}_{2} \mathrm{O}_{3}: \mathrm{C}$}

\subsubsection{Curvas de emissão}

Os dosímetros foram expostos aos diferentes feixes disponíveis a fim de verificar alterações no formato da curva de emissão OSL. Na Figura 34 estão apresentadas as curvas de emissão OSL para os dosímetros feitos de óxido de alumínio, lidos no equipamento Risø utilizando-se da mesma fonte de estimulação, com mesma potência e dose absorvida aproximadamente igual a 2 Gy. O sinal OSL foi normalizado para o valor máximo (inicial) a fim de facilitar a comparação qualitativa do formato da curva. Também foi subtraído de cada curva o sinal de fundo conforme a seção 3.7.1.

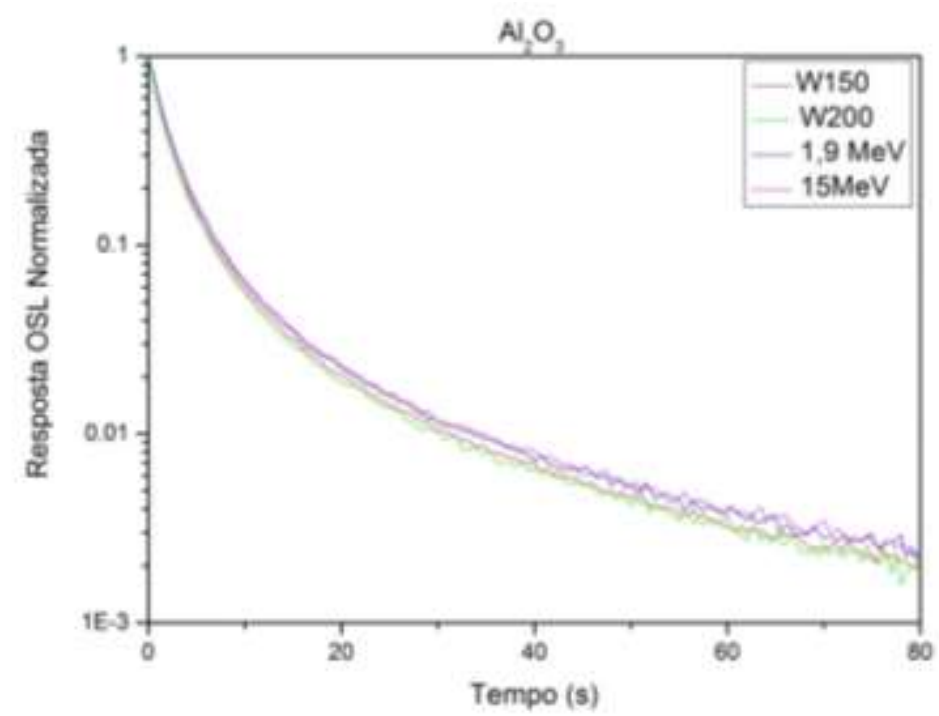

Figura 34: Curvas de emissão OSL para $\circ \mathrm{Al}_{2} \mathrm{O}_{3}$ irradiado com doses absorvidas aproximadamente 2 Gy para quatro dos feixes estudados nos primeiros $80 \mathrm{~s}$ de leitura. As curvas para irradiações com os demais feixes são semelhantes e não estão apresentadas para melhor visualização. 
É perceptível que as curvas de emissão OSL são fracamente afetadas pela energia de irradiação dos dosímetros. Para $\circ \mathrm{Al}_{2} \mathrm{O}_{3}$, há uma leve tendência de decaimento mais rápido do sinal OSL para os feixes de energias mais baixas.

$\mathrm{Na}$ Figura 35 temos as curvas de emissão OSL de dosímetros $\mathrm{Al}_{2} \mathrm{O}_{3}$ irradiados utilizando o feixe do Microtron com energia máxima de 1,9 MeV variandose as doses absorvidas para esta mesma qualidade de feixe. As curvas também foram normalizadas pelo valor inicial a fim de facilitar a comparação qualitativa e subtraídos os sinais de fundo. É perceptível que o formato é praticamente idêntico ao variar a dose. As condições de medição foram mantidas idênticas para todos os casos. Nos demais feixes o comportamento foi semelhante à irradiação com feixe de $1,9 \mathrm{MeV}$ do Microtron.

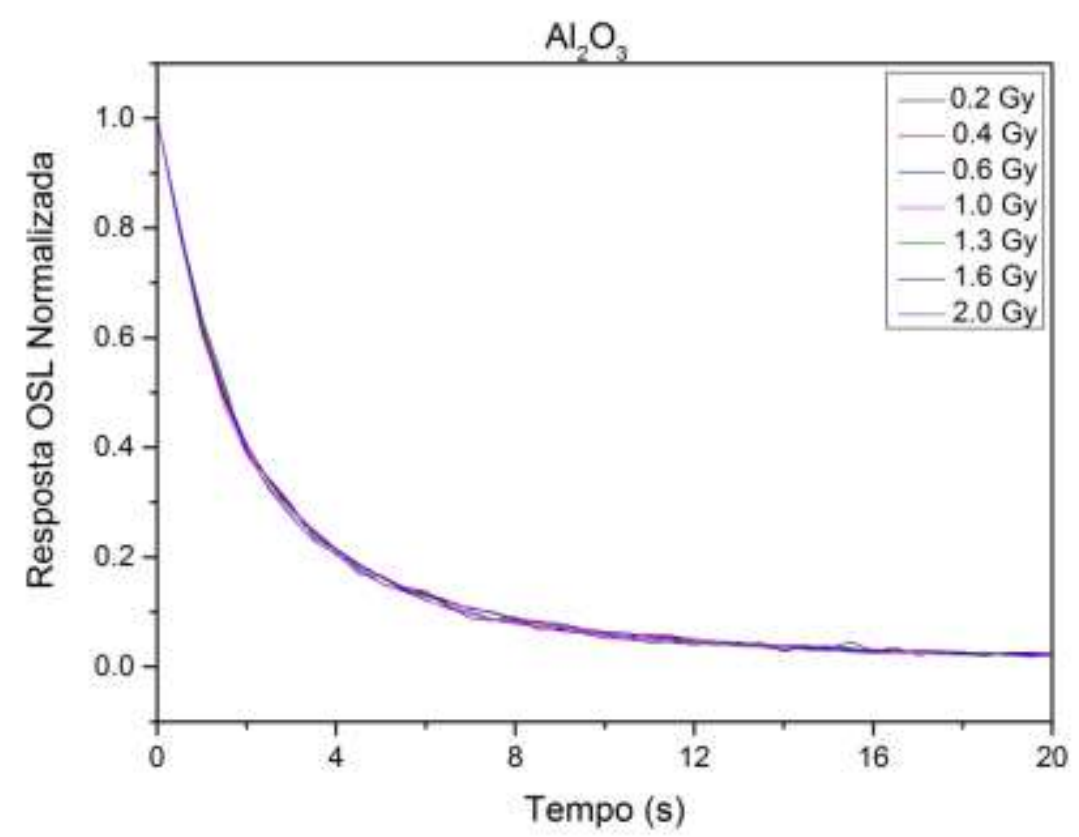

Figura 35: Curvas de emissão OSL normalizadas pelo valor máximo para os dosímetro de $\mathrm{Al}_{2} \mathrm{O}_{3}$ quando irradiados no feixe com energia de $1,9 \mathrm{MeV}$ do Microtron.

\subsubsection{Dependência energética da resposta dosimétrica}

Os dosímetros baseados em $\mathrm{Al}_{2} \mathrm{O}_{3}$ foram irradiados com os diversos feixes e lidos no equipamento Risø fazendo o processo de normalização por sinal padrão da fonte emissora de beta desse equipamento. A Figura 36 ilustra o comportamento do sinal OSL deste material quando submetido a estes feixes. Para a análise foi utilizado o sinal inicial das curvas de emissão OSL. 


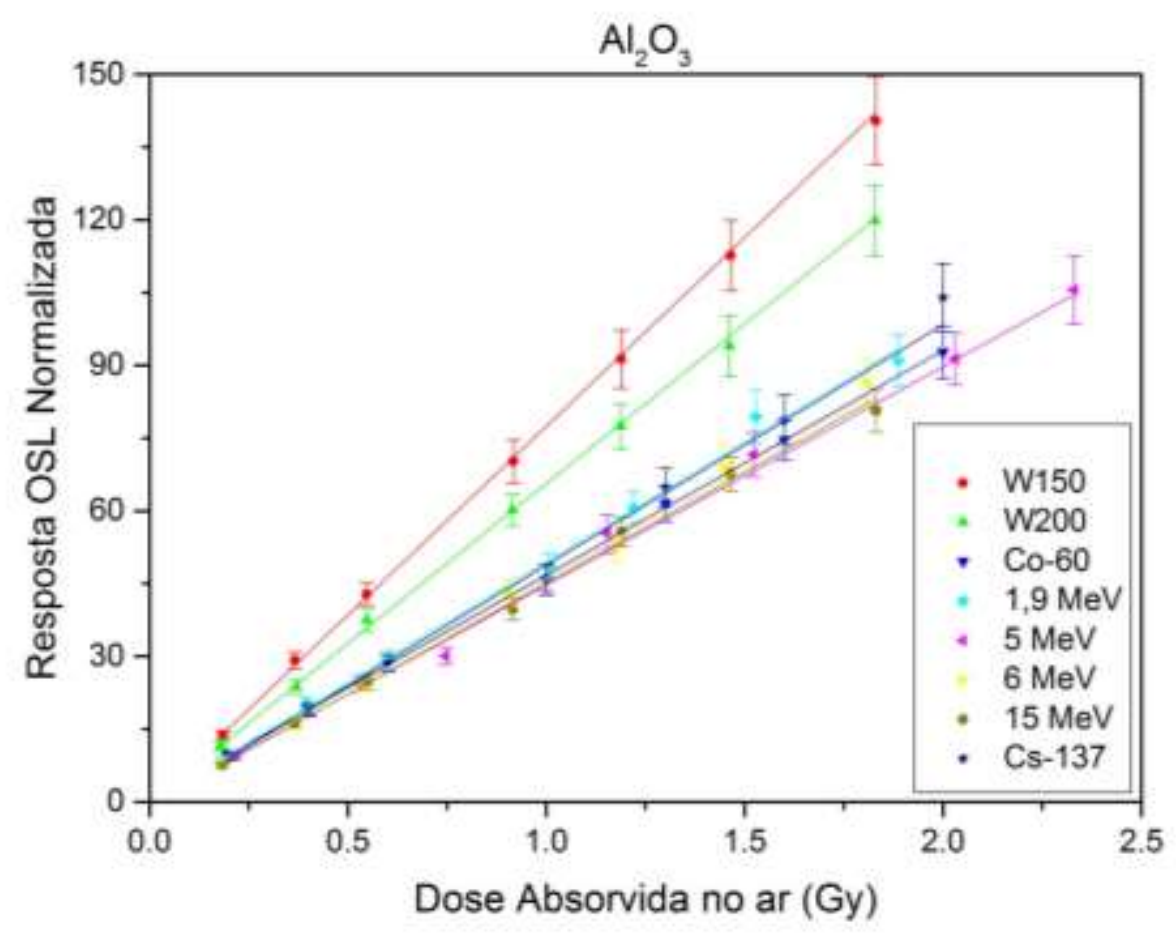

Figura 36: Resposta normalizada dos dosímetros de óxido de alumínio a diversos feixes.

Os dosímetros feitos de óxido de alumínio têm suas respostas parecidas nos feixes com energia máxima mais elevada (Cs-137, Co-60 e aceleradores) enquanto que nos feixes de raios $X$ convencional de espectro largo a resposta para a mesma dose é maior. Nesta faixa de doses estes dosímetros têm resposta aproximadamente linear. $\mathrm{Na}$ Tabela 10 temos os coeficientes angulares ajustados pelo método dos mínimos quadrados para $0 \mathrm{Al}_{2} \mathrm{O}_{3}$, bem como os coeficientes de correlação $\left(\mathrm{R}^{2}\right)$.

Tabela 10: Dependência energética da resposta dosimétrica para $\circ \mathrm{Al}_{2} \mathrm{O}_{3}$.

\begin{tabular}{ccc}
\hline Feixe & Coeficiente angular $\left(\mathbf{G y}^{-1}\right)$ & $\mathbf{R}^{\mathbf{2}}$ \\
\hline W150 & $77,8(9)$ & 0,999 \\
W200 & $65,9(9)$ & 0,999 \\
Microtron 1,9 MeV & $49,6(10)$ & 0,998 \\
Cs-137 & $49,6(10)$ & 0,997 \\
Microtron 5,0 MeV & $45,0(16)$ & 1,000 \\
Co-60 & $46,3(3)$ & 0,992 \\
Varian 6 MeV & $46,1(11)$ & 0,997 \\
Varian 15 MeV & $45,8(8)$ & 0,998 \\
\hline
\end{tabular}




\subsection{Resposta OSL dos dosímetros constituídos de BeO}

\subsubsection{Curvas de emissão}

A comparação entre emissão OSL em função do tempo em energias diferentes também foi feita com o intuito de verificar se há mudanças com a energia do feixe. As condições foram as mesmas utilizadas anteriormente: dose absorvida igual a 2 Gy, intensidade de estimulação e potência dos LEDs constantes. O comportamento das curvas está apresentado na Figura 37. Para os dosímetros de óxido de berílio, analisando qualitativamente, é perceptível uma tendência de emissão OSL mais rápida para os dosímetros irradiados com energias mais elevadas.

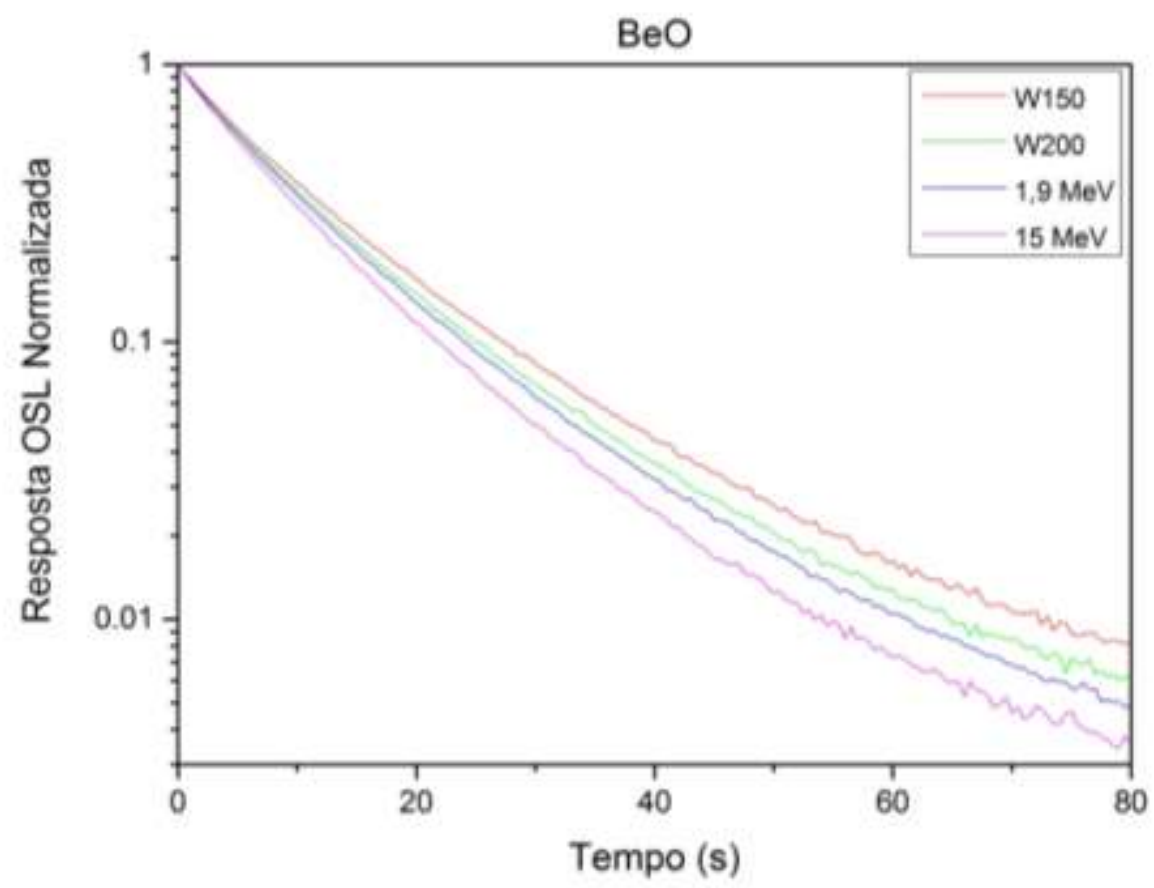

Figura 37: Curvas de emissão OSL para o $\mathrm{BeO}$ irradiado com doses absorvidas aproximadamente 2 Gy para quatro dos feixes estudados nos primeiros $80 \mathrm{~s}$ de leitura. As curvas para as irradiações com os demais feixes são semelhantes e não estão apresentadas para melhor visualização.

Na Figura 38 temos a curva de emissão OSL dos dosímetros de óxido de berílio quando irradiado num mesmo feixe e condições de leitura do sinal (no caso apresentado no feixe de bremsstrahlung de 1,9 MeV do acelerador Microtron) com diversas doses. Analisando qualitativamente é possível verificar que as curvas se sobrepõem não indicando, portanto, efeito da dose absorvida na forma da curva de 
emissão OSL do material na faixa de doses utilizada. Para os demais feixes obtivemos o mesmo comportamento.

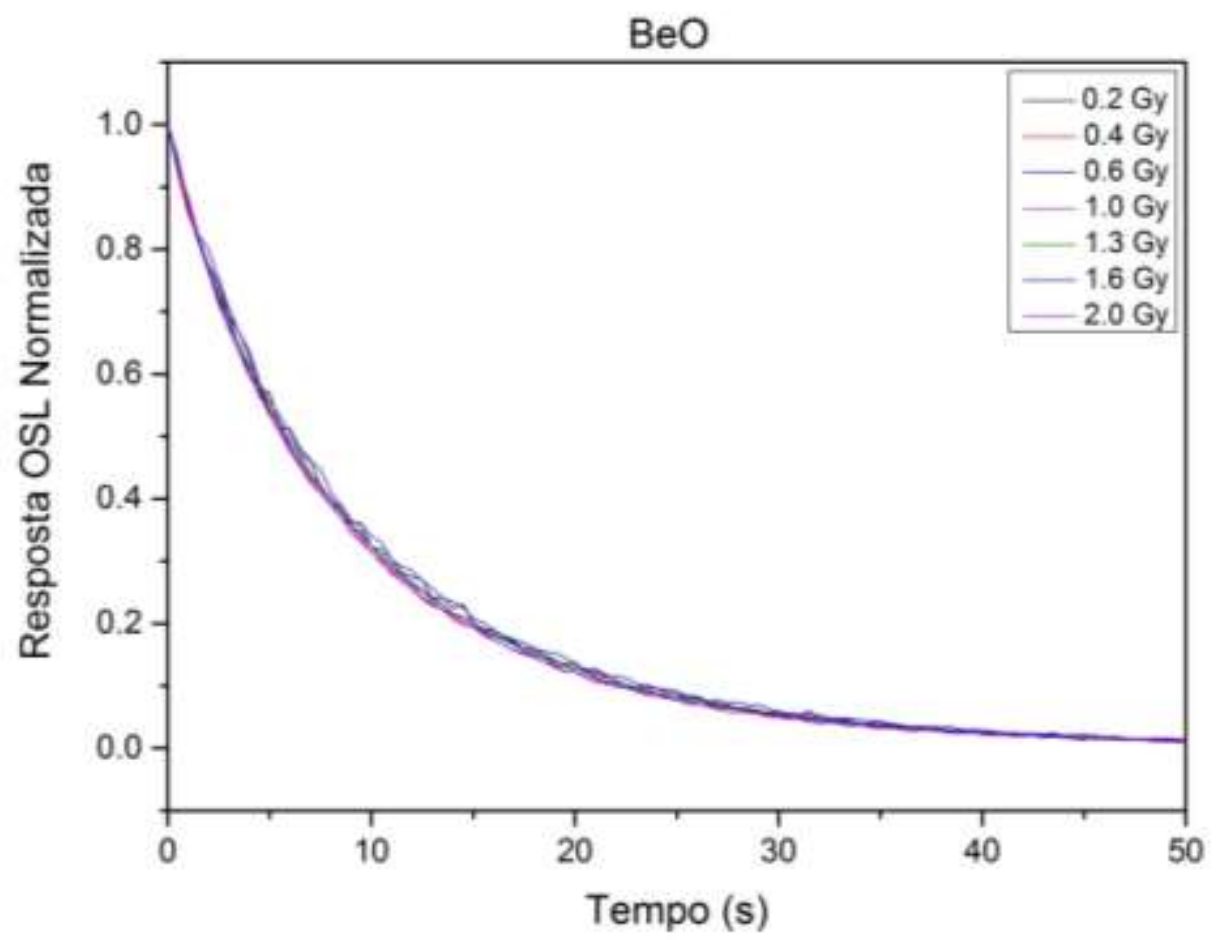

Figura 38: Curvas de emissão OSL normalizadas pelo valor máximo para os dosímetro de BeO quando irradiados no feixe com energia de 1,9 MeV do Microtron.

\subsubsection{Dependência energética da resposta dosimétrica}

Irradiando-se o conjunto de dosímetros de óxido de berílio com os feixes disponíveis foram obtidas as respostas normalizadas apresentadas na Figura 39. O procedimento de leitura foi idêntico para todas as amostras: irradiação com o feixe de fótons, medição no equipamento Risø, irradiação com feixe beta, leitura do sinal proveniente desta irradiação e normalização. 


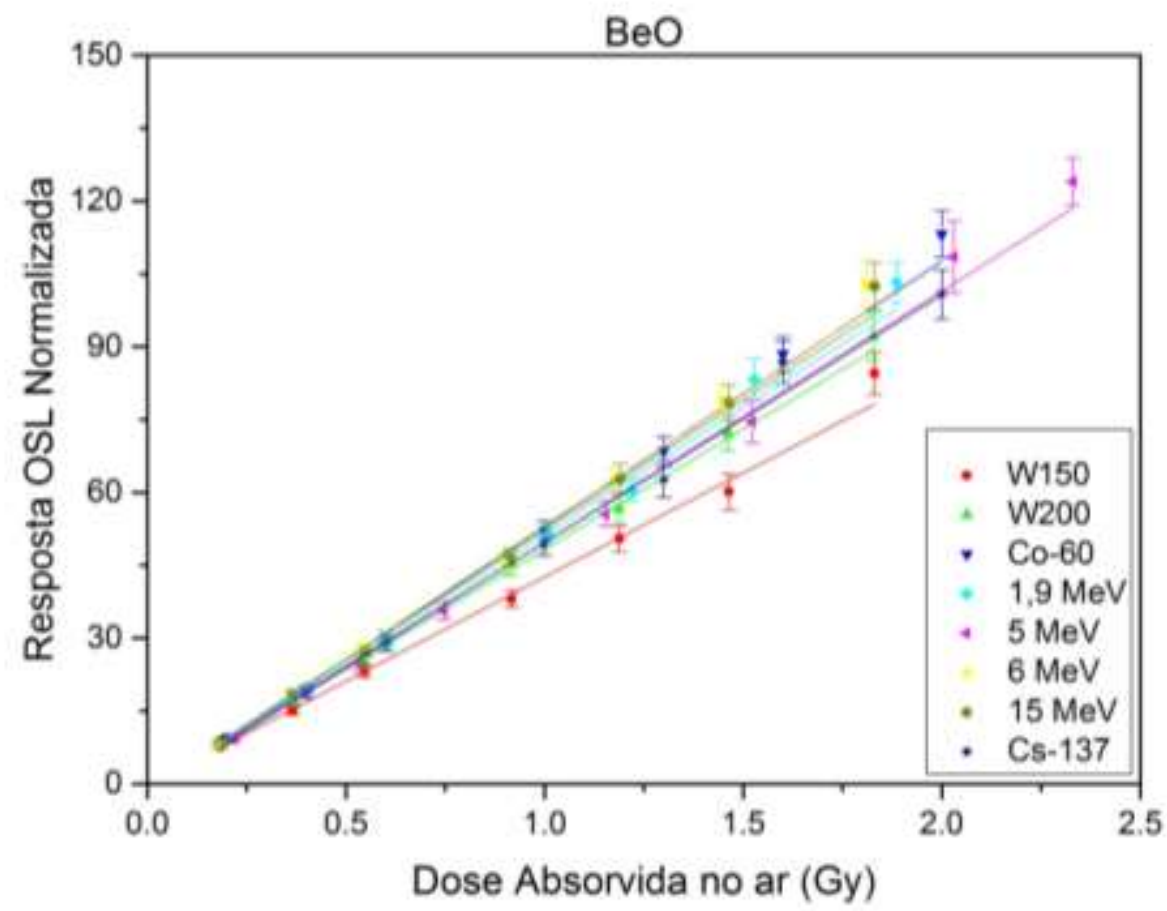

Figura 39: Resposta OSL normalizada para os dosímetros de $\mathrm{BeO}$ irradiados nos feixes descritos.

É visível o fato da resposta dos dosímetros aumentar em função da dose absorvida conforme se aumenta a energia média do feixe até estabilizar ao se aproximar da energia média do cobalto. Os coeficientes angulares foram obtidos através de ajuste linear das curvas apresentadas acima e estão apresentados na Tabela 11.

Tabela 11: Dependência energética da resposta dosimétrica do $\mathrm{BeO}$.

\begin{tabular}{ccc}
\hline Feixe & Coeficiente angular $\left(\mathrm{Gy}^{-1}\right)$ & $\mathbf{R}^{\mathbf{2}}$ \\
\hline W150 & $42,9(10)$ & 0,997 \\
W200 & $49,4(8)$ & 0,998 \\
Microtron 1,9 MeV & $52,5(12)$ & 0,997 \\
Cs-137 & $51,0(12)$ & 0,997 \\
Microtron 5,0 MeV & $51,7(11)$ & 0,998 \\
Co-60 & $54,7(11)$ & 0,997 \\
Varian 6 MeV & $54,6(11)$ & 0,998 \\
Varian 15 MeV & $53,4(10)$ & 0,998 \\
\hline
\end{tabular}




\subsection{Fator de dependência energética experimental}

A partir dos ajustes lineares da resposta normalizada em função da dose absorvida, foram calculados os fatores de dependência energética que estão apresentados na Tabela 12.

Tabela 12: Fatores de dependência energética obtidos experimentalmente para os materiais OSL utilizados nos diferentes feixes. Os valores foram calculados por ajuste linear.

\begin{tabular}{ccc}
\hline Feixe & $\boldsymbol{f}_{\boldsymbol{C o}}^{\boldsymbol{x}}\left(\mathrm{Al}_{2} \mathbf{O}_{3}\right)$ & $\boldsymbol{f}_{\boldsymbol{C o}}^{\boldsymbol{x}}(\mathrm{BeO})$ \\
\hline W150 & $1,68(2)$ & $0,78(2)$ \\
W200 & $1,42(2)$ & $0,90(2)$ \\
Microtron 1,9 MeV & $1,07(2)$ & $0,96(3)$ \\
Cs-137 & $1,07(2)$ & $0,93(3)$ \\
Microtron 5,0 MeV & $0,97(4)$ & $0,95(3)$ \\
Co-60 & $1,00(1)$ & $1,00(3)$ \\
Varian 6 MeV & $1,00(2)$ & $1,00(3)$ \\
Varian 15 MeV & $0,99(2)$ & $0,98(3)$ \\
\hline
\end{tabular}

No gráfico do fator de dependência energética em função da energia média dos fótons de cada feixe (Figura 40) é possível observar uma tendência de independência da resposta dos dosímetros ao aumentar a energia média do feixe fatores próximos a 1 para energias a partir de $~ 600 \mathrm{keV}$. Nos feixes de espectro largo por conta das energias menores e das diferenças de número atômico dos materiais, o comportamento difere muito entre os materiais. A energia média utilizada no eixo horizontal refere-se à energia média obtida por simulação em Monte Carlo cujos valores serão apresentados em 4.6. 


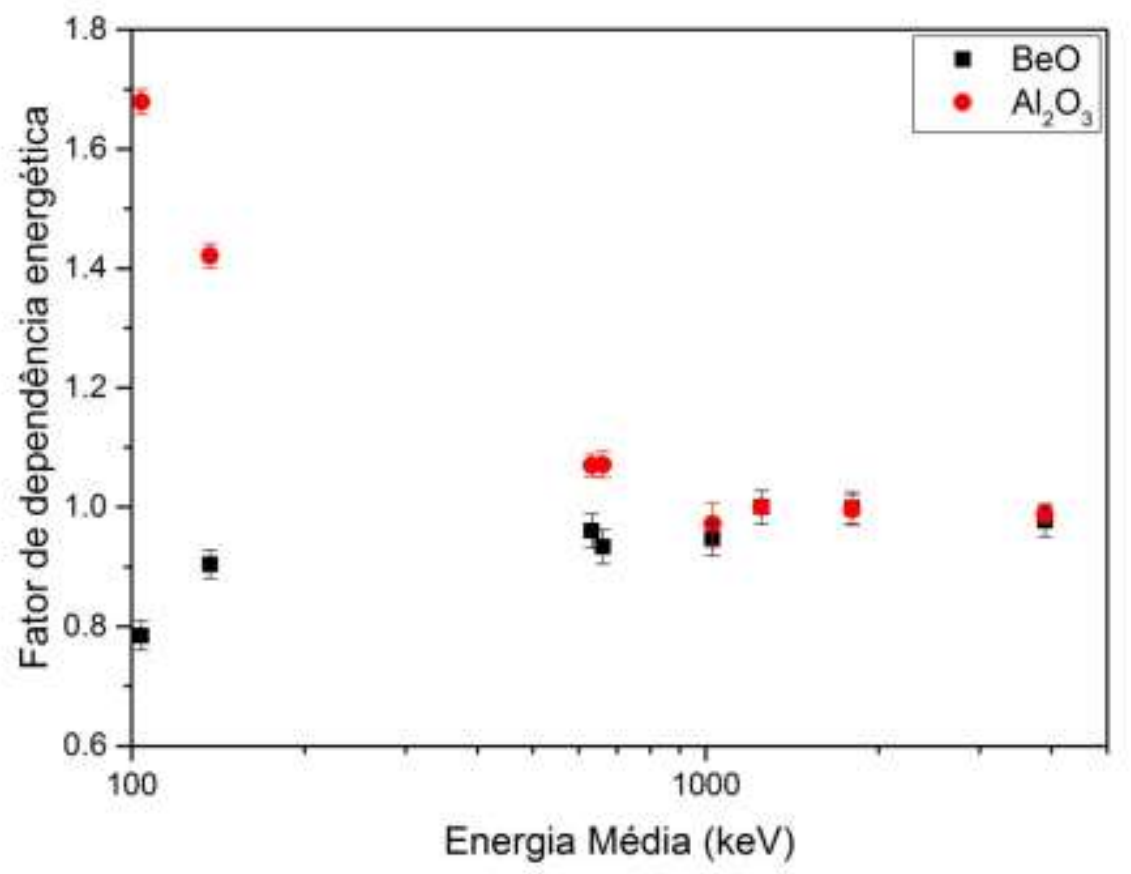

Figura 40: Gráfico da dependência energética experimental dos dosímetros em função da energia média do feixe.

\subsection{Simulações em Monte Carlo}

\subsubsection{Espectros simulados}

O espectro gerado por TBC foi calculado já considerando a filtração inerente do tubo de raios $X$ para depois ser utilizado na simulação do feixe espectro largo empregado para simular a deposição de energia nos materiais. Na Figura 41 temos os feixes de raios $X$ convencional com espectros largos simulados e os respectivos espectros apresentados pela norma (ABNT NBR ISO 4037-1). Com o aumento da energia e o emprego de filtros com maior espessura e maior número atômico, as linhas características $\mathrm{K}_{\alpha}$ e $\mathrm{K}_{\beta}$ do tungstênio são atenuadas por conta da filtração adicional. 

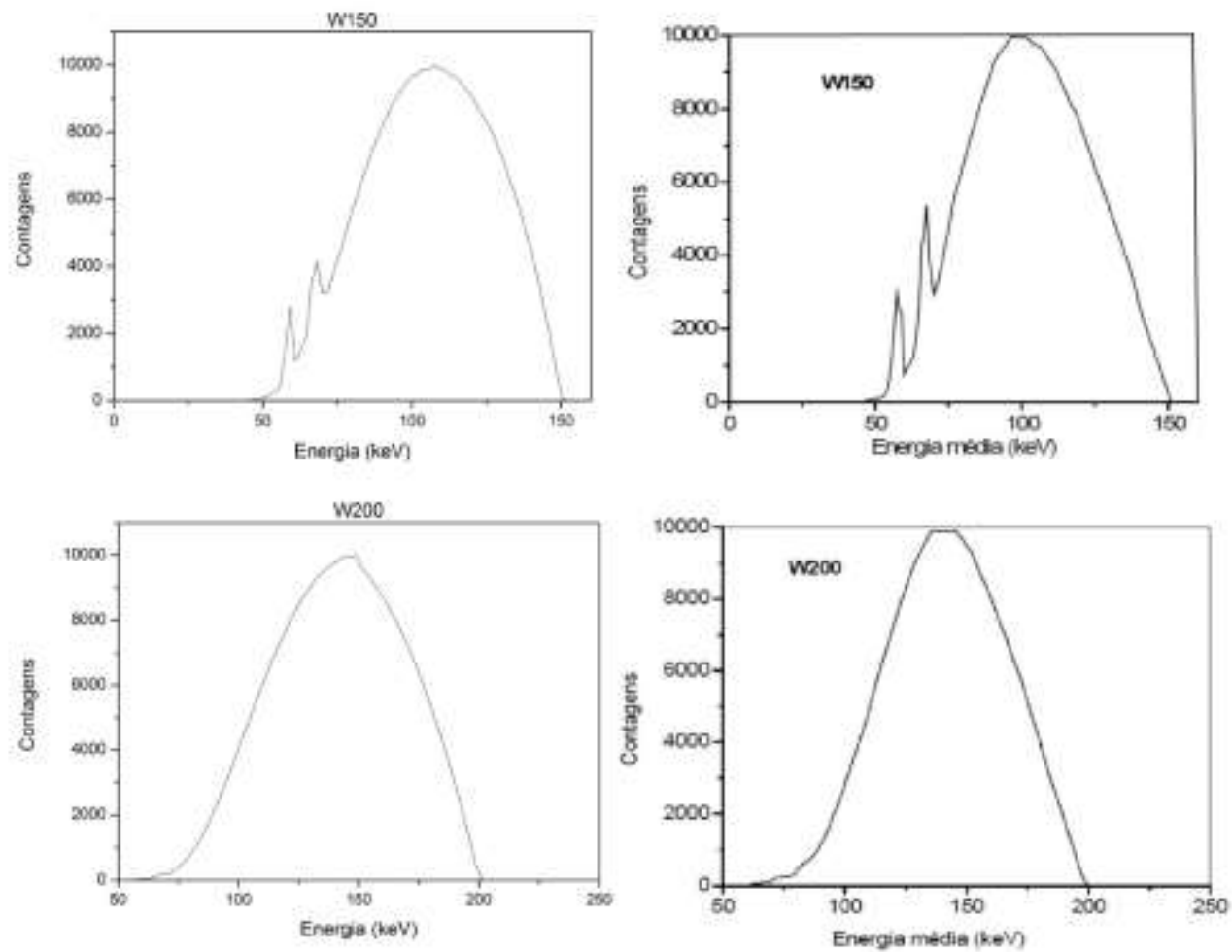

Figura 41: Os espectros à direita são os espectros largos conforme a norma (ABNT ISO 4037-1) e à esquerda são os espectros obtidos neste trabalho através da geração de espectros por TBC e da simulação por Monte Carlo utilizando o código PENELOPE, através da atenuação do feixe nos filtros metálicos indicados na Tabela 1.

\subsubsection{Validação dos feixes convencionais de espectro largo}

Para a validação dos feixes de espectro largo gerados utilizando conjuntamente o cálculo pelo modelo TBC e simulação em Monte Carlo, foram feitas comparações da energia média e das camadas semirredutoras. Na Figura 42 temos um exemplo da curva de atenuação do kerma no ar para feixes de fótons incidentes em atenuadores de cobre com diversas espessuras empregadas para obter a camada semirredutora. 


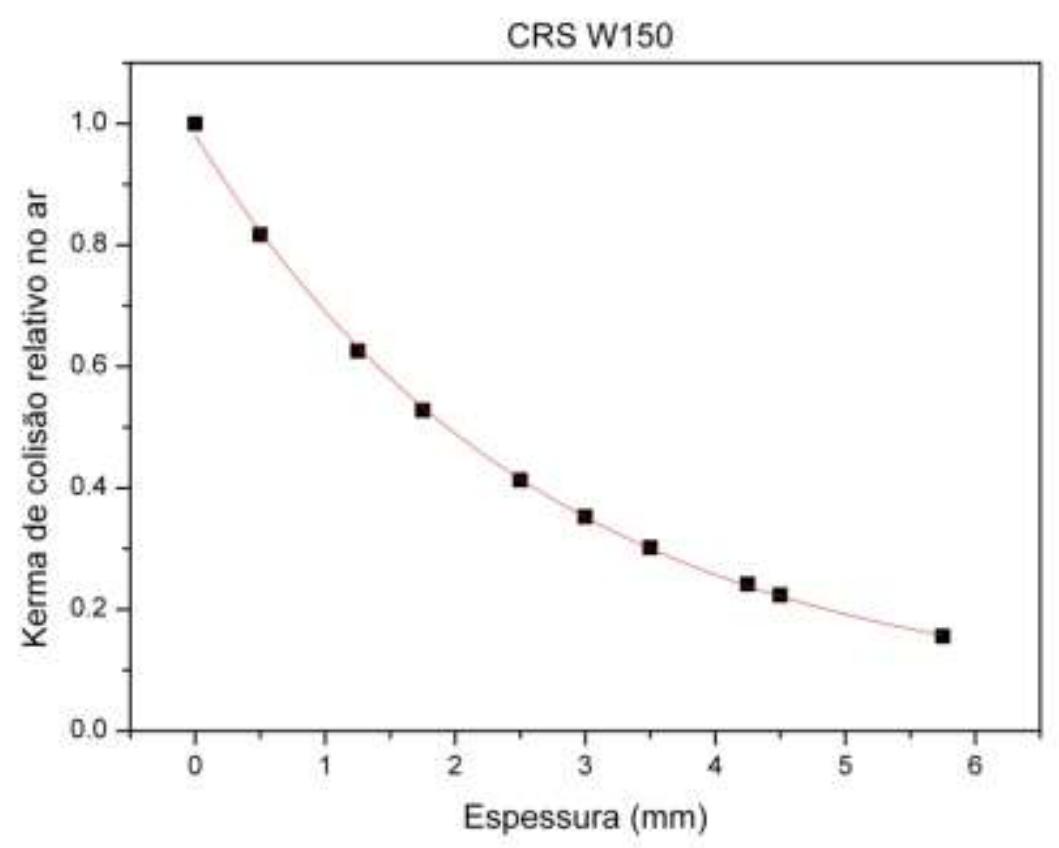

Figura 42: Curva de kerma de colisão no ar relativa de fótons para o cálculo das camadas semirredutoras para o feixe W150 simulado com o código PENELOPE. Em vermelho está a curva ajustada.

$\mathrm{Na}$ Tabela 13 estão apresentados os valores especificados na norma e os valores obtidos na simulação para as camadas semirredutoras, além do coeficiente de homogeneidade do feixe $(h)$, que é a razão entre a primeira e segunda camada semirredutora. De acordo com a norma, o valor deve concordar em $5 \%$ com o tabelado.

Tabela 13: Comparação entre as camadas semirredutoras simuladas e os valores da norma (ISO 4037-1).

\begin{tabular}{cccccc}
\hline $\begin{array}{c}\text { Qualidade } \\
\text { da radiação }\end{array}$ & Primeira CSR $(\mathbf{m m C u})$ & Segunda CSR $(\mathbf{m m C u})$ & $\begin{array}{c}\text { Coeficiente de } \\
\text { Homogeneidade }\end{array}$ \\
\cline { 2 - 5 } & Simulado & ISO & Simulado & ISO & Simulado \\
W150 & $1,91(4)$ & 1,86 & $2,14(4)$ & 2,10 & 0,90 \\
W200 & $3,09(12)$ & 3,08 & $3,42(12)$ & 3,31 & 0,90 \\
\hline
\end{tabular}

A partir dos espectros obtidos foram calculadas as energias médias dos feixes de espectro largo a fim de comparar com a norma. A Tabela 14 ilustra esses dados. Vale ressaltar que, segundo a norma ABNT NBR ISO 4037-1: 2015, um laboratório de referência deve obter em uma medição espectral com valor de energia média com desvio percentual dentro de $\pm 3 \%$. 
Tabela 14: Comparação entre as energias médias simuladas e da norma.

\begin{tabular}{cccc}
\hline Qualidade & \multicolumn{2}{c}{ Energia Média (keV) } & Resolução \\
\cline { 2 - 3 } da radiação & Simulado & ISO & Espectral Simulada (\%) \\
W150 & $105,2(1)$ & 104 & 56 \\
W200 & $141,3(5)$ & 137 & 52 \\
\hline
\end{tabular}

\subsubsection{Feixes Microtron}

Foram simulados os espectros para os feixes de $1,9 \mathrm{MeV}$ e 5,0 $\mathrm{MeV}$ utilizando todos os componentes da situação real: feixe monoenergético de elétrons, placa de alumínio na saída do feixe, alvo de liga de tungstênio, placas de build-up e detectores. Na Figura 43 estão os espectros obtidos pela simulação. A partir destes espectros foram calculadas as energias médias.
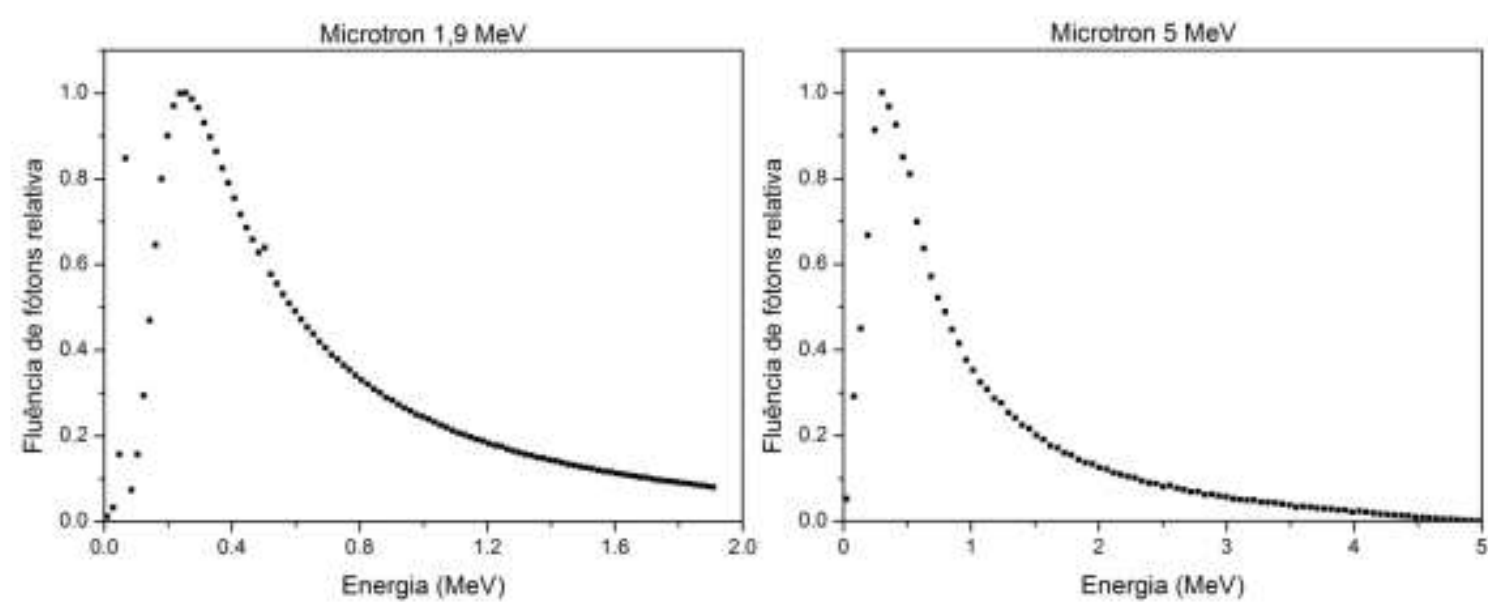

Figura 43: Espectros simulados em PENELOPE para os feixes do Microtron nas energias máximas de 1,9 e 5,0 $\mathrm{MeV}$.

Os valores calculados para a energia média foram 632,8 (6) e 1028 (3) keV para os feixes produzidos a partir das energias cinéticas de elétrons de 1,9 $\mathrm{MeV}$ e $5,0 \mathrm{MeV}$ respectivamente.

\subsubsection{Feixes Clínicos}

Foram avaliadas as curvas de deposição de energia em função da profundidade de água para os feixes clínicos. A equipe de física médica do hospital cedeu a curva de PDP (percent depth dose) dos aceleradores utilizados na irradiação de modo que possibilitou a comparação com a mesma curva obtida 
através da simulação nas mesmas condições. Com isso pode-se validar a utilização do espectro obtido na literatura. A geometria de irradiação consistiu em um phantom composto por água com dimensões de $30 \times 30 \times 32 \mathrm{~cm}^{3}$ a $100 \mathrm{~cm}$ da fonte, irradiado por fótons colimados em um feixe cônico com diâmetro de $10 \mathrm{~cm}$ na entrada do phantom. As curvas simulada e medida estão na Figura 44 e mostram boa concordância.
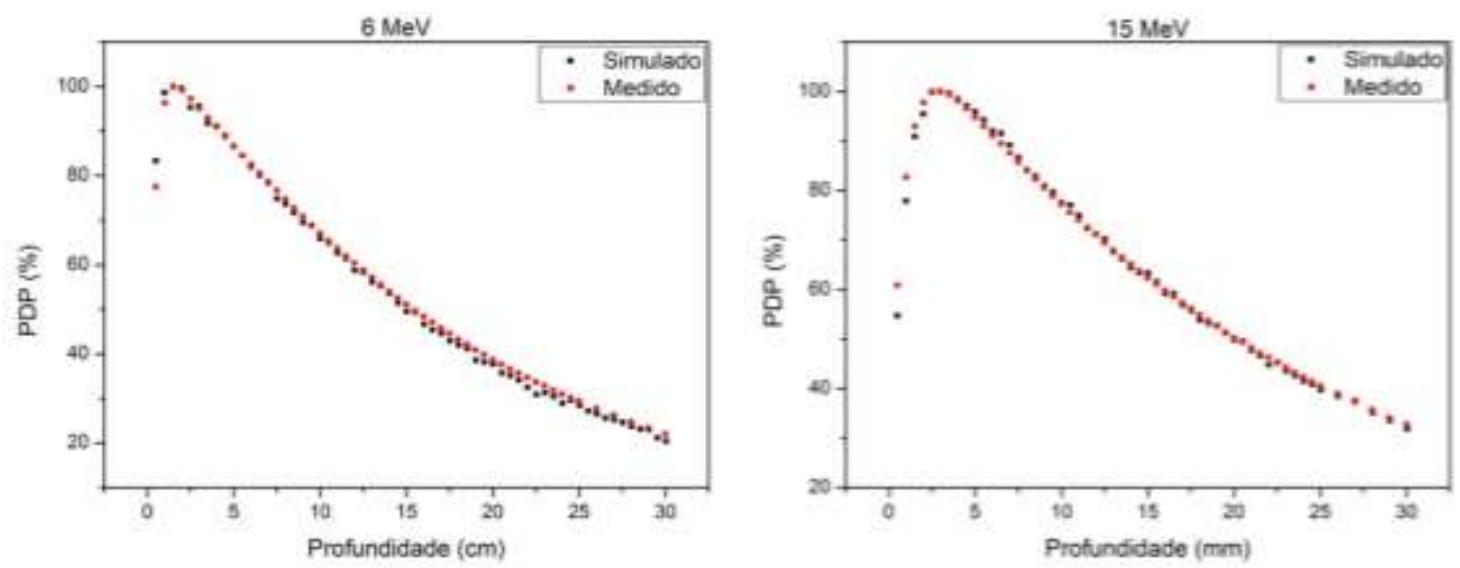

Figura 44: Comparação entre as curvas PDP simuladas e medidas para os aceleradores clínicos com energias máximas de $6 \mathrm{MeV}$ e $15 \mathrm{MeV}$ respectivamente. A normalização foi feita pelo ponto onde é depositada a maior dose.

O valor máximo de dose absorvida do feixe de $6 \mathrm{MeV}$ foi encontrado em 1,5 $\mathrm{cm}$ e do feixe de $15 \mathrm{MeV}$ em $3 \mathrm{~cm}$. Esses valores estão coerentes com a medição feita no hospital cujos dados foram cedidos pela equipe responsável pela dosimetria dos equipamentos. A diferença entre a localização onde ocorre a deposição máxima de dose considerando a mesma geometria nos dois casos é devida à energia empregada em cada feixe. Fatores como tamanho do campo, dimensão do objeto simulador, distância entre a fonte de radiação e o objeto simulador além da energia do feixe alteram o formato da curva e o ponto de máximo. 
Comparando qualitativamente em ambos os feixes, os formatos das curvas são muito semelhantes excetuando-se os pontos desde o início da curva até o valor onde a dose absorvida é máxima (região de build-up). Experimentalmente esta é a região de maior dificuldade de medida, devido às próprias dimensões da câmara de ionização empregada para as medidas. As maiores incertezas das simulações foram de $3 \%$ do valor simulado e há compatibilidade entre as curvas simulada e medida após a região de build-up. Na Figura 45 temos o gráfico da diferença percentual entre as curvas em toda a extensão do objeto simulador.
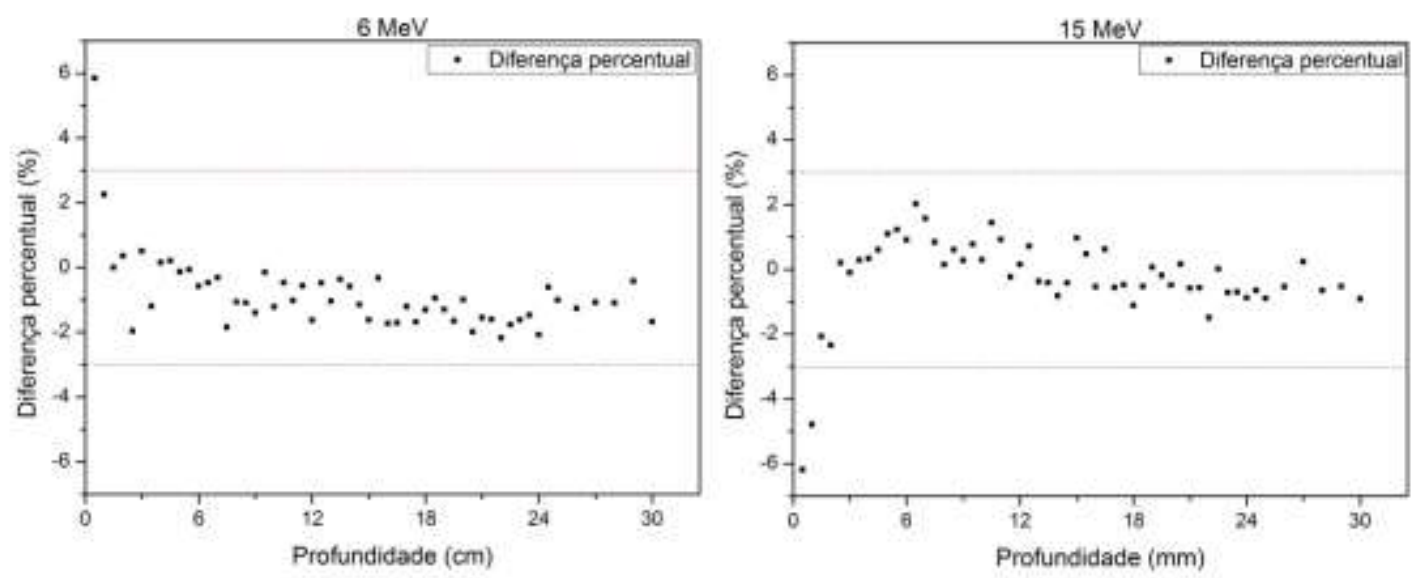

Figura 45: Diferença percentual entre a simulação e os valores medidos das curvas de PDP.

\subsubsection{Fator de dependência energética simulado}

O fator de dependência energética foi calculado utilizando a energia depositada nos materiais simulada com PENELOPE. A Tabela 15 ilustra os valores obtidos do $\boldsymbol{f}_{C o}^{x}$ para ambos os materiais utilizados neste trabalho.

Tabela 15: Fatores de dependência energética simulados para os diversos feixes usando o código PENELOPE.

\begin{tabular}{cccc}
\hline Feixe & Energia média (keV) & $\boldsymbol{f}_{\boldsymbol{C o}}^{\boldsymbol{x}} \mathbf{B e O}$ & $\boldsymbol{f}_{\boldsymbol{C o}}^{\boldsymbol{x}} \mathbf{A l}_{\mathbf{2}} \mathbf{O}_{\mathbf{3}}$ \\
\hline W150 & $105,2(1)$ & $0,79(2)$ & $1,16(2)$ \\
W200 & $141,3(5)$ & $0,89(3)$ & $1,07(3)$ \\
Microtron 1,9MeV & $632,8(6)$ & $0,98(3)$ & $1,02(3)$ \\
Cs-137 & 662 & $0,97(3)$ & $1,02(3)$ \\
Microtron 5,0 MeV & $1028(3)$ & $0,99(3)$ & $1,01(3)$ \\
Co-60 & 1125 & $1,00(2)$ & $1,00(2)$ \\
Varian 6 MeV & $1797(2)$ & $1,00(3)$ & $1,00(3)$ \\
Varian 15 MeV & $3897,2(37)$ & $0,97(3)$ & $1,00(3)$
\end{tabular}




\section{DISCUSSÃO DOS RESULTADOS}

\subsection{Dispersão das respostas do lote de dosímetros}

O estudo sobre a dispersão das respostas OSL teve como objetivo verificar a redução da incerteza utilizando uma segunda leitura OSL após reirradiar um dosímetro já lido (primeira irradiação foi feita no feixe de interesse) com um feixe padrão beta. Foi significativa a redução na dispersão utilizando o método de normalização por dose padrão: nos dosímetros feitos com $\mathrm{BeO}$, a dispersão reduziuse de aproximadamente $14 \%$ para $4,8 \%$ e nos dosímetros feitos com $\mathrm{Al}_{2} \mathrm{O}_{3}$ de aproximadamente $9 \%$ para $4,3 \%$, confirmando a expectativa de bons resultados utilizando-se deste método. YUKIHARA et al (2005) utilizaram este mesmo método apenas para os dosímetros de óxido de alumínio e também obtiveram uma redução significativa da dispersão do conjunto.

A redução da dispersão é devida a correlação nas dispersões obtidas no feixe de interesse e o feixe padrão. Parte dos dosímetros com menor ou maior resposta que a média em uma leitura se mantém a tendência nas leituras subsequentes. Esse fato pode ser correlato às variações de massa entre dosímetros e podem ser provocadas, no caso do $\mathrm{Al}_{2} \mathrm{O}_{3}$, pela utilização de partes distintas da fita de Luxel®, cuja homogeneidade pode não ser a ideal ou mudanças na transparência do filme polimérico à luz de estímulo ou de emissão. No caso do $\mathrm{BeO}$, poderia haver perda de material por abrasão durante o manuseio nos processos de bleaching e posicionamento no equipamento de leitura.

\subsection{Homogeneidade dos feixes}

No estudo de homogeneidade do feixe um dos parâmetros avaliados foi a simetria. A diferença máxima percentual encontrada em todos os feixes foi de 3,5\% no feixe de espectro largo com potencial de aceleração de $200 \mathrm{kV}$. Para as varreduras com distâncias verticais de $\pm 4 \mathrm{~cm}$ do centro do feixe foi encontrada uma diferença acentuada que possivelmente é originada pelo efeito heel, que é esperado para este equipamento na direção vertical que corresponde à linha catodo-anodo. Em estudo sobre o efeito heel utilizando simulações em Monte Carlo feito por AY et 
al (2004) a exposição relativa de dois pontos equidistantes ao centro do feixe pode ter diferenças consideráveis como, por exemplo, uma diferença de aproximadamente $20 \%$ entre as exposições nas bordas do campo, para feixe de 100 kV. MESBAHI e ZAKARIAEE (2013) apresentaram também este mesmo efeito variando-se o ângulo do anodo e encontrando diferenças na fluência de fótons com relação ao centro do feixe. Este efeito também é mais evidenciado por conta da pequena distância entre o alvo e o ponto de medição. Outro fato importante de salientar sobre a redução drástica da intensidade de fótons em. $\pm 4 \mathrm{~cm}$ do centro do feixe é o fato de o cone de radiação que está delimitado pelo colimador ser muito pequeno. Através de triangulação, a área de irradiação seria um círculo de raio de aproximadamente $3 \mathrm{~cm}$ e parte da varredura foi feita muito próximo às extremidades, favorecendo desvios grandes de kerma com pequenas variações no posicionamento e irradiação não uniforme da câmara de ionização. Ademais, também pode haver contribuição de espalhamento no próprio colimador e produção de penumbra pelo fato de o foco do equipamento de raios $X$ não ser pontual $(4 \mathrm{~mm})$. Visto que os valores das doses medidas deslocando a câmara de ionização até certo ponto do centro do feixe para ambos os lados e variando-se as posições verticais foram compatíveis, foi possível definir uma área de irradiação para um conjunto de dosímetros e garantir a irradiação uniforme dos dois tipos de material simultaneamente. No feixe do Microtron produzido a partir do feixe de elétrons com energia máxima de 1,9 e 5,0 MeV, a região de irradiação se deu entre zero (centro do feixe) e $-2 \mathrm{~cm}$ em relação ao centro do feixe no eixo vertical e $\pm 2 \mathrm{~cm}$ no horizontal. Já no feixe de espectro largo a região definida foi entre o ponto central e $2 \mathrm{~cm}$ na vertical e $\pm 2,5 \mathrm{~cm}$ na horizontal. Os critérios para a definição da área de irradiação foram a compatibilidade entre os valores de dose absorvida nas posições em relação ao centro do feixe, verificação da simetria (menores que 3,5\%) e planura do feixe que, na região escolhida, não ultrapassou $2,2 \%$.

\subsection{Análise das curvas OSL}

Avaliando as curvas de emissão OSL em função do tempo de forma qualitativa para os materiais estudados, as diferenças no formato variando a dose absorvida utilizada foram praticamente imperceptíveis para ambos os tipos de dosímetros em todos os feixes de irradiação (Figuras 34 e 37). Esse efeito já foi 
discutido por YUKIHARA e MCKEEVER (2011) e esperava-se que para doses até aproximadamente 1 Gy as curvas seriam indistinguíveis. Neste trabalho estendemos a faixa de doses até 2 Gy para todos os feixes de fótons estudados. Outra análise feita foi a comparação das curvas de emissão OSL para doses semelhantes, porém variando a energia do feixe de irradiação. Neste caso, foi verificado que para os dosímetros de $\mathrm{Al}_{2} \mathrm{O}_{3}$, quanto maior a energia do feixe de irradiação, mais lento foi o decréscimo da intensidade do sinal OSL com o tempo de iluminação. O efeito é inverso para o $\mathrm{BeO}$, o sinal OSL decai mais rápido para altas energias dos raios $\mathrm{X}$. Essas variações na emissão OSL segundo MALTHEZ (2015) estão relacionadas com a densidade de ionização no material e com as armadilhas envolvidas no processo de emissão luminescente.

\subsection{Resposta OSL}

Com relação à resposta OSL normalizada em função da dose absorvida, ambos os materiais apresentaram comportamento linear. Foi obtida uma qualidade estatisticamente adequada nos ajustes lineares das curvas dose-reposta para as diversas energias de irradiação na faixa de doses absorvidas estudada. É sabido que em doses altas pode haver supralinearidade da resposta OSL nos dosímetros de óxido de alumínio, porém, neste estudo, não foi observado. Segundo YUKIHARA e MCKEEVER (2011) os dosímetros de $\mathrm{Al}_{2} \mathrm{O}_{3}$ têm esses efeitos percebidos a partir de doses maiores que 10 Gy sendo que, inicialmente haveria supralinearidade com posterior sublinearidade em dose dependendo se a análise foi feita utilizando sinal OSL inicial ou a área da curva OSL. REFT (2009) mostra em seu trabalho que, para estes dosímetros OSL, a resposta começa a não ter proporcionalidade com a dose absorvida também a partir de aproximadamente 10 Gy. Estes dados reforçam que na faixa de doses utilizadas neste trabalho, os dosímetros têm resposta linear. Para os dosímetros de $\mathrm{BeO}$, nossos resultados confirmam estudos anteriores em que observaram que a resposta OSL em função da dose absorvida também tem boa linearidade desde a faixa de $\mu \mathrm{Gy}$ até alguns Gy produzidas por raios gama de Cs137, segundo SOOMER et al (2008). Diferenças mais expressivas da linearidade (saturação) ocorrem em doses altas sendo que o desvio é menor que $5 \%$ para a dose de 30 Gy (SOMMER e HENNINGER, 2006). 


\subsection{Fator de dependência energética}

Nas energias que abrangem a faixa de radioterapia os fatores de dependência energética se aproximaram da unidade, fato que indica a independência da resposta OSL da energia do feixe. BATISTA (2011) realizou estudo semelhante, porém utilizando técnica de termoluminescência, verificou também este fato utilizando dosímetros de diversas composições.

Os materiais estudados apresentaram um desvio do valor unitário máximo de $3 \%$ nesse fator para os dosímetros feitos de $\mathrm{Al}_{2} \mathrm{O}_{3}$ e $5 \%$ para o $\mathrm{BeO}$ nos feixes de $5,0 \mathrm{MeV}$ do Microtron e nos aceleradores clínicos em relação à irradiação no ${ }^{60} \mathrm{Co}$. Para $\circ{ }^{137} \mathrm{Cs}$ e o Microtron com 1,9 MeV, os fatores de dependência energética obtidos seguiram a tendência esperada para cada um dos dosímetros, resposta maior que a unidade para $\circ \mathrm{Al}_{2} \mathrm{O}_{3}(1,07)$ e menor que um $(0,96$ para o Microtron e $0,93 \mathrm{com} \circ{ }^{137} \mathrm{Cs}$ ) para $\circ \mathrm{BeO}$. Em energias mais baixas (feixes de raios $\mathrm{X}$ convencional com espectro largo) o valor se distancia da unidade, com resposta de 1,68 para $\circ \mathrm{Al}_{2} \mathrm{O}_{3}$ e 0,78 para $\circ \mathrm{BeO}$ para $\circ$ feixe $\mathrm{W} 150$, evidenciando que há dependência energética mais forte nestes dois tipos de dosímetros OSL conforme já visto em outros estudos para o $\mathrm{Al}_{2} \mathrm{O}_{3}$ (REFT, 2009; AKSELROD et al, 1998; SCARBORO e KRY, 2012) e para o BeO (SOMMER e HENNINGER, 2006; JAHN A. et al., 2014 e MALTHEZ, 2015). Como $\circ \mathrm{Al}_{2} \mathrm{O}_{3}$ tem coeficiente de absorção de energia mássico para raios $\mathrm{X}$ maior que $\mathrm{o}$ ar para energias baixas, é de se esperar um aumento na resposta em energia para as irradiações com os feixes de raios $X$ de espectro largo.

Como já é de conhecimento geral, um dosímetro ideal deveria ter resposta independente da energia de irradiação, porém, na prática não é o que ocorre. Se a calibração do conjunto de dosímetros foi feita utilizando-se apenas os dados obtidos no feixe de Co-60, por exemplo, utilizar o dosímetro calibrado em energias mais baixas implicaria em perda de exatidão por conta de a resposta com a dose diferir da resposta no feixe de referência. Conhecendo-se os fatores de dependência energética e aplicando a correção necessária ao valor, é possível obter uma melhor estimativa da dose entregue ao tecido. 


\subsection{Simulações em Monte Carlo}

As validações por comparação de parâmetros importantes para cada tipo de feixe mostraram que, no geral, as simulações em Monte Carlo foram satisfatórias. Os espectros de energia obtidos resultaram em boas estimativas para os espectros reais e puderam ser utilizados na simulação de deposição de energia.

Comparando-se as curvas medida e simulada para a deposição de dose em função da profundidade para os feixes de raios $X$ produzidos em aceleradores clínicos, obteve-se valores muito próximos, sendo que o maior desvio percentual foi igual a 2,3 \% nos feixes de $6 \mathrm{MeV}$ e $15 \mathrm{MeV}$ (não considerando a região de buildup). A profundidade onde se localiza o máximo de dose depositada no phantom de água também foi compatível ao fazer a comparação entre a situação experimental e a simulação. Com esses dados podemos concluir que o espectro utilizado na simulação da resposta com a dose absorvida é compatível com o experimental.

Os feixes de espectro largo obtidos com técnica mista (Modelo TBC + PENELOPE) foram compatíveis com os valores prescritos pela norma ISO 4037-1 verificando-se que os valores de energia média, resolução espectral, coeficiente de homogeneidade e camadas semirredutoras, possibilitando assim a utilização desses feixes neste trabalho. Para o feixe W150, foram obtidos para a primeira e segunda camada semirredutoras os desvios percentuais de 2,7 e $1,9 \%$ respectivamente e energia média de 105,2(1) keV, que representa um desvio de 1,1\%. Já para o W200, as CSRs tiveram desvios de 0,32 e 3,3\% e energia média de 141,3(5) keV, ou seja, $3,1 \%$. Segundo esta norma, um feixe pode ser considerado satisfatório se as camadas semirredutoras não distarem mais que $5 \%$ e a energia média estiver compatível em 3\%.

A resolução espectral calculada para o feixe W150 foi igual a $56 \%$ enquanto que, para o W200, foi de 52\% evidenciando, também, coerência com os valores estipulados. Avaliando qualitativamente os espetros simulados, é visível a semelhança com os apresentados na norma ABNT NBR ISO 4037-1, tanto no que tange às faixas de energia onde começam e terminam as contagens, quanto à forte atenuação nas linhas características Ka e K $\beta$.

Os fatores de dependência energética simulados apenas contemplam a deposição de energia no material do dosímetro. Mecanismos de emissão luminescentes envolvidos, desexcitações não-radiativas, tipos e concentrações de 
defeitos no material, influência da forma de análise de sinal usada (GASPARIAN et al, 2012) não foram contemplados. Sendo assim, os resultados obtidos por Monte Carlo servem para observar não linearidades na conversão da energia armazenada nos cristais pela radiação em uma resposta OSL. As diferenças observadas nas simulações evidenciam que, no processo físico da produção de sinal OSL, há dependência da energia dos fótons. Como já dito no capítulo 3, não se sabe ao certo as impurezas contidas no $\mathrm{BeO}$ e nem a composição química do filme polimérico que envolve $\circ \mathrm{Al}_{2} \mathrm{O}_{3}$ dificultando, assim, uma estimativa exata do fator de dependência energética em ambos os dosímetros por simulação. Na faixa de baixa energia (feixes de raios $X$ convencional de espectro largo), os fatores de dependência energética simulados se distanciaram do valor 1 , referente ao feixe de Co-60, pois a variação dos coeficientes de absorção de energia mássicos é mais expressiva nos materiais estudados. A tendência para um fator maior que um para $\circ \mathrm{Al}_{2} \mathrm{O}_{3}$ foi percebida e menor que um para o BeO também. Nos demais feixes, os valores de $f_{C o}^{x}$ se aproximaram de 1 e tiveram compatibilidade entre a simulação e a situação experimental. Na Figura 46 estão apresentados os fatores de dependência energética para ambos os materiais.

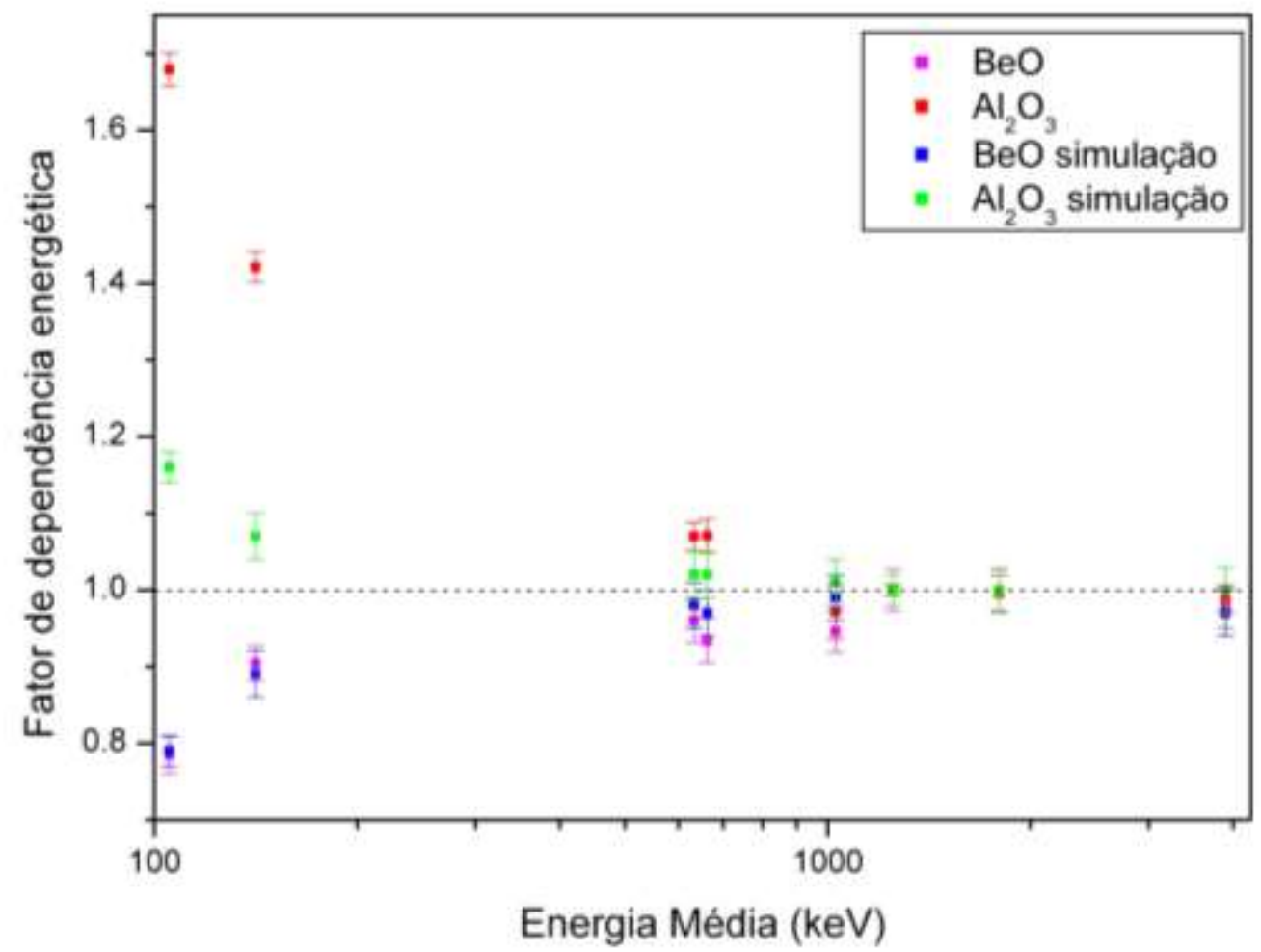

Figura 46: Gráfico da dependência energética experimental e simulada dos dosímetros em função da energia média do feixe. 
Analisando a Figura 46, podemos observar que o os fatores de dependência energética para o $\mathrm{BeO}$ foram compatíveis (simulado e experimental) em toda a faixa de energia enquanto que no $\mathrm{Al}_{2} \mathrm{O}_{3}$ foram encontrados desvios percentuais de $31 \mathrm{e}$ $25 \%$ para os feixes W150 e W200 respectivamente evidenciando a necessidade de melhor conhecimento da composição do Luxel® e a possível influência da falta dos mecanismos OSL na simulação. Nos demais pontos houve compatibilidade entre o simulado e o experimental. Segundo ATTIX (1986), a razão dos coeficientes de absorção de energia mássicos seria uma boa aproximação para a resposta de um dosímetro. Os valores dessa razão para o $\mathrm{Al}_{2} \mathrm{O}_{3}$ e $\circ$ ar para os feixes W150 e W200 são de 1,3 e 1,08 respectivamente, apontando para a necessidade de simular o material Luxel® em sua totalidade, pois as substâncias não conhecidas completamente tanto podem alterar a absorção de energia, como podem interferir no mecanismo de emissão luminescente. REFT (2009) em seu estudo verificou diferença semelhante entre valores simulados e experimentais para feixes com energia efetiva de aproximadamente $100 \mathrm{keV}$. 


\section{Conclusões}

Neste trabalho foi estudada a resposta dos dosímetros de óxido de berílio e óxido de alumínio em diversos feixes de fótons (raios $X$ e gama) que abrangem desde a faixa chamada de ortovoltagem até feixes utilizados em radioterapia e produzidos em aceleradores clínicos e no acelerador Microtron do Instituto de Física da Universidade de São Paulo.

O estudo de homogeneidade das doses absorvidas nos campos de radiação foi feito com um sistema de varredura desenvolvido neste trabalho e possibilitou uma metodologia prática de irradiação dos dosímetros garantindo assim uma irradiação com uniformidade de doses absorvidas conhecidas.

$\mathrm{Na}$ faixa de doses utilizadas experimentalmente foi observado que a resposta OSL é linear com a dose absorvida para os dois materiais utilizados. Este fato foi comprovado pela qualidade dos ajustes lineares obtidos. Também não foi observada supralinearidade nem sublinearidade nas doses mais elevadas utilizadas neste estudo.

Verificando os valores dos fatores de dependência energética para os materiais estudados podemos concluir que, para as energias mais altas de raios $\mathrm{X}$, os dosímetros não possuem variação apreciável da resposta com relação à energia do feixe utilizado tornando possível a utilização do valor medido sem necessidade de correção para a energia do feixe, dependendo da exatidão necessária. Para os feixes de energias mais baixas os fatores de dependência energética se distanciaram da unidade, indicando a necessidade de calibrar os dosímetros com feixes de fótons com energias próximas ao que se vai medir. As simulações utilizando o PENELOPE permitiram observar essa tendência através da deposição de energia.

Quanto às curvas da emissão OSL normalizadas em função do tempo para as diversas qualidades de feixes foram observadas diferenças sutis nos formatos (tempos de decaimento do sinal OSL em CW) para o $\mathrm{Al}_{2} \mathrm{O}_{3}$ e mais pronunciada para - $\mathrm{BeO}$ e em sentidos opostos. As curvas de emissão OSL tiveram diferenças imperceptíveis variando-se a dose absorvida (para uma mesma energia de feixe) por conta destes efeitos serem notados provavelmente apenas em doses maiores que as utilizadas neste trabalho. 
A validação dos feixes utilizados foi feita através da simulação das curvas de PDP para os feixes de radioterapia e dos parâmetros de caracterização dos feixes de espectro largo (camadas semirredutoras, energia média e resolução espectral) permitiram a utilização dos espectros obtidos na literatura (aceleradores clínicos) e obtidos utilizando técnica mista (modelo TBC em conjunto com simulação no PENELOPE), nas simulações. Com o programa PENELOPE, foi simulada a deposição de energia de feixe de fótons com espectros semelhantes aos usados experimentalmente, de forma a obter a dependência energética.

$\mathrm{O}$ feixe de raios $\mathrm{X}$ produzido com o acelerador Microtron utilizando os alvos desenvolvidos para este trabalho se mostrou eficiente para futuros estudos na área de Física Médica visto que foi possível definir uma região com uniformidade de doses para os feixes de 1,9 MeV e de 5,0 MeV garantindo irradiações uniformes de conjuntos de dosímetros. Outra vantagem na irradiação com este acelerador se dá pelo fato da obtenção de um feixe com energias médias próximas às energias de irradiadores com ${ }^{137} \mathrm{Cs} \mathrm{e}{ }^{60} \mathrm{Co}$, cuja utilização ainda é difundida em calibração de medidores de dose absorvida.

Diferentemente dos feixes produzidos nos aceleradores clínicos, não foi possível validar o espectro simulado por conta das dificuldades na obtenção de feixes estáveis por tempos longos, e na montagem do sistema específico para avaliar a penetração em água em um volume grande. O Microtron passou por alguns trabalhos de manutenção de longo prazo permitindo acesso ao feixe somente por curtos períodos. A validação do espectro simulado em Monte Carlo através da penetração em água ou da medida experimental desse espectro é uma sugestão de trabalho para o futuro. 


\section{REFERÊNCIAS BIBLIOGRÁFICAS}

AAPM. AAPM code of practice for radiotherapy accelerators: Report of AAPM. Radiation Therapy Task Group No. 45. Report No. 47. Woodbury, NY, 1994.

ABNT NBR ISO 4037-1. Radiação X e gama de referência para calibração de dosímetros e medidores de taxa de dose e determinação da resposta em função da energia do fóton. Parte 1: Características da radiação e métodos de produção, 2015.

AKSELROD, M. S.; KORTOV, V. S.; GORELOVA, E. A. Preparation and properties of $\alpha-$ $\mathrm{Al}_{2} \mathrm{O}_{3}$ :C. Radiation Protection Dosimetry. Vol. 47, p. 159-164, 1993.

AKSELROD, M. S.; POLF, J.; MCKEEVER, S. W. S. Optically stimulated luminescence of Al2O3:C. Radiation Measurements. Vol. 29(3), p.391-399, 1998.

ANDREO, P. Improved calculations of stopping-power ratios and their correlation with the quality of therapeutic photon beams (IAEA-SM-330/62), 1994.

ATTIX F. H. Introduction to Radiological Physics and Radiation Dosimetry. New York: Wiley, 1986. 607 p.

AY, M. R.; SHAHRIARI, M.; SARKAR, S.; ADIB, M.; ZAIDI, H. Monte Carlo simulation of xray spectra in diagnostic radiology and mammography using MCNP4C. Physics in Medicine and Biology. Vol. 49, p. 4897-4917, 2004.

BATISTA B. J. B. Avaliação de dosímetros termoluminescentes para uso em radioterapia com fótons de alta energia. Dissertação de Mestrado, IFUSP, 2011. Disponível em: http://www.teses.usp.br/teses/disponiveis/43/43134/tde-26042012-152350/pt-br.php.

BOS, A. J. J. High sensitivity thermoluminescence dosimetry. Nuclear Instruments \& Methods in Physics Research B. Vol. 184, p. 3-28, 2001. 
BERGER, M. J.; SELTZER, S. M. Stopping powers and ranges of electrons and positrons, Washington DC: National Bureau of Standards, 1983. 173 p.

BOtTER-JENSEN, L.; MCKEEVER, S. W. S.; WINTLE, A. G. Optically Stimulated Dosimetry, Amsterdam: Elsevier Science, 2003. 374 p.

BOYER, A. L. Quality Assurance foundations in equipment specifications, acceptance testing, and commissioning. Quality Assurance in Radiotherapy Physics. Madison, WI: Medical Physics Publishing, p. 5-21, 1991.

BUBE, R. H. Photoconductivity of solids, New York: Wiley, 1960. 461 p.

BULUR, E.; GÖKSU, H.Y. OSL from BeO ceramics: new observations from an old material. Radiation Measurements. Vol. 29, p. 639-650, 1998.

BULUR, E.; YELTIK A. Optically stimulated luminescence from BeO ceramics: An LM-OSL study. Radiation Measurements. Vol. 45, p. 29-34, 2010.

COSTA, P. R.; NERSISSIAN, D. Y.; SALVADOR, F. C.; RIO, P. B.; CALDAS, L. V.. Generation of calibrated tungsten target x-ray spectra: Modified TBC model. Health Physics. Vol. 92, n. 1, p. 24-32, 2007.

DTU (Denmark Technical University), Manual do Equipamento, disponível em: http://www.nutech.dtu.dk/english/Products-and-Services/Dosimetry/Radiation-MeasurementInstruments/TL_OSL_reader. Acessado em julho de 2016.

GIGLIOLI, M. Avaliação da distribuição da dose absorvida em radioterapia com campos irregulares e alargados. Dissertação de Mestrado, IPEN, 2012. Disponível em: http://www.teses.usp.br/teses/disponiveis/85/85133/tde-29062012-103322/pt-br.php

GUIMARÃES, C. C. Monitoração individual externa: experimentos e simulações com o método de Monte Carlo. Tese de doutorado, IFUSP, 2005. Disponível em: http://www.teses.usp.br/teses/disponiveis/43/43134/tde-06072009-185822/pt-br.php

IAEA (International Atomic Energy Agency). Safety Report Series No. 16 - Calibration of 
Radiation Protection Monitoring Instruments. International Atomic Energy Agency, 2000.

IAEA (International Atomic Energy Agency), Absorbed Dose Determination in External Beam Radiotherapy: An International Code of Practice for Dosimetry based on Standards of Absorbed Dose to Water, Technical Report Series nㅜ98, Vienna, 2000.

ICRP (International Commission on Radiation Protection). The 2007 Recommendations of the International Commission on Radiological Protection. Annals of the ICRP, Publication 103, 2008.

INTERNATIONAL COMISSION ON RADIATION UNITS AND MEASUREMENTS, ICRU. Radiation Quantities and Unities. Bethesda. 1980. (ICRU Report 33).

INTERNATIONAL COMISSION ON RADIATION UNITS AND MEASUREMENTS, ICRU. Radiation Dosimetry: Electron Beams with Energies Between 1 and $50 \mathrm{MeV}$. 1984a. (ICRU Report 35).

INTERNATIONAL COMISSION ON RADIATION UNITS AND MEASUREMENTS, ICRU. Stopping Powers for Electrons and Positrons, International Commission on Radiation Units and Measurements. Bethesda. 1984b. (ICRU Report 37).

INTERNATIONAL COMISSION ON RADIATION UNITS AND MEASUREMENTS, ICRU. Radiation dose and image-quality assessment in computed tomography. Bethesda. 2012. (ICRU Report 87).

JAHN, A.; SOMMER, M.; HENNIGER, J. OSL efficiency for BeO OSL dosimeters. Radiation Measurements. Vol. 71, pp. 104-107, 2014.

JOHNS, H. E.; CUNNINGHAM, J. R. The Physics of Radiology.Fourth Edition. Springfield U.S.A, Thomas Book, 1983. 288 p.

KEER, H. V. Principles of Solid State. New Delhi: New Age, 1993. p. 379.

KHAN, F. N. Physics of Radiation Therapy. Third Edition. Philadelphia, USA: Lippincott 
Williams \& Wilkins, 2003. 560 p.

KNOLL, G. F. Radiation Detection and Measurement. Third Edition. New York: John Wiley \& Sons, $1979.802 \mathrm{p}$.

LABORATÓRIO DO ACELERADOR LINEAR (LAL-IFUSP). Disponivel em: $<$ http://portal.if.usp.br/microtron/>. Acessado em abril de 2017.

LEO, W. R. Techniques for Nuclear and Particle Physical Experiments. Second Revised Edition. Germany: Spring - Verlag, 1994. 365 p.

MALTHEZ, A. M. C. Desenvolvimento e caracterização de dosímetros para monitoração individual de trabalhadores ocupacionalmente expostos à radiação combinando as técnicas de termoluminescência (TL) e luminescência opticamente estimulada (OSL). Tese de Doutorado, Unicamp, 2015.

MARTINS, M.N.; TAKAHASHI, J.; MALAFRONTE, A.A.; RIOS, P.B.; LOPES, M.L.; BONINI, A.L.; LIMA, R.R. The IFUSP Microtron: Status and Perspectives. Brazilian Journal of Physics. Vol. 34, n. 3a, p. 951-953, 2004.

MCKEEVER, S. W. S.; MOSCOVITCH, M.; TOWNSEND, P.D. Thermoluminescence dosimetry materials: Properties and uses. Ashford: Nucl. Tech. Pub., 1995.

MCKEEVER, S. W. S. Optically stimulated luminescence: A brief overview. Radiation Measurements, vol. 46, pp. 1336-1341, 2011.

MESBAHI, A.; ZAKARIAEE, S. Effect of anode angle on photon beam spectra and depth dose characteristics for X-RAD320 orthovoltage unit. Practical Oncology and Radiotherapy. Vol. 18, p. 148-152, 2013.

METROPOLIS, N.; ULAM, S. The Monte Carlo Method. Journal of the American Statistical Association, vol. 44, pp. 335-341, 1949.

National Institute of Standards and Technology (Berger MJ et al). XCOM: Photon Cross 
Sections Database. Disponível em: < http://physics.nist.gov/PhysRefData/Xcom/html/xcom1.html >. Acessado em outubro de 2016.

NUDAT (Nuclear Structure and Decay Data). National Nuclear Data Center, Brookhaven National Laboratory. http://www.nndc.bnl.gov/nudat2/. Acessado em outubro de 2016.

OKUNO, E.; YOSHIMURA, E. M. Física das Radiações. São Paulo, Oficina de Textos. 2010. 296 p.

PODGORSAK, E. B. Radiation Oncology Physics: A Handbook for Teachers and Students. IAEA Viena, 2005.

REFT, C. S. The energy dependence and dose response of a commercial optically stimulated luminescent detector for kilovoltage photon, megavoltage photon, and electron, proton and carbon beams. Medical Physics. Vol. 36, p. 1690-1699, 2009.

RIOS, P. B. Linha de transporte de feixe do acelerador Mícrotron do IFUSP. Dissertação de Mestrado, $\quad 2002.2$ Disponível em: http://repositorio.ipen.br:8080/xmlui/handle/123456789/11064.

SALVAT, F.; FERNÁNDEZ-VAREA, J. M.; BARÓ, J.; SEMPAU, J. PENELOPE, an algorithm and computer code for Monte Carlo simulation of electron-photon showers. University of Barcelona Report, 1996. P. 157.

SALVAT, F.; FERNÁNDEZ-VAREA, J. M.; SEMPAU, J. PENELOPE-2006: A code system for Monte Carlo simulation of electron and photon transport. In: Workshop Proceedings Barcelona, Spain. Citeseer, 2006. p. 403.

SANTOS, J. C. Estudo experimental das relações entre Kerma no ar e equivalente de dose ambiente para o cálculo de barreiras primárias em salas radiológicas. Dissertação de Mestrado, IFUSP, 2013. Disponível em: http://www.teses.usp.br/teses/disponiveis/43/43134/tde-26032014-113306/pt-br.php

SANTOS, A. M. C.; MOHAMMADI, M.; AFSHAR, V. S. Energy dependency of a water- 
equivalent fibre-coupled beryllium oxide $(\mathrm{BeO})$ dosimetry system. Radiation Measurements. Vol 73, p. 1350-4487, 2015.

SCARBORO, S. B.; S. F. KRY. Characterisation of Energy Response of $\mathrm{Al}_{2} \mathrm{O}_{3}: \mathrm{C}$ Optically Stimulated Luminescent Dosimeters (OSLDs) Using Cavity Theory. Radiation Protection Dosimetry. Vol. 153(1), p. 23-31, 2013.

SHEIKH-BAGHERI, D.; ROGERS, D. W. O. Monte Carlo calculation of nine megavoltage photon beam spectra using the BEAM code. Medical Physics. Vol. 29, p. 391-402, 2002.

SOMMER, M.; FREUDENBERG, R.; HENNIGER, J. New aspects of a BeO-based optically stimulated luminescence dosimeter. Radiation Measurements. Vol. 42, pp. 617-620, 2007.

SOMMER, M.; HENNIGER, J. Investigation of a BeO-based optically stimulated luminescence dosimeter. Radiation Protection Dosimetry. Vol. 119, pp. 353-356, 2006.

SOMMER, M.; JAHN, A.; HENNIGER, J. Beryllium oxide as optically stimulated luminescence dosimeter. Radiation Measurements. Vol. 43, pp. 353-356, 2008.

SPOONER, N. A. On the optical dating signal from quartz. Radiation. Measurements. Vol. 23, p. 593-600, 1994.

TUCKER, D. M.; BARNES, G. T.; CHAKRABORTY, D. P. Semiempirical model for generating tungsten target $x$-ray spectra. Medical Physics. Vol. 18, n. 2, p. 211-218, 1991.

VASSILIEV, O. N.; TITT, U.; PÖNISCH, F.; KRY, S. F.; MOHAN, R; GILLIN, M. T. Dosimetric properties of photon beams from a flattening filter free clinical accelerator. Physics in Medicine and Biology. Vol. 51, p. 1907-1917, 2006.

VUOLO, J. H. Fundamentos da teoria de erros. 2ª Edição. São Paulo. Blucher, 1996. 264 p.

YORIYAZ, H. Método de Monte Carlo: princípios e aplicações em Física Médica. Revista Brasileira de Física Médica. Vol. 3, pp. 141-149, 2009. 
YUKIHARA, E. G. Luminescence properties of $\mathrm{BeO}$ optically stimulated luminescence (OSL) detectors. Radiation Measurements. Vol. 46, pp. 580-587, 2011.

YUKIHARA, E. G.; YOSHIMURA, E. M.; LINDSTROM, T. D.; AHMAD, S.; TAYLOR, K. K.; MARDIROSSIAN, G. High-precision dosimetry for radiotherapy using the Optically Stimulated Luminescence (OSL) technique and thin $\mathrm{Al}_{2} \mathrm{O}_{3}: \mathrm{C}$ dosimeters. Physics in Medicine and Biology. Vol. 50, p. 5619-5628, 2005.

YUKIHARA, E. G.; MCKEEVER, S. W. S., Optically Stimulated Luminescence: Fundamentals and Applications, West Sussex, UK: John Wiley and Sons, Ltd., 2011. 362 p. 